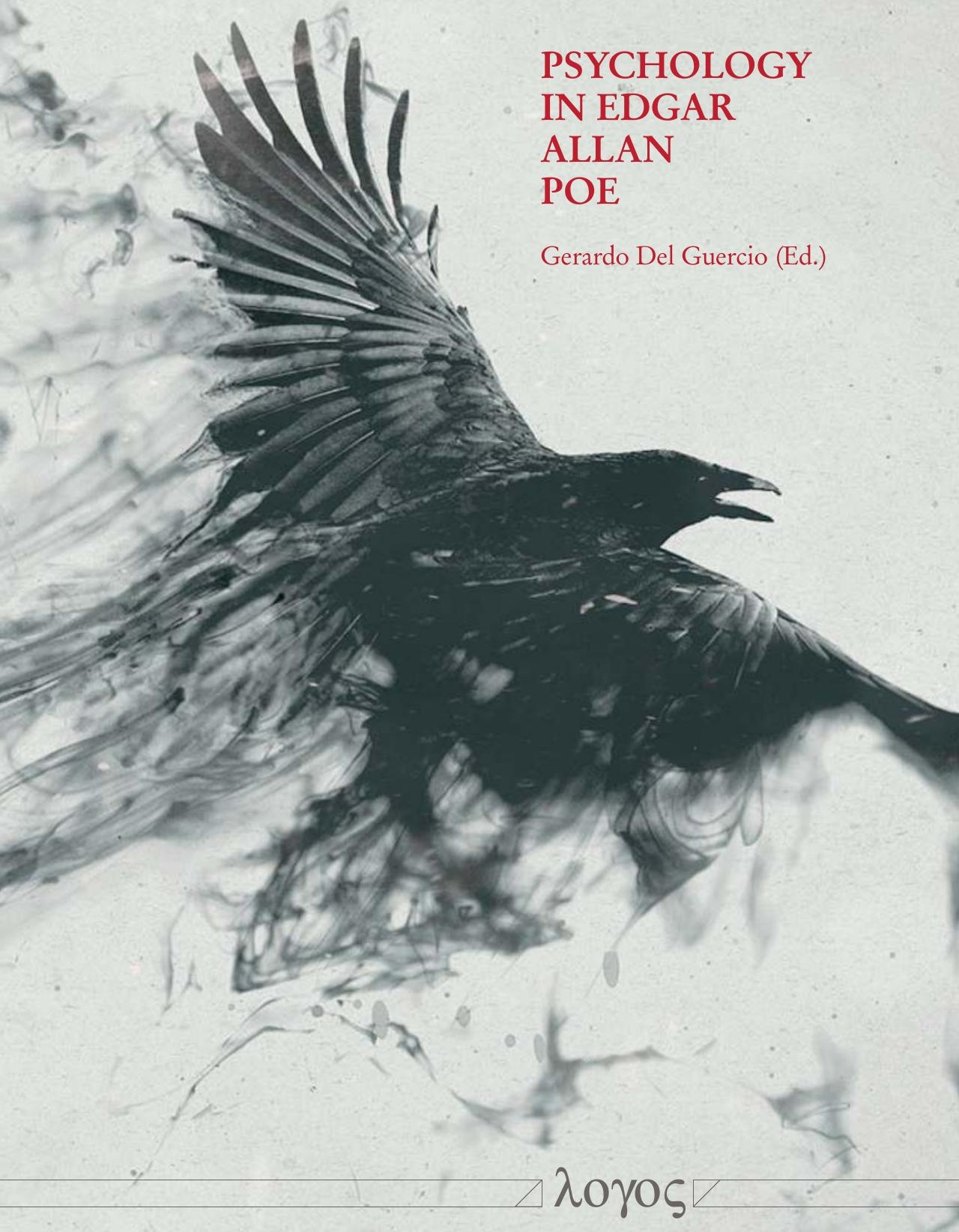



Psychology in Edgar Allan Poe 



\section{Psychology in \\ Edgar Allan Poe}

Gerardo Del Guercio (Ed.)

Logos Verlag Berlin 
Bibliographic information published by Die Deutsche Bibliothek

Die Deutsche Bibliothek lists this publication in the Deutsche Nationalbibliografie; detailed bibliographic data is available in the Internet at http://dnb.ddb.de.

The electronic version of this book is freely available under CC BY-SA 4.0 licence, thanks to the support of libraries working with Knowledge Unlatched (KU). KU is a collaborative initiative designed to make high quality books Open Access for the public good. More information about the initiative and links to the Open Access version can be found at www.knowledgeunlatched.org.

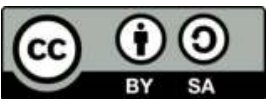

Logos Verlag Berlin GmbH, 2019

ISBN 978-3-8325-4940-4

DOI: $10.30819 / 4940$

Logos Verlag Berlin GmbH

Georg-Knorr-Str. 4, Geb. 10

D-12681 Berlin

Germany

phone: $\quad+49(0) 30 / 42851090$

fax: $\quad+49(0) 30 / 42851092$

http://www.logos-verlag.com 


\section{Contents}

Introduction $\quad 7$

Gerardo DEL Guercio

1 Poe and the Contemporary Serial Killer Narrative

KAREN J. RENNER

2 Perverse Selves: Unwanted Impulses and Obsession in Poe

RACHEL MCCOPPIN

3 Staging Nothing:

The Figure of Das Ding in Poe's “The Raven”

SEAN J. KELLY

4 The Doppelgänger, Psychology, and Poe

101 TATIANA PROROKOVA

5 All Things in Heaven and Earth:

The Ethics of Vision in "The Tell-Tale Heart"

PHILLIP GRAYSON

6 Mapping German Poetics onto the American Psyche: Masculinity and Metaphysics from E.T.A. Hoffmann to Edgar Allan Poe

Gerardo Del Guercio

About the Contributors 



\title{
Introduction
}

\author{
Gerardo Del Guercio
}

This volume presents recent critical work on Edgar Allan Poe and psychology. It began in 2012 after careful consideration of what was lacking in Poe scholarship. Upon months of combing through archives at McGill University, Concordia University, as well as JSTOR I discovered that nothing on Edgar Allan Poe and psychology had come around in many years. After more consideration I posted a Call for Papers and received at least thirty responses from scholars from all areas of the world. Finally, in August 2018 I made a selection of the six manuscripts which reflect the current attitudes toward Poe's work and psychology.

In the first chapter, Karen J. Renner examines how Edgar Allan Poe's fictional confessions of murderers and his detective stories provided models for both the serial killer and the profiler respectively. Many of the primary characteristics of serial killers can be traced back to Poe, including their ability to blend in with "normal" society, the ways that the details of their seemingly motiveless murders contain clues to their psyches, and their so-called God complexes. In addition, Poe himself and his detective Dupin have served as prototypes for the criminal profiler, the serial killer's imagined rival. Poe's work may have even influenced actual serial killers by giving them a framework through which to understand-and perhaps even to model- their murderous desires.

The book then moves to Rachel McCoppin's "Shadow Selves: Unwanted Impulses and Obsession in Poe." McCoppin advocates that Edgar Allan Poe's works are defined by obsessed narrators. 
Their obsessions are often baffling to readers: an "evil eye," a merciless cat, or an identical twin, but what makes Poe's narratives truly horrific is the sense that the narrators' obsessions come from within. Poe's narrators have lost touch of reality; they focus conflict within their own unconscious outward which creates irrational obsessions. Carl Jung declares that the unconscious can force the individual to come face-to-face with one's true self through obsessive means, and Poe's narrators do just this. The narrators of "The Imp and the Perverse," "The Tell-Tale Heart," "The Black Cat," "Berenice," "Morella," and "William Wilson" all reveal their unconscious obsession to unmask themselves, revealing a self that does not adhere to societal expectations.

Sean J. Kelly intelligently examines, through a Lacanian psychoanalytic framework, the aesthetic effects of Edgar Allan Poe's poem "The Raven" (1845), specifically those effects produced by the poem's sublime architectonics of present-absence. While critics have examined the role of the sublime and uncanny in the poem, most of these studies have focused on providing an historical context for Poe's aesthetics or establishing cultural sources for the poem's symbolic imagery. By contrast, Kelly aims to demonstrate that both the form and content of "The Raven" anticipate the psychoanalytic, specifically Freudian-Lacanian, concept of das Ding-the mythical "Thing"-which Jacques Lacan, in Seminar VII, argues is the lost object "attached to whatever is open, lacking, or gaping at the center of our desire." Because, according to Lacan's theory, this concept names the void around which human subjectivity forms and all subsequent desire turns, art functions, in essence, to "creat $[\mathrm{e}]$ the void and thereby introduce[e] the possibility of filling it." In this essay, Kelly examines both how the void is staged through aesthetic means in "The Raven" and "filled" by the enigmatic raven, which takes on the function of a sublime object in the speaker's melancholic fantasy. This article is used by permission of The Pennsylvania State University Press." I should like to acknowledge The Edgar Allan Poe Review for granting copyright permission to reuse "Staging Nothing: The Figure of Das 
Ding in Poe's 'The Raven,'” which appeared in The Edgar Allan Poe Review, Vol. 17, No. 2, 2016, pages 116-141.

Tatiana Prorokova's chapter "The Doppelgänger, Psychology, and Poe" demonstrates how already in the mid-nineteenth century, one of the most famous "Dark Romantics" Edgar Allan Poe meticulously examined the problem of human mind in his short stories. Investigating the connections between one's behavior and the psyche, Poe undoubtedly became one of the pioneers of psychology. While literally each story written by Poe deals with the problem of human psyche, this chapter focuses on four of his works, namely "The Black Cat," "The Tell-Tale Heart," "The Fall of the House of Usher," and "William Wilson," to analyze the issue of the doppelgänger as represented in Poe's oeuvre. Apparently, the existence of the dichotomy of the "good" self vs. "bad" self, which inevitably results in the split of one's personality, was one of the issues from human psychology that interested Poe. Criticizing the notion of human perfection and exploring the questions of sin and self-destruction as an inherent part of the human nature, Poe's stories question human morality, overtly hinting at the depravity of individuals and society in general as well as undermining the sanity of human mind. Thus, the chapter explores the characters' doppelgängers that Poe's stories introduce to their readers to understand the problem of one's psychological mutilation and its various manifestations.

In "A Hideous Veil," Phillip Grayson argues that Edgar Allan Poe's "The Tell-Tale Heart" is a story about how the mind recognizes the reality of other people, and ultimately of the world. Grayson finds in the story a striking demonstration of the cognitive processes that connect us to others and to the world around us. The darkness of the solipsism of a world known only superficially, sensorily, cut off from the reality of the minds of others. Central to these processes is a concept called extramission. Extramission is the idea that vision is accomplished by emitting some force or substance from the eyes. While scientifically inaccurate, this idea has been perennially and universally popular, seen in fig- 
ures from Medusa to Superman, and undergirding folklore and ancient anatomical systems alike. The key to extramission's persistent appeal is that it reveals a key aspect of the consciousnesses of others, allowing us to track their attention and recognize their existence outside of ourselves. Nowhere is this more evident than in "The Tell-Tale Heart." Here, the inhuman eye of the narrator's benefactor eventually drives the narrator to murder. This penultimate chapter argues that the failure of the old man's eye to reveal his inner consciousness, its failure to emit some energy or material to confirm the inner life of the old man, lies at the heart of the narrator's murder, and allows the story to explore ways in which we experience reality and the importance of these experiences.

Written by the volume editor, "Mapping German Poetics onto the American Psyche: Masculinity and Metaphysics from E.T.A. Hoffmann to Edgar Allan Poe" argues that the German influence on Edgar Allan Poe was indeed essential in his formation of the short story form that arguably best maps out the motions and poetics of the mind freed from the divisions between language, sensation, and elevated perception and not merely a doppelgänger per se. It is Poe's attempt to venture into borderlands of the creative process that is designed to bridge the gap between hyperrational poetics and metaphysical speculations. Mesmerized by the malleability of the material world to imaginative faculties, Poe adapts Hoffmann's dualist stories dealing with the "feminine in men (that) inevitably results in destruction or a life half lived" even further to create a space where unifying forces replace the new psychological language of a woman's creative energies as well as traditional notions of the doppelgänger motif.

The intention of the particular layout of this book is not to suggest that the chapters be read in any particular order. Chapters should be consumed in the order that helps most readers understand the association between Poe and psychology. Taken together, even though we are one hundred and seventy years after Poe's death, his writings and world are still very much alive. The various interpretations of Poe and Psychology presented in these essays highlight 
the richness, complexity, and pertinence of this classic author. A special gratitude to my contributors for donating their abstract to the present Introduction. 



\title{
1 Poe and the Contemporary Serial Killer Narrative
}

\author{
KAREN J. RENNER
}

Authors and filmmakers have long envisioned natural connections between Edgar Allan Poe and the serial killer, although his role in those texts varies. On the one hand, Poe is the serial killer's dark muse, his writings offering inspiration to the homicidally inclined. In the first season of the television show The Following (2013-), for example, Poe's works inspire the macabre murders of a modern serial killer. Joe Carroll (James Purefoy), an English professor, kills a string of victims, taking cues from the works of his beloved Poe, but his homicidal reign does not end when he is brought to justice by his nemesis, FBI agent Ryan Hardy (Kevin Bacon), for Carroll manages to recruit a group of followers (hence the show's title) to carry out crimes he concocts while in prison. Carroll and his minions give clues regarding their next acts of violence through coy references to Poe, forcing Hardy to take on the role of literary critic in addition to detective in order to foil their plans. Other texts focus on the murders Poe wrote, imagining them as inspiring actual murders. A fictional killer commits crimes that resemble Poe's stories in William Hjortsberg's Nevermore (1994), prompting Harry Houdini and Arthur Conan Doyle to join forces to track down the killer (though Poe's ghost plays a part as well). In addition to serving as muse to fictional serial killers, Poe has been cited as inspiring at least one actual one as well: in a documentary entitled H. H. Holmes: America's First Serial Killer, he is cited as an influence for the crimes committed by Holmes in Gilded Age Chicago: at one point, the narrator of the documentary omi- 
nously exclaims, "As others received inspiration from Rockefeller and Carnegie, H. H. Holmes drew his dark desires from the torture chambers of Edgar Allan Poe."1

On the other hand, Poe is also imagined to be the serial killer's consummate nemesis, a skill he has no doubt gained in the cultural imaginary by fathering the mystery genre. For instance, in the 2012 film The Raven, a serial killer is on the loose in 1840s Baltimore, committing a series of slayings that resemble the most gruesome of Poe's stories. The first murder involves two victims-a young girl whose body has been stuffed up a chimney and her practically decapitated mother-as well as a window that opens when a hidden spring is activated; the text referenced is clearly "The Murders in the Rue Morgue." During the next homicide, a man is strapped to a table while an elaborate mechanism of gears causes a blade to slash back and forth in the air above his stomach, slowly lowering until it slices the man in half; the obvious model for this murder is Poe's "The Pit and the Pendulum." As police realize the connections between these gruesome murders and Poe's short stories, Poe himself (played by John Cusack) is brought on to help the police predict the next crimes that the killer plans to commit. Other contemporary works also imagine Poe as accomplished detective. In Batman: Nevermore (2003), for example, Poe pairs up with the Dark Knight to solve a string of murders in nineteenth-century Baltimore. In Harold Schechter's series of novels (Nevermore: A Novel [2000], The Hum Bug [2002], The Mask of the Red Death [2004], The Tell-Tale Corpse [2006]), Poe works alongside other notable nineteenth-century figures, such as P. T. Barnum, Davy Crockett, and Louisa May Alcott, to solve various murders.

Poe's imagined detective genius seems to be partly a result of his own dark leanings: the belief is that he can track down the serial killer because on some level he thinks like him. The descriptions

${ }^{1}$ H. H. Holmes: America's First Serial Killer, directed by John Borowski (2004; Toronto, Ont.: Waterfront Productions), Netflix. 
of Schechter's novels on his website, for example, portray Poe as a tormented and troubled man. The synopsis for Schechter's Nevermore pictures Poe "plagued by dreadful ruminations and horrific visions" while the summary of Hum Bug imagines that "his realm of terror lies in the shadows of imagination." It is precisely Poe's supposed ability to empathize with disturbed men that, combined with his skills of detection, allows him to successfully track down serial murderers. Poe's affiliation with the dark side is, of course, largely a fabrication initiated by Rufus Griswold's unflattering 1849 obituary and perpetuated by critics and fans ever since. Mark Neimeyer writes, for example, that "Poe has largely been taken up by popular culture because of its ability to exploit his personal suffering and the sad, and sometimes strange, realities of his life as well as the even more fantastic myths that have grown up around him. Poe has become the archetype of the mad genius or the tortured Romantic artist." ${ }^{3}$ As Caleb Puckett puts it in "The Man of the Crowd: Following Poe and Finding Evil in Popular Culture," artists (and readers) connect not only to Poe's works but also "to the image of Poe himself in the role of shadowy, artistic genius who is tortured by his awareness of evil and his own vices" (77).

The image of Poe as haunted by and highly conversant in the darkest realms of human nature is largely an outcome of the two groups of texts he wrote in the 1840s. During that decade, Poe published three fictional first-person confessions of murderers so similar in style and plot that they read almost like three variations of a single story: "The Tell-Tale Heart" (1843), "The Black Cat" (1843), and "The Imp of the Perverse" (1845). ${ }^{4}$ All three feature an

2 "Nevermore: A Novel," http://haroldschechter.com/books/nevermore-novel, and "The Hum Bug," http://haroldschechter.com/books/hum-bug.

3 "Poe and Popular Culture," 209.

${ }^{4}$ While "The Cask of Amontillado" would also seem to fit into this category, it differs in some important ways. For one, its first-person narrator, Montresor, has a more commonplace motive for killing Fortunato: Fortunato has insulted him in some undisclosed way that Montresor feels warrants his death. More significantly, Montresor gets away with murder, and therefore his confession 
anonymous narrator who kills an equally anonymous victim with whom he is intimate on some level but for whose death he exhibits little remorse. The motives they offer for their murders are unclear, unconvincing, or, in the case of "The Black Cat," downright questionable. In each story, the narrator attempts to hide the crime-the narrator of "Imp" makes the murder look like a natural death while the other two narrators simply hide the bodies-but eventually each ends up revealing his homicide in some way. During the same decade, Poe also wrote the three tales that would birth the mystery genre: "The Murders of the Rue Morgue" (1841), "The Mysteries of Marie Rogêt" (1842), and "The Purloined Letter" (1844). The protagonist of these stories, C. Auguste Dupin, a largely armchair sleuth who solves crimes that stump the police simply for the pleasure of it, would later serve as a model for many detectives to come. Together, these two sets of stories and their central figures-the murderer and the investigator-have come to represent the two faces of Poe: the madman and the genius.

In this essay, I wish to uncover the impact that Poe's work and persona have had on the way serial killers are constructed in both media and fiction and quite possibly even the ways in which actual murderers have understood their own identities and acts. ${ }^{5}$ I argue that many of the primary characteristics of the fictional serial killer can be traced back to Poe's works, including his ability to blend in with "normal" society, the ways that the details of his seemingly motiveless murders contain clues to his psyche, and his so-called God complex. In addition, Poe himself and his detective Dupin, I claim, have served as prototypes for the criminal profiler, the serial killer's rival. Often, the profiler's proficiency at tracking down killers is due to his ability to empathically enter into their dark mindsets-a skill that both Dupin and supposedly Poe

lacks the self-destructive quality of Poe's other stories; his crime seems more of a triumph committed for reasons he finds logical, and so he has little to explain.

${ }^{5}$ For a discussion of Poe's impact on true crime narratives, see Christine A. Jackson's The Tell-Tale Art: Poe in Modern Popular Culture (Jefferson: McFarland, 2012). 
himself readily display. This emotional capacity frequently marks the profiler as a morally ambiguous character, either corrupted by exposure to evil or already somewhat depraved to begin with, in much the same way that Dupin is portrayed as morally and emotionally questionable and Poe as a man tormented by the darkness of his own mind.

The fictional serial killer narrative, which grew in popularity during the last quarter of the twentieth-century, was not the spontaneous brainchild of popular culture but rather took its inspiration from the true crimes committed by actual twentieth-century serial killers, who grew in number to such a degree that it sparked a veritable panic. These men, I will argue, could very well have been shaped by Poe's texts as well. A surprising number of them were born in the middle of the twentieth-century and educated in subsequent decades, at the exact time that Poe's prose-and particularly those murderous confessions-superseded his poetry in American literature anthologies and high school curricula. While I would never go so far as to blame Poe for turning men into serial killers, it is possible that his works shaped the ways in which men already predisposed to violence have understood their impulses and actions. Thus, Poe's connection to the serial killer narrative is twofold. In addition to inspiring the creators of serial killer fictions, he may have influenced the very real men responsible for the genre in the first place.

\section{Poe and the Serial Killer Narrative}

Although official agencies, such as the FBI and National Institute of Justice (NIJ), specify slightly different criteria, a serial killer is generally understood to be someone who "murders at least two people in distinctly separate incidents, with a psychological rest period between." In addition, the murders typically are neither reactive nor committed with a particular goal in mind but appear 
to be "satisfying act[s]" in and of themselves. ${ }^{6}$ Although actual serial killers vary quite widely, the image that has seized the popular imagination is of a white man of above average intelligence who kills strangers for deeply personal reasons often related to early childhood experiences; the details of their troubled psychology are symbolically embedded in the consistent features of their methodology.

Technically speaking, then, Poe did not write about serial killers, for neither the crimes that Dupin investigates nor the homicides committed by Poe's murderers fit the definition. "The Purloined Letter" does not even contain a killing, the culprit in "Rue Morgue" is revealed to be an orangutan, not a man, and there is only one victim in "Marie Rogêt." In the confessions, only one homicide occurs, and the victims are no strangers to their murderers, as is commonly the case with the targets of serial killers, but, on the contrary, are acquaintances of some sort, if not housemates. The terms that we use-psychopath, sociopath, antisocial personality, serial killer- are twentieth-century inventions as the figure itself largely appears to be. In Serial Killers: Death and Life in America's Wound Culture, Mark Seltzer claims, "Serial killing, by all accounts, became a career option at the turn of the century." Philip Jenkins similarly notes that FBI data suggests "that recorded serial murder cases have accelerated rapidly over time, with the mid-1960s as the crucial turning point in this trend." Fictional serial killer narratives increased in response to the dramatic rise in actual crimes of this type; Philip L. Simpson dates the subgenre as beginning in "the late 1970s or early 1980s with the coinage and widespread dissemination of the term 'serial murder." "' Simply put, Poe could not have written about serial killers because they didn't exist yet, at least not in their common form.

\footnotetext{
${ }^{6}$ Katherine Ramsland, xi.

7 Seltzer, 1; Jenkins, Using Murder, 29; Simpson, Psycho Paths, 14; Jenkins, 2.
} 
Although Poe's writings predate the "discovery" of the serial killer, people with similar brands of mental illness were beginning to be "officially" identified as early as the mid-nineteenth century, when Poe was writing. At that time, though, they would have been diagnosed with "moral derangement" or "moral insanity." In fact, when Poe was writing his tales, a debate was raging over whether the insanity plea should be expanded to include people diagnosed with these mental illnesses. Poe himself was very interested in the subject, even serving, as Paige Matthey Bynum points out, as "a trial reporter in the 1843 murder-by-reason-of-moralinsanity trial of James Wood." ${ }^{8}$ In delving into the minds of the morally insane, even if only in his imagination, Poe was among the first to fictionalize the act of criminal profiling and thus paved the way for the serial killer narrative.

Certain aspects of Poe's mysteries and murders are also starkly similar to serial killer stories, both factual and fictional, as critics have pointed out. ${ }^{9}$ One feature of the popularized notion of the serial killer that can be traced back to Poe's work is his anonymity and unremarkable nature, his ability to blend into "normal" soci-

${ }^{8}$ Bynum, 145. Furthermore, just six months before the publication of "Imp," the opening article of the North American Review was a 37-page piece devoted to the subject of insanity that used three texts as a springboard for its discussion: the second edition of Isaac Ray's A Treatise on the Medical Jurisprudence of Insanity; a report of the trial of Abner Rogers, Jr., a murderer who had been acquitted by reason of insanity; and The Plea of Insanity in Criminal Cases by Forbes Winslow, a British psychiatrist who would later gain notoriety for his involvement in the investigation of the Jack the Ripper murders. Poe's "Imp of the Perverse," published a mere six months later, contains a paragraph which almost exactly duplicates a passage from this article, which suggests that Poe not only read this article but incorporated its ideas into his short story. See Renner, "Perverse Subjects." See also John Cleman, Dan Shen, and Elizabeth Phillips.

${ }^{9}$ Dennis R. Perry directly refers to Poe-and especially the versions of his stories presented in 1940s films-as an "impetus for stories about serial killers" (157). In "Evolutions in Torture," for example, Sandra Hughes draws connections between Poe's "The Pit and the Pendulum" and the movie Saw. See also Tony Magistrale's "Proportioning Poe: The Blurring of Horror and Detection in The Silence of the Lambs." 
ety. Poe captures this characteristic in two ways. First, he gives his killers very few defining characteristics. In addition to being unnamed, we have no idea what they look like or even where they live. They are literally unidentifiable. Furthermore, their ability to at least momentarily escape suspicion suggests a knack for pantomiming normalcy, a talent that triggers a deep fear about our inability to detect dangerous individuals amongst the crowds of strangers and even acquaintances that we encounter every day. Such a fear is conjured up by depictions of contemporary serial killers as well, who are portrayed as able to wear a "mask of sanity" (so termed after a seminal book on psychopathy written by Hervey Cleckley in 1941). As a white male between the ages of 20 and 40, the average serial killer is also shrouded by what Nicole Rehling describes as the "implied emptiness of white heterosexual masculinity." ${ }^{10}$ Contemporary accounts of serial killers emphasize their ability to blend in and remain undetected. An A \& E documentary entitled The B. T. K. Killer Speaks, for example, begins with the question, "What could turn an ordinary, unassuming man into a monster?"11 Another describes Green River Killer Gary Ridgway as "unremarkable" and has one savvy expert explain that Ridgway "looks and acts like everybody else and he acts and looks like nobody in particular, so he gets away with it." ${ }^{2}$ Poe's stories laid the groundwork for what would become a prominent contemporary anxiety about serial murderers, namely that they walk amongst us unnoticed, a fear expressed effectively in the tagline for the film Disturbia: "Every killer lives next door to someone."

One of the most important contributions that Poe made to the serial killer narrative is centering these stories on an understanding of motive. Although his Dupin mysteries are whodunits and

\footnotetext{
10 "Everyman and No Man," 245.

11 "BTK Confession, Full Version," https://www.youtube.com/watch?v= BvWOje46Xp8.

12 "Gary Ridgway - The Green River Killer - Documentary Films," https: //www.youtube.com/watch?v=Z_9CHWKPWyE, 5:13, 5:20-27.
} 
howdunits, Poe's confessions are whydunits. They begin with the killer already apprehended and so lack the extended cat-and-mouse game between the uncaught killer and cop. What is left to detect, then, is not the identity of the murderer but his motives, both for committing and for confessing his crimes. Poe gives the readers of his confessions a mystery to solve, but it is one focused on psychological matters. The job of literary critic and forensic psychologist become intertwined.

Many contemporary serial killer narratives force their audiences into a similar position, one that privileges comprehending the killer over apprehending him. The reader/viewer is encouraged to take on this role through point of view. Unlike the police, who only know the killer through his crime scenes, the reader/viewer is often allowed to eavesdrop on the criminal and watch him not only commit his gruesome crimes but also struggle with the cravings and consequences of his mental disturbance. For example, in The Silence of the Lambs, we see Buffalo Bill carefully apply makeup, don a diaphanous gown, tuck away his penis and testicles, and live out his fantasy of being a woman; the film allows us access to behavior that provides clues about his motives for kidnapping and skinning women. The story of fictional serial killer Francis Dolarhyde, as presented in Thomas Harris's prequel to The Silence of the Lambs, Red Dragon (1981), follows a similar pattern, as do its 1986 cinematic adaption Manhunter, its 2002 remake Red Dragon, and its revisit in season three of Hannibal. In fact, the practice of alternating between scenes that update us on the progress of the criminal investigation and others that apprise us of the killer's mental condition and violent acts is key to the serial killer narrative, as is apparent, for instance, by its consistent use in the television show Criminal Minds (2005-). In the typical serial killer narrative, then, the viewer/reader knows who the killer is from the get-go, or, if not, then that knowledge proves inconsequential. Our primary task becomes understanding the killer's psyche and why he is driven to commit such heinous acts of violence. 
While serial killer narratives today often point to the killer's childhood as the cause of psychological disturbance, Poe's stories force us to take a more abstract approach, for he gives very little in the way of background to analyze. As a result, Poe's killers often seem bound by what they believe are higher purposes, killing for philosophical or even spiritual reasons. Almost fifty years ago, Joseph J. Moldenhauer described them as "inspired to kill" and as "practic[ing] a fine art of killing."13 The narrators of both "Imp" and "Tell-Tale Heart" certainly present murder as a painstaking process that can only be accomplished by those with a particular talent for it. The narrator of "Imp," for example, declares, "It is impossible that any deed could have been wrought with a more thorough deliberation. For weeks, for months, I pondered upon the means of the murder. I rejected a thousand schemes"; the narrator of "Heart" similarly boasts about how "wisely [he] proceeded-with what caution-with what foresight-with what dissimulation [he] went to work" stalking his victim and, later, lingers upon "the wise precautions [he] took for the concealment of the body." ${ }^{14}$ We especially see murder portrayed as the work of an imaginative and hardworking artist in the "The Black Cat," when the narrator describes the various plans he devised for disposing of his wife's corpse: the "many projects" that "entered [his] mind" included "cutting the corpse into minute fragments, and destroying them by fire," "casting it in the well in the yard," and "packing it in a box, as if merchandize ... and ... getting a porter to take it from the house." 15

Seltzer similarly describes serial killing as "something to do (a lifestyle, or career, or calling)." ${ }^{16}$ His comment draws attention to how the contemporary serial killer, like Poe's murderers, often view their crimes as "works" of some sort, be they artistic endeavors or morally-tinged missions. In his confessions, BTK Killer

\footnotetext{
13 "Murder as a Fine Art," 292.

14 "Imp," 1224; “The Black Cat," 796.

15 Poe, "The Black Cat," 856

16 Seltzer, Serial Killers, 4.
} 
Dennis Rader describes the planning phase of his murders in language that dramatically recalls Poe's "The Black Cat": "I had many projects. I had people I would watch around town... . It was basically, a selection process." 17 Today's most notorious fictional serial killers-Hannibal Lecter and Francis Dolarhyde, John Doe in the film Se7en, Dexter from the series that bears his name, and Jigsaw of the Saw films-also see their work as having a higher purpose.

Poe's murderers, I argue, also kill for a religious reason: to test the existence of God. To them, getting away with murder would prove that punishment is meted out only by fallible human authority and that no divine eye is watching. If through their murders they can prove that God does not exist, they can then usurp his place as rulers of their own universes. Each of Poe's narrators provides clear evidence of a desire to supplant divine authority. The narrator of "The Tell-Tale Heart" believes that his hearing has attained supernatural acuity and that he can hear "all things in the heaven and in earth" and "many things in hell." It is not a surprise, then, that he so fears the old man's evil eye, for he believes it has a God-like ability to see and hear things only the narrator can sense. In other words, the Eye will know of his wicked deeds, regardless of how well he masks himself. He believes that his ability to hide the old man's body such that "no human eye-not even his-could have detected anything wrong" is a sign of his triumph over God's moral laws. ${ }^{18}$

The narrator of "Black Cat" demonstrates similar aspirations for a godlike mastery over his world that would leave him unbound by traditional moral mandates. Every act of violence he perpetrates is preceded by a perceived act of disobedience: he gouges out the cat's eye after it scratches him, and he hangs it because it reminds him of his previous cruelty by fearfully avoiding his advances. He kills his wife for a similar act of insubordination when she prevents him from killing the second cat. The narrator's need

\footnotetext{
17 "BTK Confession, Full Version," https://www.youtube.com/watch? $=$ BvWOje46Xp8.

18 Poe, “The Tell-Tale Heart," 792, 792, 796.
} 
for complete control takes on religious implications when he describes the sense of satisfaction he felt after he buried his wife's corpse behind the wall. He claims that he "looked around triumphantly, and said to [him]self-'Here at least, then, my labor has not been in vain." "19 This oft-overlooked quotation demonstrates the extent to which the narrator sees his own self-interest as superseding any moral or religious obligations. According to the Bible, labor done in vain is labor that is not the Lord's work. Thus, hiding a corpse and escaping punishment-in other words, self-preservation via immoral acts- is, for this narrator, equivalent to God's work, for he believes he is God.

The narrator of "Imp" demonstrates equivalent ambitions of achieving a Godlike position in which he alone determines the moral code by which he shall live. The cause of death determined for his victim, "Death by the visitation of God," is especially fitting since this is, in a sense, exactly what has happened: the victim was killed by a man who has promoted himself to the position of God through his belief that he can define right and wrong based on his own solipsistic viewpoint. The narrator's narcissism is most evident during the lengthy, opening preamble to the tale in which he defines perversity. He claims that phrenologists have gone about determining the natural faculties of man in a faulty way, "deducing and establishing everything from the preconceived destiny of man." The narrator claims that it would be "safer to classify ... upon the basis of what man usually or occasionally did, and was always occasionally doing, rather than upon the basis of what we took it for granted the Deity intended him to do." 20 In other words, the narrator believes it would be safer to define God's intentions for humankind by looking at what we actually do rather than what we idealistically believe that God wants us to do. Since he bases his understanding of human nature on his own behavior, he considers his propensity for perverseness to be representative of the "normal" tendencies of man. Thus, the nature of

\footnotetext{
${ }^{19}$ Poe, "The Black Cat," 857.

20 Poe, "Imp," 1220
} 
man, for this narrator, is defined not by divine ideals dictated by God but rather by his own actions. In short, all of Poe's narrators demonstrate characteristics of what Ernest Jones in 1913 termed a "God complex," a non-clinical term for which "narcissism" might now be a more official synonym and which is cited today as a key characteristic of the serial killer.

The implicit motives for Poe's narrators to commit murder are also similar to those of today's factual and fictional serial killers, according to scholars and experts. True killer Edmund Kemper explained that part of the gratification he derived from murder was that he "was making life-and-death decisions ... playing God in [his victim's] lives." ${ }^{21}$ Authors and directors often exaggerate the God complexes of their fictional killers. Leonard Cassuto writes that Dolarhyde, in Thomas Harris's Red Dragon, is “[o]bsessed by the idea of his 'becoming,' a process that will make him into a self-styled mythological deity."22 Simpson echoes this point more generally when he describes "serial killers in fiction $a[s]$ debased and traumatized visionaries, whose murders privately re-empower them with a pseudo-divine aura." ${ }^{23}$ A serial killer's God complex is given a stunningly visual representation in The Cell (2000), in which a psychologist is able, through the magic of technology, to enter into mind of a comatose killer and finds him ruling over his surrealistic dream world like a demonic overlord.

Poe is not only responsible for influencing the depiction of the serial killer but also for shaping the character of his nemesis, the profiler, whose virtues and vices were both prefigured in Dupin, a connection that more than one critic has noted. ${ }^{24}$ In "Rue Morgue," for example, Dupin displays a remarkable ability to precisely track

${ }^{21}$ Quoted in Schechter, The Serial Killer Files, 96.

${ }^{22}$ Cassuto, 253.

${ }^{23}$ Simpson, Psycho Paths, 14.

${ }^{24}$ Seltzer, for example, writes that the profiler "works-like Poe's prototype detective ... by identifying himself with the killer" (16). John Gruesser credits Poe for "conceiv[ing] of detection as an intellectual duel between one or more sets of opponents" (142), which in the serial killer narrative becomes the competition between murderer and profiler. 
the thoughts of his companion, the narrator. The narrator claims that the skills of an "analyst" like Dupin arise from his ability to "throw himself into the spirit of his opponent, identif[y] himself therewith, and not unfrequently see thus, at a glance, the sole methods (sometimes indeed absurdly simple ones) by which he may seduce into error or hurry into miscalculation." 25 In "The Purloined Letter," Dupin explains that his ability to foil a criminal is due to his capacity to identify almost entirely with him. Dupin compares himself to a schoolboy he once observed who was expert at games of chance that required him to guess the thoughts of his opponent. The boy claimed, "When I wish to find out how wise, or how stupid, or how good, or how wicked is any one, or what are his thoughts at the moment, I fashion the expression of my face, as accurately as possible, in accordance with the expression of his, and then wait to see what thoughts or sentiments arise in my mind or heart, as if to match or correspond with the expression." ${ }^{26}$ Like the profiler-or at least the popular perception of the figure-Dupin's detective skills arise directly from his empathy.

A recent trend in serial killer narratives imagines that the profiler is no longer the squeaky clean representative of the law and a stark contrast to the killer he seeks but rather a far more morally ambiguous figure. In The Following, for example, the suggestion is that detective Ryan Hardy can successfully anticipate serial murderer Joe Carroll's next move because Hardy has a violent past and problematic connection to murder himself. In Hannibal (20132015), profiler Will Graham's exposure to Hannibal Lecter turns his capacity for pure empathy to the dark side. Graham's transformation is hardly surprising, considering that in Harris's original series of novels, agent Clarice Starling ultimately ends up in a romantic relationship with Hannibal. That a common danger of the profiling profession is falling prey to the darkness to which their job exposes them is an idea promoted by profilers themselves, too. After all, former FBI profiler Robert Ressler suggestively ti-

\footnotetext{
25 Poe, "Rue Morgue," 529.

26 Poe, "Purloined Letter," 984.
} 
tled his memoir Whoever Fights Monsters, a reference to Friedrich Nietzsche's famous quotation, "Whoever fights monsters should see to it that in the process he does not become a monster."

The moral ambiguity of the profiler is a trope that can be traced back to Poe as well. Dupin himself is troubling in terms of his emotional and moral disconnection from the crimes he investigates. Dupin's response to the horrifying murders committed in "Rue Morgue" is bizarre enough that the narrator comments on it several times. After hearing the gory details of the crime, for example, Dupin expresses great enthusiasm to investigate it, saying, "An inquiry will afford us amusement"; in response, the narrator interjects in a sidenote to the reader, "I thought this an odd term, so applied, but said nothing." After examining the gruesome scenes, Dupin asks the narrator "if [he] had observed any thing peculiar at the scene of the atrocity." Again, the narrator subtly points out Dupin's emotionlessness: "There was something in his manner of emphasizing the word 'peculiar,' which had caused me to shudder, without knowing why." 27 As Peter Goodwin puts it, "[ $t]$ he pleasure Dupin takes in vicariously experiencing the orangutan's murder of Madame and Mademoiselle L'Espanaye proves that he has not remained uncontaminated by the perversions of this economy." 28

Ultimately, though, the best model for the profiler would be Poe himself. Consider, for example, the similarities between the description of Poe's popular image as "an author with an imagination wondrous yet disturbed, chronicling his darkest and most terrifying thoughts as if by compulsion" in an introduction to a recent anthology of his works and the following description of the fictional criminal profiler: "As portrayed by authors and screenwriters, these fictional heroes are touched by darkness and yet are typically not of the darkness," "involved with the shadow-their own and that of culture-at-large." ${ }^{29}$ In inventing Dupin, the first

\footnotetext{
${ }_{27}$ Poe, "Rue Morgue," 545, 547, 547.

${ }^{28}$ Goodwin, 66

${ }^{29}$ Lubertozzi, “Introduction”; Daniels, Jungian Crime Scene Analysis, 22.
} 
fictional profiler, Poe himself could be credited as being the first real one.

\section{Poe and the Serial Killer}

The connections between Poe and the serial killer extend beyond similarities in narrative structure and conventions. The two also share a similar position in society. Poe is a pop culture phenomenon. Arguably, the only other writer who can rival his cult status is Shakespeare. Poe has, after all, served as the inspiration for an NFL football team, a 1995 video game (The Dark Eye), the persona of an American professional wrestler, and is credited as a "writer" 369 times on imdb.com (up from the 251 that Scott Meslow reported for The Atlantic in 2012). Amazon.com features a whole range of Poe-themed products, including lunchboxes, socks, bandaids, coffee mugs, mousepads, onesies, pop-up books, action figures and bobblehead dolls, candy, and even a black tea blend. A search for "Edgar Allan Poe" on etsy.com yields almost 5,000 results; by comparison, "Emily Dickinson" produces only 1,136 and "Nathaniel Hawthorne" a scant 483.

The contemporary cult of celebrity surrounding serial killers is similarly fetishistic, a topic that has been tackled in a variety of academic sources, as is evident in their titles, including David Schmid's Natural Born Celebrities: Serial Killers in American Culture, Scott Bonn's Why We Love Serial Killers, Ashley Donnelly's "The New American Hero: Dexter, Serial Killers, and the Masses," and Phillip Simpson's article "Hannibal Lecter for President ... Or Why We Worship Serial Killers." Judging by a quick search on Amazon, in the twenty years since the arrest of Jeffrey Dahmer, for example, well over a dozen book-length biographies of him have been written and almost as many films made. He is also the focus of at least one major academic study (Richard Tithecott's Of Men and Monsters: Jeffrey Dabmer and the Construction of the Serial Killer) and mentioned in countless oth- 
ers. The sale of serial killer "murderabilia," collectibles related to murders, is also an active business, with items up for auction on multiple websites. In 2009, the year that a copy of Poe's Tamerlane sold for $\$ 662,500$ and set a new record for highest price garnered by a work of American literature, a website was offering a handwritten Christmas card from Ted Bundy for the bargain price of $\$ 3,000$ and a lock of Charles Manson's hair for about $\$ 500$ less; a get-well card from Ed Gein (the inspiration for Psycho's Norman Bates) was going for $\$ 4,500$. Other items have sold for much more. 30

Poe's popularity, both at home and abroad, has been discussed by a variety of critics, including Scott Peeples, John E. Reilly, and Lois Davis Vines; numerous scholars have also given serial killers and their fictional counterparts similar attention. ${ }^{31}$ Of more interest to me, however, is how the development of the two are intertwined. In Canons by Consensus, Joseph Csicla describes Poe as part of an "exclusive circle of pre-twentieth-century writers whose space apportionment in American literature anthologies has actually increased over the last eighty years." The increase was not due simply to Poe's increased popularity; it was due to the increased popularity of his prose, specifically. As Csicla explains, beginning around the late 1940s, editors of American literature anthologies began "reduc[ing] the number of Poe's poems they included while simultaneously doubling and in some cases tripling the number of his stories," thus increasing the amount of pages his works took up. One can see evidence of this change in studies of high school curricula. In James Warren Olson's study of high school literature

30 For more information, see Brian Jarvis, "Monsters Inc." and Thomas Vinciguerra, "The 'Muderabilia' Market."

31 For Jane Caputi, the popularity of the serial killer is an emblem of vicarious enjoyment of violence against women, a backlash against their gains in societal position and power. For Leonard Cassuto, the prevalence of serial killer narratives is a result of evolving U.S. government policy toward mental illness during the late twentieth-century, particularly the deinstitutionalization which moved many insane to the streets, making them visible. For Jarvis, the serial killer functions "as a gothic double of the serial consumer" (328). 
anthologies between 1917-1957, only Poe's poems "Annabel Lee" and "The Raven" make his list of most frequently anthologized works. But by the time James J. Lynch and Bertrand Evans published High School English Textbooks: A Critical Examination in 1963, Poe's "The Tell-Tale Heart" was tied for second as the most commonly appearing short story while his poetry had dropped substantially. In Arthur Applebee's 1993 study Literature in the Secondary School, Poe's "The Cask of Amontillado" and "The TellTale Heart" tie with several others as the most frequently anthologized pieces of short fiction. ${ }^{32}$

It would take some time, however, for the critical estimation of Poe's prose to rise; after all, in 1963, Gargano still began an article by referring to the "widespread critical condescension toward Edgar Allan Poe's short stories." 33 Csicla demonstrates, however, that Poe's prose quickly supplanted his poetry in terms of scholarly interest. According to his tally, of the 146 articles published on Poe between 1900 and 1945, only 60 examined his tales; yet, of the 344 articles published on Poe between 1946 and 1973, 260 focused on his short stories. ${ }^{34}$ Poe's confessions, however, did not really gain critical attention until later in the century. A quick survey of citations in the Modern Language Association's bibliography reveals that only seventeen articles total were published on "The Tell-Tale Heart," "The Imp of the Perverse," or "The Black Cat" between 1940-1979. The academic output of the 1980s alone on these three stories (sixteen articles) almost matched that of the previous forty years; the 1990s saw nineteen, and the 2000s a record-breaking 27 , and that number was easily beaten in the 2010s-38 articles have already been published on Poe's confessions this decade. The growing popularity of these three stories,

32 Olson, "Nature of Literature Anthologies," 319; Lynch and Evans, High School English Textbooks, 432-33, 466; Applebee, 235. According to Cscicla, who was kind enough to share more detail with me in an email on August 3, 2016, "The Tell-Tale Heart" appeared in thirteen anthologies between 1949 and 1998, as did "Imp," while "The Black Cat" was included in eight.

${ }^{33}$ Gargano, "The Question of Poe's Narrators," 177.

${ }^{34}$ Csicla, Canons by Consensus, 37, 38, 38. 
especially among youth, was also surely aided by the Universal Studios adaptations of his works in the 1930s and 1940s, the Roger Corman American International Pictures cycle of Poe films in the 1960s, and the tremendous number of comic book versions of Poe's works released. ${ }^{35}$ The popularity of Poe's confessions grew steadily over the course of twentieth-century.

It was during this period, too, that the serial killer genre began to emerge. Jenkins argues that by the 1940s, "the American public was thoroughly accustomed to stories of serial murder in the news media"; however, from roughly 1970-1990, “serial murder cases overall were eight times more likely ... than in midcentury; and extreme cases were reported over ten times as frequently." The genre that sprang up around these figures hit its stride soon after. As Jenkins points out, "Both in fiction and in true crime, there were considerably more publications in the three years from 1991 through 1993 than in the 1960s and 1970s combined."36 The increased popularity of the genre was due to a direct response to the dramatic increase in serial murders reported during the 1970s and 1980s, exactly when Poe's more violent stories were gaining prominence.

One could argue that something in the culture (the atrocities of Vietnam, perhaps, or the violent image of Kennedy's assassination and others) simply made violence more permissible, in turn allowing for both the concurrent rise of the serial killer and the popularity of Poe's more gruesome prose; correlation need not imply causation, of course. Nevertheless, I wonder if we can't connect the rise of serial murder to Poe more concretely. The majority of serial murders were, after all, committed by men born during an incredibly short span of time-just fifteen years around the midcentury. By my count, 73 white, American serial killers with five

\footnotetext{
${ }^{35}$ For a discussion of the 1940s films, see Perry, "Poe, Horror, and the Cinematic Mystery Hybrids of the 1940s"; for more on Corman's Poe cycle, see Ormrod, "In the Best Possible Tastes"; and for more on graphic novel adaptations, see Inge, "Comic Book and Graphic Novel Adaptations."

${ }^{36}$ Using Murder, 36, 37, 2.
} 
or more victims have been convicted since 1900 ; a full 45 or $62 \%$ of these men were born between 1938 and 1955, and that group is responsible for 567 documented murders or $70 \%$ of the total victims. These men went to middle and high school roughly between the years of 1949 and 1973, precisely the time when, as we have seen, Poe's murderous confessions were being given increasing attention in school curricula and textbooks.

I do not mean to suggest anything as naive as that reading Poe causes people to kill. However, I do believe that it is possible, as Nicole Rafter has said, that fictional texts "create narratives, giving us plots, imagery, and 'scenarios' that we store in our reservoirs of narrative lines" and that when these fictions "coincide with our own experiences," they may "open up new possibilities of interpretation or even action. In such cases, texts do not cause us to act in any particular way, but they may give us a clearer or more compelling story line for action we have been contemplating." 37 Elana Gomel has proposed a similar argument about serial killers specifically, suggesting that they borrow from standardized and familiar plot conventions in order to explain their own behaviors; the result is a life story that is "highly polished and articulated in accordance with some instantly recognizable narrative pattern-the melodrama of victimization, the boastful memoir of the unrepentant social enemy, the romance of erotic obsession." Gomel tellingly adds that "[i]t is remarkable how many of them use literary models to make sense of what they simultaneously deny has any sense." ${ }^{38}$ Researchers Deborah Cameron and Elizabeth Frazer have also pointed out that serial killers' accounts of themselves are "representations, often consciously constructed, which draw on cultural as opposed to individual resources." ${ }^{39}$ One of those cultural resources may perhaps be Poe's short stories. And since so many "serial killers themselves are often avid consumers of films and books about serial killers," according to Jarvis, Poe's influ-

\footnotetext{
37 "Why They Went Bad," 68.

38 "Written in Blood," 26, 27.

${ }^{39}$ Quoted in Gomel, "Written in Blood," 31.
} 
ence could be part of a self-perpetuating cycle. ${ }^{40}$ If one murderer presents his crimes according to a Poe-esque framework, his model may be replicated by other subsequent killers.

Although this argument would require a systematic investigation beyond the scope of this article, I have already found some compelling parallels between the confessions of serial killers and those penned by Poe. For example, in a 2005 interview, BTK Killer Dennis Rader said of his own propensity to kill, "I just know it's a dark side of me. It kind of controls me. I personally think it's ... a demon that's within me... . At some point in time it entered me when I was very young." ${ }^{\prime 1}$ Rader's statement sounds similar to claims made by the narrator of "The Imp of the Perverse" of having had "(long ago, during childhood) some experience in ... fits of Perversity... . [I]n no instance I had successfully resisted their attacks"; perversity is, of course, a topic discussed by the narrator of "The Black Cat," as well. ${ }^{42}$ Scholars have also wondered about the extent to which the Zodiac Killer may have also been paying respects to Poe in the letters he sent to the press, which contained cryptography not unlike that featured in Poe's "The Gold Bug." At one point, Zodiac also made a reference to the "Red Phantom," which some have interpreted as a nod to "The Masque of the Red Death."

It is in Ted Bundy's final confession, though, that I find the most overt references to Poe, specifically to "The Black Cat." Jonathan Elmer has argued that Ted Bundy "occupies a very Poe-esque milieu" and that "the Bundy interview, and its treatment by The New Yorker, is essentially a tale by Poe." ${ }^{33}$ Nonetheless, Elmer does not go into detail about the connections, which are striking; in addi-

\footnotetext{
${ }^{40}$ Jarvis, 328. See also Lendon, "Serial Killer a Murder Addict, Police Say."

41 "BTK Confession, Full Version," https://www.youtube.com/watch?v= BvWOje46Xp8.

${ }^{42}$ Poe, "The Imp of the Perverse," Graham's Magazine 28 (July 1845), http://www. eapoe.org/works/tales/impa.htm, 3. This parenthetical comment appears only in this version.

${ }^{43}$ Reading at the Social Limit, 128, 129.
} 
tion to describing similar experiences and emotions, Bundy often even uses similar vocabulary. In “The Black Cat," for instance, Poe's narrator insists that he is giving as objective an explanation as possible, merely "detailing a chain of facts"; Bundy similarly states at one point that he is simply relating "an indispensable link in the chain of behavior, the chain of events that led to behaviors." Furthermore, Poe's narrator maintains that his criminality was neither the result of parental mistreatment nor a natural predisposition to violence: "From my infancy I was noted for the docility and humanity of my disposition... . I was especially fond of animals, and was indulged by my parents with a great variety of pets." 44 Bundy likewise claims, "I grew up in a wonderful home with two dedicated and loving parents, as one of five brothers and sisters. A home where we, as children, were the focus of my parent's lives" and that therefore "the basic humanity and basic spirit that God gave [him] was intact."

Moreover, in the same way that Poe's narrator describes a sequence of events in which an addiction to alcohol leads to him committing more and more serious acts of violence, Bundy charts the effects of an escalating addiction to pornography. Poe's narrator claims that his "intemperance" caused a progression of violence that began with the verbal and then physical abuse of his wife and eventually led to the abuse of his most beloved cat, Pluto. He depicts his "general temperament and character-through the instrumentality of the Fiend Intemperance" as undergoing "a radical alteration for the worse." Bundy depicts pornography as "fuel[ing] this kind of thought process. Then, at a certain time, it is instrumental in crystallizing it, making it into something which is almost a separate entity inside." Like Poe, he personifies his impulses as an evil entity that came to possess him. Poe's narrator portrays a slow devolution in character, writing that "the feeble remnant of the good within [him] succumbed," that he "grew, day by day, more

${ }^{44}$ All quotations from Bundy are from "Fatal Addiction: Ted Bundy's Final Interview with James Dobson," https://vimeo.com/96877731. Poe, "The Black Cat," 850, 853. 
moody, more irritable, more regardless of the feelings of others," until finally " $\mathrm{t}]$ he moodiness of [his] usual temper increased to hatred of all things and of all mankind." 45 Bundy similarly imagines his declension as involving a decreased reverence for the rights of others: "These barriers ... I had learned as a child, that had been instilled in me, were not enough to hold me back with respect to seeking out and harming somebody,"

Bundy and Poe's narrator also describe acts of violence in similar ways. The narrator of "The Black Cat" claims that before he gouged out the eye of his beloved cat Pluto, "[t]he fury of a demon instantly possessed me. I knew myself no longer" and, later, when he kills the cat, that he is committing "a deadly sin that would so jeopardize my immortal soul as to place it-if such a thing were possible-even beyond the reach of the infinite mercy of the Most Merciful and Most Terrible God." His description here sounds dramatically similar to that given by Bundy, who states, "I can only liken it to ... being possessed by something so awful and alien, and the next morning waking up and remembering what happened and realizing that in the eyes of the law, and certainly in the eyes of God, you're responsible. To wake up in the morning and realize what I had done with a clear mind, with all my essential moral and ethical feelings intact, absolutely horrified me." Poe's narrator claims after maiming Pluto that he "experienced a sentiment half of horror, half of remorse, for the crime of which I had been guilty; but it was, at best, a feeble and equivocal feeling, and the soul remained untouched. I again plunged into excess." 46 Similarly, Bundy explains that after committing violence, he would feel "an enormous amount ... of horror, guilt, remorse afterwards, but then that impulse to do it again would come back even stronger."

Fully illustrating Poe's influence on the thinking of actual serial killers requires a lot more research and space than I have left here, but the parallels uncovered so far are compelling. Edgar Allan

\footnotetext{
45 Poe, “The Black Cat,” 851, 851, 851, 851, 856.

46 Poe, “The Black Cat,” 851, 852, 851.
} 
Poe may have made the serial killer narrative possible not only for the literary world but also for the serial killers themselves by giving them a framework through which to understand-and perhaps partly to legitimize-their murderous desires. ${ }^{47}$ Poe's influence therefore extends to both the fictional and factual. He provided literary models for the imagined killers created by writers and directors as well as psychological ones for their real-life counterparts.

\section{Works Cited}

Applebee, Arthur N. Literature in the Secondary School: Studies of Curriculum and Instruction in the United States. Urbana: National Council of Teachers in English, 1993.

Bonn, Scott. Why We Love Serial Killers: The Curious Appeal of the World's Most Savage Murderers. New York: Skyhorse, 2014.

"BTK Confession, Full Version." YouTube video, 46:37. Posted February 26, 2014. https://www.youtube.com/watch?v=BvWOje46Xp8.

Bynum, Paige Matthey. "'Observe How Healthily-How Calmly I Can Tell You the Whole Story': Moral Insanity and Edgar Allan Poe's 'The Tell-Tale Heart.” In Literature and Science as Modes of Expression, edited by Frederick Amrine, 14152. Boston Studies in the Philosophy of Science, vol. 115. Dordrecht: Kluwer Academic Publishers, 1989.

Caputi, Jane. "American Psychos: The Serial Killer in Contemporary Fiction." Journal of American Culture 16, no. 4 (1993): 101-12.

-. "The New Founding Fathers: The Lore and Lure of the Serial Killer in Contemporary Culture." Journal of American Culture 13, no. 3 (1990): 1-11.

Cassuto, Leonard. Hard-Boiled Sentimentality: The Secret History of American Crime Stories. New York: Columbia University Press, 2009.

Cleman, John. "Irresistible Impulses: Edgar Allan Poe and the Insanity Defense." American Literature 63 (1991): 623-40. doi: 10.2307/2926871.

47 Thanks to Nicole Walker for expressing this so eloquently and for her endless support during the writing of this article. 
Csicsila, Joseph. Canons by Consensus: Critical Trends and American Literature Anthologies. Tuscaloosa: University of Alabama Press, 2004.

Daniels, Aaron B. Jungian Crime Scene Analysis: An Imaginal Investigation. London: Karnac Books, 2014.

Donnelly, Ashley. "The New American Hero: Dexter, Serial Killer for the Masses." Journal of Popular Culture 45, no. 1 (2012): 15-26. doi: 10.1111/j.15405931.2011.00908.x.

Elmer, Jonathan. Reading at the Social Limit: Affect, Mass Culture, and Edgar Allan Poe. Stanford: Stanford University Press, 1995.

"Fatal Addiction: Ted Bundy's Final Interview with James Dobson." Vimeo video, 32:51. Posted May 30, 2014. https://vimeo.com/96877731.

Gargano, James. “The Question of Poe’s Narrators.” College English 25, no. 3 (1963): 177-81. doi: 10.2307/373684.

Gomel, Elana. "Written in Blood: Serial Killing and Narratives of Identity." Post Identity 2, no. 1 (Winter 1999): 24-70.

Goodwin, Peter. "The Man in the Text: Desire, Masculinity, and the Development of Poe's Detective Fiction." In Edgar Allan Poe: Beyond Gothicism, edited by James M. Hutchisson, 49-68. Newark: University of Delaware Press, 2011.

Gruesser, John. "Poe’s Progeny: Varieties of Detection in Key American Texts, 1841-1861.” In Poe's Pervasive Influence, edited by Barbara Cantalupo, 139-50. Bethlehem: Lehigh University Press, 2012.

H. H. Holmes: America's First Serial Killer. Netflix. Directed by John Borowski. Toronto, Ont.: Waterfront Productions, 2004.

Hughes, Sandra. "Evolutions in Torture: James Wan's Saw as Poe for the TwentyFirst Century." In Adapting Poe: Re-Imaginings in Popular Culture, edited by Dennis R. Perry and Carl H. Sederholm, 71-80. New York: Palgrave Macmillan, 2012.

Inge, M. Thomas. "Comic Book and Graphic Novel Adaptations of the Words of Edgar Allan Poe: A Chronology.” In Adapting Poe: Re-Imaginings in Popular Culture, edited by Dennis R. Perry and Carl H. Sederholm, 231-47. New York: Palgrave Macmillan, 2012.

Jackson, Christine A. The Tell-Tale Art: Poe in Modern Popular Culture. Jefferson: McFarland, 2012. 
Jarvis, Brian. "Monsters Inc.: Serial Killers and Consumer Culture." Crime Media Culture 3 (2007): 326-44. doi: 10.1177/1741659007082469.

Jenkins, Phillip. Using Murder: The Social Construction of Serial Homicide. New York: Gruyter, 1994.

Lendon, Brad. "Serial Killer a Murder Addict, Police Say." CNN.com, December 12, 2012. http://www.cnn.com/2012/12/11/justice/alaska-serial-killer/index. html.

Lubertozzi, Alex. "Introduction." In Edgar Allan Poe: Complete Tales and Poems. Oak Park: Top Five Books, 2013.

Lynch, James J., and Bertrand Evans. High School English Textbooks: A Critical Examination. Boston: Little, Brown, and Company, 1963.

Magistrale, Tony. "Proportioning Poe: The Blurring of Horror and Detection in The Silence of the Lambs." In Poe's Children: Connections between Tales of Terror and Detection, edited by Tony Magistrale and Sidney Poger, 77-91. New York: Peter Lang, 1999.

Meslow, Scott. "Pop Culture's Undying Edgar Allan Poe Obsession." The Atlantic, April 26, 2012. http://www.theatlantic.com/entertainment/archive/2012/ 04/pop-cultures-undying-edgar-allan-poe-obsession/256417/.

Moldenhauer, Joseph J. "Murder as a Fine Art: Basic Connections between Poe's Aesthetics, Psychology, and Moral Vision.” PMLA 83, no.2 (May 1968): 284-97. doi: $10.2307 / 1261183$.

Neimeyer, Mark. "Poe and Popular Culture." In The Cambridge Companion to Edgar Allan Poe, edited by Kevin J. Hayes, 205-24. Cambridge: Cambridge University Press, 2004.

Olson, James Warren. “The Nature of Literature Anthologies Used in the Teaching of High School English 1917-1957.” PhD diss., University of Wisconsin, 1969.

Ormrod, Joan. "In the Best Possible Tastes: Rhetoric and Taste in AIP's Promotion of Roger Corman's Poe Cycle." In Adapting Poe: Re-Imaginings in Popular Culture, edited by Dennis R. Perry and Carl H. Sederholm, 145-63. New York: Palgrave Macmillan, 2012.

Peeples, Scott. The Afterlife of Edgar Allan Poe. Rochester: Camden House, 2007.

Perry, Dennis R. "Poe, Horror, and the Cinematic Mystery Hybrids of the 1940s." In Recovering 1940s Horror Cinema: Traces of a Lost Decade, edited by Mario 
Degiglio-Bellemare, Charlie Ellbé, and Kristopher Woofter, 147-59. Lanham: Lexington Books, 2015.

Phillips, Elizabeth. "Mere Household Events: The Metaphysics of Mania.” In Edgar Allan Poe: An American Imagination, 99-137. Port Washington: Kennikat Press, 1979.

Poe, Edgar Allan. “The Black Cat.” In Tales, by Edgar A. Poe, 37-46. New York: Wiley and Putman, 1845. http://www.eapoe.org/works/tales/blcatb.htm.

-. "The Imp of the Perverse." Graham's Magazine, July, 1845. http://www.eapoe. org/works/tales/impa.htm.

-. "The Murders in the Rue Morgue." In The Collected Works of Edgar Allan Poe. Vol. II. Tales and Sketches, edited by Thomas Ollive Mabbott, 521-74. Cambridge, MA: The Belknap Press of Harvard University Press, 1978.http://www.eapoe.org/ works/mabbott/tom2t043.htm.

-. "The Purloined Letter." The Collected Works of Edgar Allan Poe. Vol. III. Tales and Sketches, edited by Thomas Ollive Mabbott, 972-97. Cambridge, MA: The Belknap Press of Harvard University Press, 1978. http://www.eapoe.org/works/ mabbott/tom3t011.htm.

-. "The Tell-Tale Heart." The Collected Works of Edgar Allan Poe. Vol. III. Tales and Sketches, edited by Thomas Ollive Mabbott, 789-99. Cambridge, MA: The Belknap Press of Harvard University Press, 1978.

Puckett, Caleb. “The Man of the Crowd: Following Poe and Finding Evil in Popular Culture." In History of Evil in Popular Culture: What Hannibal Lecter, Stephen King, and Vampires Reveal about America. Vol. II. Evil in Words, Imagery, the News, Trials, Myths, and Religion, edited by Sharon Packer and Jody Pennington, 77-87. Santa Barbara: Praeger, 2014.

Rafter, Nicole. "Why They Went Bad: Criminology in Crime Films." In Shots in the Mirror: Crime Films and Society, 47-70. New York: Oxford University Press, 2000 .

Ramsland, Katherine. The Human Predator: A Historical Chronicle of Serial Murder and Forensic Investigation. New York: Berkley Books, 2005.

Rehling, Nicole. "Everyman and No Man: White Masculinity in Contemporary Serial Killer Movies.” In Extra-Ordinary Men: White Heterosexuality Masculinity in Contemporary Popular Cinema, 227-47. Lanham: Lexington Press, 2009. 
Reilly, John E. "Poe in Literature and Popular Culture." In A Companion to Poe Studies, edited by Eric W. Carlson, 471-93. Westport: Greenwood Publishing, 1996.

Renner, Karen J. "Perverse Subjects: Drunks, Gamblers, Prostitutes, and Murderers in Antebellum America.” PhD diss., University of Connecticut, 2010.

Schechter, Harold. The Serial Killer Files: The Who, What, Where, How, and Why of the World's Most Terrifying Murderers. New York: Random House, 2003.

Schmid, David. Natural Born Celebrities: Serial Killers in American Culture. Chicago: University of Chicago Press, 2005.

Seltzer, Mark. Serial Killers: Death and Life in America's Wound Culture. New York: Routledge, 1998.

Shen, Dan. "Edgar Allan Poe's Aesthetic Theory, the Insanity Debate, and the Ethically Oriented Dynamics of 'The Tell-Tale Heart'." Nineteenth-Century Literature 63, no. 3 (Dec. 2008): 321-45. doi:10.1525/ncl.2008.63.3.321.

Simpson, Philip L. "Hannibal Lecter for President ... Or Why We Worship Serial Killers.” In Cult Pop Culture: How the Fringe Became Mainstream. Vol. I Film and Television, edited by Bob Batchelor, 83-96. Santa Barbara: Praeger, 2012.

-. Psycho Paths: Tracking the Serial Killer through Contemporary American Film and Fiction. Carbondale: Southern Illinois University Press, 2000.

Stout, Martha. The Sociopath Next Door: The Ruthless Versus the Rest of Us. New York: Broadway Books, 2005.

“The Green River Killer Gary Ridgway.” BBC Documentary. YouTube video, 58:49. Posted April 19, 2018. https://www.youtube.com/watch?v=Z_9CHWKPWyE.

Tithecott, Richard. Of Men and Monsters: Jeffrey Dabmer and the Construction of the Serial Killer. Madison: University of Wisconsin Press, 1997.

Vinciguerra, Thomas. “The 'Muderabilia' Market.” The New York Times, June 4, 2011. http://www.nytimes.com/2011/06/05/weekinreview/05murderabilia. html?_r=0. 


\title{
2 Perverse Selves: Unwanted Impulses and Obsession in Poe
}

\author{
RACHEL MCCOPPIN
}

Edgar Allan Poe's works are defined by obsessed narrators. Their obsessions are often baffling and mysterious to readers: an "evil eye," a merciless cat, or menacing teeth, but what makes Poe's narratives truly horrific is the sense that the narrators' obsessions come from within their own unexplored unconscious. Poe's narrators repress natural, yet fearful and unwanted, impulses, which results in irrational obsessions and ultimately leads to horror.

Poe's works have inspired psychiatrists and psychologists to examine the hidden, darker elements of the human brain. Many contend that Poe delivers works that portray mentally unbalanced individuals, but what makes his tales truly terrifying is that he also provides tremendous insight into the dark and terrifying aspects of the healthy mind within us all; "There lives no man who at some period has not been tormented" (Poe, "Imp", 155). David M. Wegner explores the unwanted thoughts that enter into one's consciousness, that if repressed become obsessions. He contends that unwanted thoughts start in a healthy brain as annoyances and can become burdens, but if successfully repressed in "some people at some times", they can become "a devastating affliction, worse than any disease" (Wegner 1).

Poe's "The Imp of the Perverse" offers insight into many of his most memorable protagonists, and will be the foundation that this paper will draw from to analyze his other short stories: "The TellTale Heart," "The Black Cat," "Berenice," "Morella," and "William 
Wilson," which all reveal heightened examples of repressing and not examining one's natural, dark impulses as signals of the unconscious.

"The Imp of the Perverse" is a unique story for Poe because of the level that he examines the natural, dark impulses of the human psyche; most of the story is devoted to an abstract discussion of this analysis. Poe states that "in the pure arrogance of reason, we have all overlooked" this natural perversity of self (Poe, "Imp", 155). He maintains that mankind has tried to ignore or rationalize the natural human impulse to imagine and envision the worst possible scenario of any given situation. Similarly, Lee Baer states:

I am convinced that Poe captured a universal human condition....Few in number are those people who can honestly say that they have never recognized the imp at work in themselves. Fortunately...for most people, these occasional bad thoughts are nothing but a fleeting annoyance. But many people who come to see me are not so fortunate. Their bad thoughts may be about violence or sex or blasphemy and may bombard them every waking hour....Many contemplate suicide at some time. (Baer 5)

Poe's "Imp of the Perverse" discusses this concept of contemporary research:

We tremble with the violence of the conflict within us...there grows into palpability, a shape...it is but a thought, although a fearful one, and one which chills the very marrow of our bones...it involves that one most ghastly and loathsome of all the most ghastly and loathsome images of death and suffering which have ever presented themselves to our imagination.....And because our reason violently deters us from the brink, therefore, do we the more impetuously approach it....If there be no friendly arm to check us, or if we fail in a sudden effort to prostrate ourselves backward from the abyss, we plunge, and are destroyed. (Poe, "Imp", 157-8)

This phenomenon of the mind has been studied by psychologists for years. Sigmund Freud was in part influenced by Poe's works 
(Yang 598); he attributed the dark, taboo, and fearful impulses of the mind to the unconscious. Freud's subconscious is his conception of the mind's way of behaving itself to fit the expectations of society by limiting and checking the unconscious flashings of "perversity."

Carl Jung, as a student of Sigmund Freud's psychoanalysis, expanded upon Freudian theory with his Jungian analytical psychology, which stresses a process of self-actualization through merging one's internal "shadow" of the unconscious with external reality. Jung continues by saying that the intrinsic shadow induces dark impulses, which can produce heavy emotion, causing the individual to feel possessed by the emotion that accompanies the shadow impulse (Jung, "Shadow", 112-3). If these impulses and subsequent emotions go unchecked or unexamined, then the individual may project dark or fearful impulses onto other sources, objects or people, as obsessions. Jung's goal of analytical psychology calls for each individual to examine all aspects of the self, even the dark shadow, in order to self-actualize. Jung states that the shadow is a natural, though dark, part of each individual, and it exists as part of one's unconscious (Jung, "Shadow, 112-3). Jung states that "no one can become conscious of the shadow without considerable moral effort. To become conscious of it involves recognizing the dark aspects of the personality as present and real. This act is the essential condition of any kind of self-knowledge, and it therefore, as a rule, meets with considerable resistance" (Jung, "Shadow, 112). Failure to harmonize one's external reality with the unconscious can create neurosis, such as obsession and psychic splitting.

Many scholars, such as David R. Saliba, Eric. W. Carlson, Barton Levi St. Armand, James Gargano, and Martin Bickman, have analyzed Poe's works as achievements of psychological fiction, citing both Freudian and Jungian concepts within many of his works; in fact, Saliba states that Poe "was far ahead of his time as a psychologist" (Saliba 15). In agreement with these scholars, this article analyses how Poe, in "The Imp of the Perverse", and many of his other stories of obsessed narrators, often portrays characters who 
cannot, or simply do not, face the dark impulses of their own Jungian shadows. Poe's narrators are repeatedly depicted as isolated within their own minds, and left unchecked, they fall prey to their very natural unconscious impulses by repressing them instead of examining their possible origins.

Wegner states that when one's unconscious dark impulses, that are natural to every human, are repressed out of fear of them, they can become obsessions (Wegner 1). Speaking of Poe's narrators, Saliba contends that they experience irrational impulses that come from their unconscious, and unable to recognize these dark impulses as natural, they fear them and resort to defense mechanisms that to Freud and Jung were "unconscious compulsions that function to save the conscious mind from unwanted shock or pain" in an attempt at self-preservation, which "essentially distort[s] reality" (Saliba 40-1). Saliba continues to state that common defense mechanisms embraced by both Freud and Jung, and portrayed in many of Poe's protagonists, involve repression and projection (Saliba 41). Often the impulses of repression and projection become distorted obsessions against something that seems "hateful or unpalatable" (Saliba 45). Rachman contends that obsessions are unwanted repetitive thoughts that are difficult for the individual to control; "They are similar...to the unwanted, intrusive thoughts (images or impulses) that nearly everyone experiences, but they are...more insistent, more distressing” (Rachman 793). Rachman continues to explain that impulses can become obsessions by the way the individual misinterprets the impulse. Usually the individual misinterprets them as immoral, fearful, even criminal; the individual becomes dominated by fear of the impulse and attempts to repress the fearful thoughts because "they interpreted these thoughts, impulses or images as revealing important but usually hidden elements in their character, such as these obsessions mean that deep down I am an evil person, I am dangerous...I may become totally uncontrollable...I am going insane" (Rachman 794).

It is on the last page of "The Imp of the Perverse," that the narrator finally comes into shape, since the entire work thus far has 
not revealed a source for the sentiments expressed. In addition, the narrator remains nameless; this is an aspect of many of Poe's works and suggests the lack of identity and self-awareness on the part of the narrator. The narrator obsesses on one violent scenario of murder without particularly knowing why. His explanation for his obsession is that every human possesses uncontrollable impulses towards violence. Although, as has been stated, psychology proves this is true, Poe's narrator, in his isolated mindset is unable to quell the impulses his mind produces. The narrator apparently has spent a great deal of time justifying how a propensity towards violence or horrific thoughts are a part of human nature, but he fails to move beyond this point, as do many of Poe's other narrators. The narrator within "The Imp of the Perverse" only obsesses on his dark fantasy to murder an old man, without further examining why he fanaticizes this way. The narrator has not accepted his violent impulses as natural, nor has he analyzed them for unconscious meaning; instead, he only fears them and trusts that they prove he is evil and insane. His subsequent obsession to actually murder the man reveals a preoccupation with death and mortality.

For Jung, the at times, fearful impulses of the unconscious shadow can reveal important lessons of initiation into the vital and often frightening fact of mortality. Both Freud, in his Beyond the Pleasure Principle (1920) and Jung, in his Undiscovered Self (1957), discuss how a preoccupation for the fear of death is often linked with the unconscious, and the unconscious, as shown in some of Poe's most famous works, has a way of demanding attention. Poe presents myriad examples of narrators who form obsessions from a fear of healthy, yet terrifying, "perverse" impulses. He shows that a lack of acceptance and introspection into these urges and obsessions causes the narrators to fragment. They arguably split psychically because they have failed to examine these promptings of the unconscious shadow; they have failed to see the natural fearful impulses as simply a fact of their own mortality, and an opportunity for psychic growth. For Freud, "Fantasies of putrefaction, 
decay, sickness, compulsion, and suicidal impulses disclose" an unconscious need or "psychological perspective which seeks deepening. Freud ended his own life enraptured or fascinated with this train of thought" (Freud, "Thanatos"). In attempting to flee the idea of death, Poe's narrators' unconscious selves demand awareness, first by sending out "perverse" impulses within the narrator, then by odd obsessions that are not so odd when viewed in terms of unconscious identification, and finally by an actualization of murder. In killing others, the narrators are trying to dispel the fear of their own mortality, but in reality, they are indeed killing themselves by thrusting from them any chance of self-actualization. This is precisely what the narrator of "The Imp of the Perverse" has fallen prey to; he has repressed his fear of death, so that it has been able to grow into an obsession and dominate his psyche, until he quells its influence by enacting the feared impulse.

The narrator of "The Imp of the Perverse" ultimately enacts his obsession by poisoning a candle next to the bedside of a man to murder him. The narrator inherits the wealth of the deceased after the murder, so it can be presumed that the narrator was held in the high esteem of the victim, possibly even loved by the victim. The work suggests, as many other Poe stories more explicitly state, that the narrator was obsessed with killing this man, who seemingly loved him, because the man revealed something to the narrator that he could not face, presumably death - his own and that of this man he may love. The culmination of horror within many of Poe's stories involves the narrators often killing the ones they love, directly because of their odd obsessions. Poe's stories often show that unresolved or unexamined feelings of affection lead his narrators to an inevitability of death. Love and death are connected for Poe's narrators, as they were for Freud; obsessions as a form of repression are often tied to Freud's "Thanatos," the death impulse, and this fear of mortality is often merged with love, Freud's "Eros," the life impulse (Freud, Beyond). The inability of Poe's narrators to love, or more precisely to identify their love for another, spurs them to splinter into unnatural obsessions, until 
they enact what they unknowingly fear most-the death of their loved one, as well as the death of self. And again this is often connected to the universal dark impulses of the shadow; oftentimes, an impulse has the power to become exaggerated because it is so fearful to the individual. Those who suffer from obsession, as Rachman states, do so because they misinterpret their natural perverse impulses, as having a personal significance; this significance often involves those one loves (Rachman 794). As Baer states "obsessions-may cost people the most important things in their lives: Some cannot bear to be around their own children; others cannot have relationships...because of their bad thoughts" (Baer 5). It is precisely the fear of losing what one values most that often becomes the focal point of the obsession. In Poe's narratives, the narrator, though, is absolutely removed from almost any amount of self-knowledge. Most of narrators do not even know that they indeed do love the person they begin to connect their obsessions to, and ultimately end up harming. Their total lack of self-knowledge has devastating effects on themselves and those around them, but the narratives do end with the narrator finally starting the process of self-actualization.

Poe does not end his narratives at the point of murder; instead, he closes the work with the repressed unconscious finally being revealed, though it oftentimes causes the downfall of the narrator, it succeeds in forcing the narrator to self-actualize. In "The Imp of the Perverse," just as the narrator's mind overtook his ability to restrict his violent impulses, through his own lack of introspection and proper identification of those impulses, his unconscious further shows its dominance by now making the narrator obsess over confessing his own guilt; "to think... was to be lost" (Poe, "Imp", 159). In "The Imp of the Perverse", the narrator feels he is forced by his mind towards complete destruction through confession, but in reality the narrator's unconscious took over control to force the narrator to face himself. He bursts out, yelling openly in the streets, that he is guilty. The work ends, as does many of Poe's 
works, with the narrator apprehended through self-actualization in confession.

Through "The Imp of the Perverse" a clear format for many Poe stories has been presented: There are often Poe narrators who are isolated, either by life circumstance, or by choice, and their isolation most often involves sequestration within their own minds. Poe narrators also often become obsessed on one specific object or person as an attempt to avoid fearful impulses of the unconscious. It appears to the narrator then that his mind, through his obsessions, begins to control his actions, and this causes him to become desperate. He does not, or is not able, to examine the impulses as natural and possibly revealing of his unconscious self. The narrative often results in the narrator committing murder in an attempt to quell the disturbance of his misinterpreted impulses and unexplored mind. And finally, the narrative ends with the narrator focusing on a new obsession-confession-in order to reveal to the narrator his unconscious shadow with its harboring of the inevitable fact of death he has been trying to avoid.

Poe's "The Tell-Tale Heart" follows the same pattern presented in his "Imp of the Perverse." The narrator of this work also remains nameless, again suggesting a lack of self-identification. He appears throughout the story as intensely isolated within his own psyche, falling prey to odd impulses, like his belief that his senses have grown supernaturally refined, stating that he can even hear things in heaven and hell.

The story then presents the narrator's focus on his central misinterpreted impulse-his abhorrence towards the old man's blinded eye. He cannot relate why the impulse affects him the way that it does; "It is impossible to say how first the idea entered my brain; but once conceived, it haunted me day and night. Object there was none. Passion there was none. I loved the old man" (Poe, "Tell-Tale", 161). Still, the narrator becomes filled with dread at the feelings his abhorrence towards the eye produces. He fears the eye; he shuns all thoughts of the eye from his psyche, but as Poe, 
and psychologists have stated, the shunned object becomes the narrator's obsession. Wegner's research suggests that "the desire to suppress the thought is itself the obsession" (Wegner 5). Thus, the old man's blinded eye becomes an "Evil Eye" to the narrator. This obsession of the "Evil Eye" turns into an obsession to kill the eye, but to kill the eye, he must kill the old man.

The story is constructed to offer little explanation as to why the narrator focuses on a seemingly absurd object, like an "evil eye," and how this obsession of the object can lead to murder. Wegner expands his research by stating, "Unwanted thoughts turn up in a variety of psychological disorders...they are in center stage when people suffer from obsessions.... and are also in many cases of depression...self-control problems....and even psychotic reactions such as schizophrenia" (Wegner 7). Poe's lack of explanation of motive is key to his format presented in "The Imp of the Perverse"; the narrator has no conscious idea why he chooses the eye to obsess over; "I think it was his eye! Yes, it was this!" (Poe, "Tell-Tale, 161) Poe is revealing that a seemingly meaningless trigger drove the narrator to madness, but by examining Poe's proclamations in "The Imp of the Perverse," one can see that the eye is only a part of a deeper psychological issue.

Again, the trigger of revulsion of the eye reveals a dark shadow impulse to murder someone who he loves. This impulse may have important meaning; if explored, it may reveal unconscious elements to the narrator about himself. It seems important that the symbol of obsession is in fact an eye; the eye often is associated with consciousness, sight, seeing clearly, and being seen. The narrator's obsession of the eye suggests that the narrator is attempting to end any possibility of full self-actualization. If the narrator examined this obsession, there may be an opportunity of growth, but the narrator, as Poe makes decidedly clear, does not at all rationally face this dark impulse; the "misjudgment of the other can only mirror the 'blindness' of the self" (Wing-chi 25). Instead, he fears the trigger of the eye, not the impulse of murder. His fear of 
the eye becomes his obsession, and his obsession forces him to act out in violence in an attempt to silence the fear.

The story ends with the narrator's obsessions multiplying. Moments before he murders the man, he begins to fear the heartbeat of the old man. The obsession of a heartbeat is a clear connection to life; again, examination by the narrator into why he obsesses over the old man's heart may reveal important information about his desire for continued love from the old man, and possibly the fear of losing the old man's love through inevitable death, and further, it might show the narrator his own fear of inevitable death. But, he does not examine his unconscious; instead he fears his obsessions, believes they mean he is going insane, and then allows his mind to dominate.

The narrator of "The Tell-Tale Heart" is absolutely removed from almost any amount of self-identification, so his lack of selfknowledge produces devastating results. The narrator murders the man, hides his body under the floor boards, and following Poe's format presented in "The Imp of the Perverse," begins to obsess that now the authorities will hear the imagined still beating heart of the old man, so the narrator, as an apparent slave of his mind tells the authorities what he did, "Oh God! What could I do? I foamed-I raved-I swore” (Poe, "Imp”, 165).

Poe's "Black Cat" also shows another case where the protagonist's shadow impulses become odd obsessions, in this case centering on a cat named Pluto, which eventually leads to the narrator murdering his wife. Following the presented format in "The Imp of the Perverse," this narrator also remains nameless, again suggesting a lack of identity. In addition, because the narrator is often heavily inebriated, he suffers from inaccurate self-knowledge and is more than likely attempting to numb inner pain. Further suggestion of his lack of self-identification is his misinterpretation of the focal point of his obsession. Roberto Reeder also connects the narrator's misdirected obsessions to Jungian psychology, stating that the obsession of the cat "functions as the narrator's anima"; the con- 
cept of the "anima", for Jung, was defined "as a personification of the unconscious in general, and... a bridge to the unconscious" (Reeder 20).

The narrator describes himself as always being quite fond of animals; he states that as a young child, he was never "so happy as when feeding and caressing them", and continues to say that "this particularity of character grew with my growth, and in my manhood, I derived from it one of my principal sources of pleasure" (Poe, "Black Cat" 91). He describes his marriage in similar terms, stating that she also loved animals, so they were happy. First, the extent to which he loves animals is important; it may suggest a disassociation with self and his feelings towards others. The narrator reveals a disturbing childhood, where he was ridiculed, and it appears the he substitutes relationships with his pets rather than with humans (Piacentino 154). It is also important that he links the love for his wife with his love for animals and does not separate the two. He states that he loves animals because "there is something in the unselfish and self-sacrificing love of a brute" (Poe, "Black Cat", 91). Similarly, his love for his wife also comes from her selfless nature. She remains mostly uncharacterized by the narrator within the story; she lacks an identity because the narrator also lacks an identity.

The narrator has, what is to him, an unexplainable and immediate turn in personality. He suddenly shifts from loving animals, and his wife, to abusing them. It is revealing that he loves animals, and again his wife, because of their selflessness, but his personality shift is in direct contradiction to this value; "I grew, day by day, more moody, more irritable, more regardless of the feelings of others" (Poe, "Black Cat", 92). His unconscious shadow triggers impulses that are directed towards those who embody selflessness to him, the first of which is Pluto, which again for Reeder represents the narrator's Jungian "anima," his unconscious attempt to self-actualize. 
The narrator's obsession towards Pluto increases as the story proceeds; the narrator in a drunken state blinds one of the eyes of Pluto. The name of the cat, Pluto, is aptly named after the Roman god of the underworld, suggesting the unconscious of the narrator, and the fact that it is the eye of Pluto suggests, again like "The Tell-Tale Heart," that he is fearful of being "seen" or influenced by his unconscious self. Pluto's accusatory dead eye socket now becomes the narrator's central obsession; he feels forced to kill Pluto, and after his house burns down, he is haunted by the searing vision of Pluto hanging for all to see his crime. The narrator's obsession for the blinded eye of Pluto, again symbolic of his blindness to his own underworld/unconscious, does not die when Pluto dies though; instead, it is resurrected through another cat with a missing eye. This second cat attaches itself, to the narrator's perception, to his wife, thus finally combining obsessions for the narrator. In an attempt to kill this second cat, he ends up murdering his wife.

Throughout the story, the narrator's inability to self-analyze spurs his misinterpretation of natural, yet perverse impulses, and again this natural opportunity to become self-aware, instead turns to horror as the narrator begins to misdirect his feelings into obsession; "Evil thoughts became my sole intimates.... The moodiness of my usual temper increased to hatred of all things and all mankind; while, from the sudden, frequent, and ungovernable outbursts of a fury to which I now blindly abandoned myself, my uncomplaining wife, alas! Was the most usual and most patient of sufferers" (Poe, "Black Cat", 96). Again the narrator irrationally feared and labeled his natural shadow thoughts, as "evil," instead of a means to self-actualization and possible connection to his wife. He, similar to other Poe works, directs this obsessive hatred towards those he loves, most significantly his wife and kills her as a means to avoid facing himself and his true feelings.

The narrator develops an obsession of hatred for those who represent what he is not, which again could provide valuable insight to himself. Instead of facing his shadow tendencies, and the fact that 
he wants to attack exactly those, Pluto and then his wife, who embody the trait he stated he valued-selflessness-means that he is fleeing self-actualization, and thus, in the elevated horror of Poe, he brings to fruition the worst self he can imagine. And again, as with "The Tell-Tale Heart," the narrator's obsessive focal point is tied inherently to a repressed fear of his own mortality. The narrator is afraid to be selfless, because absolute selflessness is death of the self. He struggles to defy this unconscious fear by misdirected obsessions to harm those he deems as selfless, but again, as with many of Poe's stories, his unconscious will not remain silent, so that it seemingly forces him to confess. Like the narrator of "The Tell-Tale Heart," he too "seeks psychic release and freedom in a crime which completes his torture. To the end of his life, he is incapable of locating the origin of evil and damnation within himself" (Gargano 170).

Poe's "Berenice" also follows the presented format found in "The Imp of the Perverse." First, the narrator only provides his baptismal name of Egaeus, and states that he will not reveal his family name because he would like to preserve a sense of anonymity, signaling again his lack of self-identification. Egaeus is also an isolated narrator; "in such isolation [Poe's] characters are intensely alone" (Shear 276). He describes his unique childhood of living only as if he were perpetually in dreams after the death of his mother. This separation of reality continues into his young adulthood as well; "the realities of this world affected me as visions, and as visions only" (Poe, "Berenice", 67). This narrator's comfort in his invented world shows that he has lost touch with reality. He believes that he possesses an ability to become in tune with his past lives, instead of learning who he is today. Egaeus and Berenice are cousins, and in describing their childhood together, he presents her as vibrantly full of life, whereas he describes himself as "living within my own heart, and addicted body and soul to the most intense and painful meditation" (Poe, "Berenice", 67).

Again, as was a component of "The Black Cat," Egaeus and Berenice undergo, in his perception, a sudden personality change. 
He states that Berenice mysteriously fell ill, and because of this illness her personality changes so much for him that she is in many ways unrecognizable. He then goes on to say how he also suddenly fell ill and also became changed. The fact that Berenice, his childhood mate and later wife, is suddenly and mysteriously changed, followed by his own mysterious transformation, singles to the reader that Egaeus is another unexamined narrator. He does not know himself, so this change of both perspective towards his wife, and then later unexpected transformation of himself, surprises him and provides him no rational explanations. This change in his personality brings with it, again, the theme of obsession with misdirected objects.

This work is perhaps one of the best examples of a Poe narrator directing a misinterpreted impulse onto a seemingly insignificant object; Egaeus becomes obsessed with almost every obsolete object surrounding him and discusses at length exactly how mundane the objects are and how enthralled with them he becomes, even devoting days to just obsessing on a singular object without any attachment of meaning; "My own disease, then, grew rapidly upon me, and assumed finally a monomaniac character....This monomania...consisted in a morbid irritability of those properties of the mind in metaphysical science termed the attentive"(Poe, "Berenice" 68). First, following the presented format of many of Poe's works, Egaeus encounters natural "perverse" impulses, first shown in his belief that he and his wife have irreparably changed, and then shown as the obsession of mundane details. He fears this change in himself, and the perceived change of his wife. He fears the possible reason why he now obsesses on mundane details; to him they are obsolete, but yet again, had he been willing or able to examine the details of his obsessions, not casting them away as without meaning, he may have come closer to self-actualization. It is important that just when he feels his personality shift, he is able to see the details of his life, because up until this point, he presumably could not see these details because he was too immersed in his false, invented world of childhood. The "mundane" details 
are reality, but he does not face them; they become more intense and specific obsessions, until he finally focuses all misinterpreted force upon the one person he loves.

This obsession to intensely focus on inanimate objects then shifts, as again happens in many Poe narratives, to the person he loves-his wife. Throughout the narrative Egaeus has not faced his unconscious; again left motherless at a young age, he learned to cope with reality by inventing a false world within his mind. His life with Berenice initially works for him, as long as he can remain in his created dream-world. Egaeus states that Berenice exists for him, "not as the living and breathing Berenice, but as the Berenice of a dream-not as a being of the earth, earthy, but as the abstraction of such a being-not as a thing to admire, but to analyze" (Poe, "Berenice”, 70). But with Egaeus' sudden shift in personality, he experiences a shift in consciousness. He no longer can continue to exist in his dream-world; instead, his unconscious begins tapping at the doors of his consciousness, demanding attention.

Berenice suddenly, to his perception, appears before him, but now he sees her only as terrifying. Egaeus, immersed in his obsession of avoidance, finally becomes forced to see Berenice as she is, fully a part of reality. Egaeus now obsesses at length over her teeth, a small glimpse into the realness of her being, but once again, he does not ever stop to examine exactly why he has such an obsession, just as he did not stop at any point of the story to examine why he obsesses on seemingly mundane objects. Here Egaeus could embrace this opportunity of clear vision, but he only sees Berenice in this strikingly real state as terrifying. Egaeus then becomes fearful of what his obsessions mean about himself. Eric W. Carlson states that in Egaeus' mind, Berenice's "teeth...have become symbolic of Bernice's moral nature and, as such, are a continuing reminder to him of what he has lost or destroyed" (Carlson 170). Egaeus' fear of losing control of his actions dominates him, until he enacts the feared outcome-murdering Berenice to avoid 
reality, which means facing his feelings of love and need for her, and the fact of her, and his, eventual death.

Suddenly and presumably purposely unexplained by Poe, Berenice is said to have died. Egaeus, lacking self-identification, loses all knowledge of what happened in the night after this announcement of her death. He states that his memory has blacked out, which strongly reveals that he is almost entirely removed from his selfhood. He is terrified to learn what happened in the period of his psychic black out, and once again, as with Poe's other stories, the narrative continues, forcing Egaeus to face his unconscious.

The focus of Egaeus' obsession shifts to him discovering what exactly happened the night he blocked from his consciousness. This end seems different from the endings of the stories already discussed, where the narrators against their will confess their own guilt, but it is not all that dissimilar as Egaeus is indeed entering upon the same path of self-actualization as the other narrators. When the narrators of the other tales confessed, against their perceived wills, they in actuality were finally facing themselves and the facts of reality, mainly the mortality of themselves and those they loved; similarly, when Egaeus obsesses over figuring out what happened in the night in question, a part of him knows his own guilt. His unconscious self is demanding attention, and the end of the story suggests that Egaeus is finally able to face what he repressed. Again Carlson states that Egaeus "attempts to deal with the loss of loved ones through 'avoidance and denial'"; therefore, he is "the victim of his own lack of self-knowledge" (Carlson 172). Egaeus feared losing the love of Berenice, just as he lost his mother in the innocence of his youth, so he repressed his own feelings of love and fear at the loss of this necessity. He misinterpreted the impulses and obsessions not as psychic clues towards a healthy self-discovery, but as confirmation of his insanity. He is discovered by his staff, and to his horror, he finally sees clearly the reality he has caused-he has removed all of the teeth of his wife when she in fact was not really dead. 
Poe's "Morella" also makes use of the examined format found in "The Imp of the Perverse," but this work provides more. Once again the narrator remains nameless, again suggesting the absence of self-knowledge. The narrator meets Morella and states from the moment they meet that his "soul...burned with fires it had never before known; but the fires were not of Eros, and bitter and tormenting to my spirit was the gradual conviction that I could in no manner define their unusual meaning, or regulate their vague intensity" (Poe, "Morella", 471). Again, because he is overcome by these feelings and does not know how to react to them shows his inability to understand his own emotions, or have a sense of self-identification. Instead, the narrator states that "fate" made the two of them marry, though he believes that he does not love her. $\mathrm{He}$ also, again like other Poe narrators, believes that he lives in a type of dream world.

The character of Morella, though, adds a different element to the standard format presented in the other works thus far; she has figured out her husband's lack of self-identification and his inability to face reality. Both Carlson and Martin Bickman analyze "Morella" using Jungian archetypes (Carlson 170; Bickman 29). Bickman contends that the narrator of this work presents a psychic conflict between the conscious and unconscious self; Morella, as a representation of a Jungian "anima or female soulmate," provides the narrator an opportunity to unite his psychic self (Bickman 29). Arguably, "Morella" supports a Jungian interpretation, as Morella aptly represents what the narrator fears, but is comfortable with elements that constitute the shadow self. In this work, Morella solely attaches herself to her husband, and the connection of these two opposites serves to reveal two sides of the same person, that of the narrator. The narrator becomes attracted, not to his wife through love for her, but to her comfort with her own dark shadow, so much so that her intense interests of the macabre become his, and he states that he became in many ways "her pupil." He admits, "I abandoned myself implicitly to the guidance of my wife" (Poe, "Morella", 471); she, therefore, is the 
figure within this story that serves to guide him into the shadow of his own unconscious.

Though Morella is comfortable with the shadow elements of the unconscious, when the narrator has faced all he can of the, to him, frightening realms she readily explores, Poe's format of obsession again takes over the narrator. Once more, and mysteriously instantaneous, he feels perverse impulses of revulsion for Morella, and again the sudden shift to irrational repulsion suggests that the narrator is running from feelings spurred by experiences with Morella. These impulses in turn become obsessions of revulsion for her; they become so intense that he begins to obsess over her death. Again, as discussed in the other works, his obsession, if examined and not repressed, reveals his attempt to flee unknown or undeveloped feelings of love. He describes himself as never in love with Morella, but he marries her, adopts her interests, and is guided by her in an isolated state that involves only the two of them. Curtis Fukuchi states "a close reading of the tale suggests that he fears his wife because of the passion she arouses...the narrator [is] emotionally and perhaps sexually repressed" (Fukuchi 149). The narrator does not know his own emotional self, and presumably feelings of love terrify him, so his obsession, which could serve to reveal his love for her, reveals the opposite to him, and he wishes for her death.

What again makes this work a bit different from the others mentioned in this paper is that Morella, when she indeed is finally near death, knows that her husband believes he is repulsed by her; she knows that he thinks he longs for her death, and also knows that he thinks he never loved her. But, more importantly, she understands that he does not know his true self.

Morella's dying words are meant to instruct the narrator about who he is, thus guiding him to face the shadow elements of himself. She tells him that though she will die, she will live on, and moreover, the narrator will "adore" her in death, when he could not in life. Morella knows that she will live on because she is, 
again, the unconscious self within the narrator. She knows that even through her death, he cannot escape his unconscious promptings; she lived to guide him in the areas of the shadow, and her death and their daughter, who she gives birth to on her death bed, will continue to instruct him to face that which he needs to. The narrator indeed does love their daughter, and knows it this time, and here he appears to begin his journey towards self-knowledge, but it is short-lived.

Again, the narrator begins to connect fear with his feelings of love for his daughter. His love spurs fearful impulses of losing her, and his obsessions return. Feelings of love and affection haunt the narrator; they are foreign to him, so he invents irrational fears and obsessions to flee his feelings of love. To love is to be vulnerable, so instead of accepting this side of his true self, he turns off and shifts to fear, repression, and therefore obsession. Instead of acknowledging his great love for his daughter, and the love he indeed did feel for Morella, his fearful impulses at losing his daughter only makes him become obsessed with hiding her away. Again, this obsession is revealing; he hides his love for his wife from himself, now his open love for his daughter is switched to concealing her from the world. His obsession to hide her produces a new obsession; he now believes that his daughter in every physical, mental, and spiritual way begins to appear like Morella. This new obsession, again following format, dominates his life and leads to the fruition of the worst of his fearful impulses.

His obsession of fear that his daughter may be a sort of reincarnation of Morella, makes him resist naming her, thus, as has been discussed with other Poe works, he commits her to the level he finds himself, nameless, thus lacking identity. More significantly, the fact that he cannot name her and truly sees her as a form of his dead wife, reveals that the narrator has a single true obsession-understanding his unconscious self, because in the scope of the story, both Morella and the daughter represent the shadowed unconscious self of the narrator. The narrator fears his impulses as 
representations of darkness and evil, but, in reality they are only his unconscious signaling his repressed feelings of vulnerable love.

The narrator does finally succumb and names his daughter, but it again following format, shocks him to see that his unconscious takes over and forces him to name her Morella; "What prompted me, then, to disturb the memory of the buried dead?... What fiend spoke from the recesses of my soul" (Poe, "Morella", 473). The fact that he, without any self-control, utters his worst fear shows the power of his unconscious; his shadow forces itself to be revealed. This scene indicates that he is ready is some way to finally self-identify. In naming his daughter, he defines his fear. Yet, the instant he names his daughter Morella, he thinks that she looks up and declares "I am here" (Poe, "Morella", 474). Again following the format in "The Imp of the Perverse," the story ends with him repressing this revelation as something to fear, not embrace, so he enacts his misinterpreted obsessions. Rather than facing his fear, and acknowledging feelings for Morella, he thrusts the thought of her far from him and allows himself to kill this new Morella, his own daughter. But in this deed, he immediately recognizes the murkiness of his mind, that in his daughter's death, as he is putting her in her tomb, he finds "no traces of the first [Morella]", thus making him laugh "a long and bitter laugh" (Poe, Morella", 474), possibly signaling a final revelation of self-hood.

"William Wilson" also follows the presented format thus far of a narrator misinterpreting natural "perverse" impulses as projections of his insanity, but this story is also decidedly different than the works discussed thus far. "William Wilson" reveals a narrator who does not ultimately direct his obsessions towards an outside person who he loves, but directs them towards himself through his creation of an imagined doppelgänger. Because the narrator, William, acts quite similar to the pattern presented in the other Poe works discussed, but directs all obsessions to a clear focus of self, this work serves, perhaps best, to reveal Poe's message of terror coming from the repression of self. William fears selfactualization, and in trying to repress the impulses of his uncon- 
scious, he focuses on an obsession of a doppelgänger that clearly represents his own true identity. Carlson supports the analysis by stating that "William Wilson" provides again a tale of Jungian "psychic conflict...between a shadow self and a decadent public persona" (Carlson 190).

William chooses to go by a false name, again showing his lack of self. Once again, William identifies that he spent his childhood living in a created dream-world within his isolated mind, rather than in reality. The narrator goes away from his home to a boarding school; this shift into another reality causes him distress and results in him believing that a schoolmate is in every way like him: born on the same day, has the same name, entered the school on the same day, looks identical to him, thinks like him, dresses like him, and etc. Once at school the format of obsession in Poe narratives becomes apparent. William completely fixates on his impulses that tell him there is a second William Wilson. William, fearing these impulses, which again could reveal to him a connection of unconscious with conscious, turns the impulses into an obsession towards this doppelgänger.

The narrative is set up in such a way that it is clear to the reader that the doppelgänger is within William's mind. During his schooldays, no other student ever comments on the striking resemblance, and both William and his doppelgänger only interact in places that are hidden from others, like a closet. William leaves the school, on the same day his doppelgänger leaves, and proceeds to take part in many, as defined by William, acts of vice, from cheating in gambling, drinking too much, taking drugs, and seducing married women. But, it is at the most inopportune moments, seemingly to William's perception, that his doppelgänger appears, and in his voice that is always only a whisper, reveals the wrongness of William's actions in the given situation.

This story, arguably better than any other Poe work, not only shows that the object of William's obsession is his own unconscious, but that this obsession exists to reveal not terror to the 
narrator but possible wholeness of self, if he could just pause and examine what the impulses and obsessions reveal. Just as the other narrators in this paper, William draws his obsession to him in his very attempt to dispel it from him. William acts in consistent, direct opposition to the way his doppelgänger acts. He invents a persona that is entirely driven by his perception of evil, while his doppelgänger can embody his idea of virtue. He knows that whenever he performs an "evil" act, his doppelgänger will intervene; he thinks that he resents this, but his behavior shows that he wishes to bring forth his repressions, since every time he acts in a way he thinks is wrong, his psyche spurs the appearance of the doppelgänger. William appears in the narrative more comfortable with his, what seems to him, perverse self, but in reality, he isn't accepting of these "evil" tendencies. When William cheats a man in a card game, he begins to feel guilt over his actions when it becomes evident that the man is humiliated because he does not have as much money as he let on. At the moment the scene becomes uncomfortable for William, he morally splits. He needs his other self to rescue him, and so his doppelgänger appears, which is of course only William experiencing a sudden change in personality, and reveals the truth of his game to the unsuspecting card players, causing him to get beat up by them. William keeps himself divided as a way to repress the unification of halves, "good" with "bad," light with shadow, that comes with self-actualization.

But, again following the format presented thus far, William cannot embrace the object of his obsession, or see that his doppelgänger reveals important knowledge about himself that in all actuality is of a positive nature. Like the narrators of the other works discussed who attempted to dispel their impulses and obsessions out of fear, they failed to see the true message of their obsessions-embrace of self with realization of love and acceptance of mortality. William fears his belief that he has a doppelgänger, so he allows the obsession of a doppelgänger to control his life, so much so that he ends the narrative doing an action that is truly horrifying so that he, like the other narratives, can ultimately face 
himself. William leads his doppelgänger away from a crowd into an inner room; "the scene of confrontation is thus deep within the inner mind" (Coskren 161). In this isolated place, in an attempt to free himself from his obsession, he attacks his invented doppelgänger by stabbing him. Only after the injury is inflicted, can William finally see his unified self, as he realizes he is looking in a mirror, not at his doppelgänger, and therefore the injuries are done to him by his own hand. William kills himself as opposed to an outside other associated with a misinterpreted obsession, as in Poe's other works.

Again this story, of all Poe's works, provides the clearest example of impulses and obsessions resulting from fear and repression. William resisted and repressed his impulses that revealed another side of his identity. He turned these impulses in an obsession of a doppelgänger, instead of using these promptings to examine his unconscious and self-actualize. Only through a final, horrific enactment of misinterpreted obsession, which is usually murder, does a glimpse of selfhood become revealed in many Poe works. "William Wilson" provides a clear message of intent on the part of Poe; William in committing murder as a means to escape his dominating unconscious, actually commits suicide, and through analyzing this story, one can see that all of Poe's narrators who murder out of misinterpreted obsession commit a similar suicide of self; "You have conquered and I yield. Yet, hence forward art thou also dead-dead to the World, to Heaven, and to Hope! In me didst thou exist-and, in my death, see by this image, which is thine own, bow utterly thou hast murdered thyself" (Poe, "William", 40). Their unconscious becomes finally revealed to them, but it is at a point too late.

Lisa Scottoline states that William's "fragmented or broken identity terrifies us at a profound level...it's impossible to read 'William Wilson' and not identify with William" Poe's narrators are not self-aware; they are examples of people who have not examined their unconscious shadow selves. Their "perverse" impulses are indeed dark, but they should not be something to fear. If Poe's narra- 
tors would pause and reflect on the nature or cause of their resulting obsessions, the impulses and obsessions would perhaps lessen, as research suggests, and through this process of self-examination, the horrific tragedies could possibly be diverted. The message of Poe's works of obsessed narrators is not to fear the power an unhealthy psyche, but for the reader to determinedly examine all aspects of one's self, becoming the master of one's mind, instead of its slave; "it is important to understand these everyday glimmerings of madness in us all” (Wegner 5).

\section{Works Cited}

Baer, Lee. The Imp of the Mind: Exploring the Silent Epidemic of Obsessive Bad Thoughts. New York: Penguin, 2001.

Bickman, Martin. "Animatopoeia: Morella as Siren of the Self." Poe Studies 8, no.2 (1975): 29-32.

Carey, Benedict. "Why the Imp in Your Brain Gets Out." New York Times, July 7, 2009.

Carlson, Eric W. “Tales of Psychal Conflict: 'Bernice,' 'Morella,' 'Ligeia.”' In $A$ Companion to Poe Studies, edited by Eric W. Carlson, 168-87. Westport: Greenwood Press.

-. "Tales of Psychic Conflict: 'William Wilson' and 'The Fall of the House of Usher."' In A Companion to Poe Studies, edited by Eric. W. Carlson, 188-208. Westport: Greenwood Press, 1996.

Coskren, Robert. “'William Wilson' and the Disintegration of Self." Studies in Short Fiction (2002): 155-162.

Death and Rebirth. "Thanatos." Accessed November 12, 2012. http://zero-point. tripod.com/pantheon/Thanatos.html.

Freud, Sigmund. Beyond the Pleasure Principle. New York: Create Space Publishing, 2010.

-. The Ego and the Id. New York: Create Space Publishing, 2010. 
Fukuchi, Curtis. "Repression and Guilt in Poe's 'Morella.'” Studies in Short Fiction 24, no.2 (March 1987): 149-154.

Jung, Carl. The Undiscovered Self. New York: Penguin, 2006.

—. “The Shadow.” In Understanding Dreams, 112-13. New York: Penguin, 1998.

Gargano, James W. “The Question of Poe's Narrators," in Poe: A Collection of Critical Essays, edited by Robert Regan, 164-71. Englewood Cliffs, NJ: Prentice Hall, 2010.

Poe, Edgar Allan. "Berenice." In Edgar Allan Poe: Selected Poems and Tales, edited by Neil Gaiman, 66-73. New York: Barnes and Noble Books, 2004.

-. "The Black Cat." In Edgar Allan Poe: Selected Poems and Tales, edited by Neil Gaiman, 91-8. New York: Barnes and Noble Books, 2004.

-. "The Imp of the Perverse." In Edgar Allan Poe: Selected Poems and Tales, edited by Neil Gaiman, 155-60. New York: Barnes and Noble Books, 2004.

-. "Morella." In The Works of Late Edgar Allan Poe. Vol.I. Tales., edited by Rufus Wilmot Griswold, 471-74. New York: J.S. Redfield, 1850. http://www.eapoe.org/ works/tales/mrllah.htm.

-. "The Tell-Tale Heart." In Edgar Allan Poe: Selected Poems and Tales, edited by Neil Gaiman, 161-65. New York: Barnes and Noble Books, 2004.

-. "William Wilson." In Edgar Allan Poe: Selected Prose and Poetry, edited by W. H. Auden, 39-60. New York: Holt, Rinehart and Winston, 1961.

Piacentino, Ed. "Poe's 'The Black Cat' as Psychobiography: Some Reflections on the Narratological Dynamics.” Studies in Short Fiction 35, no.2 (1998): 153-167.

Rachman, Stanley Jack. “A Cognitive Theory of Obsessions.” Behavioral Research Theory 35, no.9 (1997): 793-802.

Reeder, Roberto. “The Black Cat as a Study of Repression.” Poe Studies, 7, no.1 (June 1974), 20-2.

Saliba, David R. A Psychology of Fear: The Nightmare Formula of Edgar Allan Poe. Washington, D.C.: University Press of America, 1980.

Scottoline, Lisa. In the Shadow of the Master: Classic Tales by Edgar Allan Poe and Essays. New York: Harper, 2010. 
Shear, Walter. "Poe's Fiction: The Hypnotic Magic of the Sense." The Midwest Quarterly 47, no.1 (2006): 276-289.

Wegner, David M. White Bears and Other Unwanted Thoughts: Suppression, Obsession and the Psychology of Mental Control. New York: Guilford Publications, Inc., 1994.

Wing-chi Ki, Magdalen. "Ego-Evil and 'The Tell-Tale Heart." Renascence 61, no.1 (Fall 2008): 25-38.

Yang, Amy. "Psychoanalysis and Detective Fiction." Perspectives in Biology and Medicine 53, no.4 (2010): 596-604. doi:10.1353/pbm.2. 


\title{
3 Staging Nothing: The Figure of Das Ding in Poe's "The Raven"
}

\author{
SEAN J. KELLY
}

\begin{abstract}
“... the Thing is not nothing, but literally is not. It is characterized by its absence, its strangeness"-Jacques Lacan, Seminar VII
\end{abstract}

According to traditional readings of Edgar Allan Poe's "The Raven" (1845) the speaker's creeping madness, though precipitated by a vexing exchange with an enigmatic raven, can ultimately be traced back to the emotional wound left by the death of his beloved Lenore. ${ }^{1}$ In the opening of the poem, the speaker, attempting to "borrow / ... surcease of sorrow" (lines 9-10) "ponder[s] ... / Over many a quaint and curious volume of forgotten lore" (1-2). At first blush, it would indeed appear that the mourning of the

\footnotetext{
${ }^{1}$ See Thomas Ollive Mabbott in his introduction to "The Raven": "The subject is of universal appeal, for every mature person has lost someone beloved, and even for the firm believer in immortality death is a separation from the living" (351). Kenneth Silverman has suggested that the poem relies on the notion that "the dead rest only as long as they remain in living memory" (240). As a consequence, "To forget is to incur the guilt of disloyalty and risk reprisal from the betrayed departed. From this point of view the student suffers not only from an inability to stop remembering, but also from a fear of forgetting" (241).
} 
physical loss of the speaker's love object, the sorrow resulting from her absence and the pain induced by her memory, is the event around which the poem's narrative turns. However, when we recall Poe's own comments in "The Philosophy of Composition" (1846) regarding the speaker's peculiar motivations, namely that he is possessed by "that species of despair which delights in self-torture" (202), the speaker's condition begins to more closely resemble the psychological state of melancholia than that of mourning. According to Sigmund Freud, the distinguishing feature of melancholia concerns what he describes as the "lowering of the self-regarding feelings to a degree that finds utterance in self-reproaches and self-revilings, and culminates in a delusional expectation of punishment" ("Mourning" 244). Most significantly, Freud observes that unlike mourning, melancholia concerns an "unknown loss" in that the sufferer "knows whom he has lost but not what he has lost in him" (245). That is, while mourning concerns only a consciously experienced loss, melancholia is "in some way related to an object-loss which is withdrawn from consciousness" (245). If Lenore is the lost object whose mourning is known to the speaker's consciousness, what is the "unknown" or unconscious object that the staging of her present-absence and the intrusion of the enigmatic figure of the raven would seem to represent? How might the critical examination of this object, and, perhaps more importantly, the aesthetic strategies utilized in the artistic representation of it, offer new possibilities for the reader's own "consideration of [the] effect $[s]$ " ("Philosophy" 194) produced by Poe's most famous poem?

In what follows, I attempt such a critical examination of the aesthetic effects of "The Raven," specifically those effects produced by the poem's sublime architectonics of present-absence. Utilizing a psychoanalytic theoretical approach, I aim to demonstrate that both the form and content of "The Raven" anticipate the Freudian-Lacanian concept of das Ding-the mythical "Thing"-which Jacques Lacan argues is the lost object "attached to whatever is open, lacking, or gaping at the center of our de- 
sire" (VII 84). Because, according to Lacan's theory, this concept names the void around which human subjectivity forms and all subsequent desire turns, art functions, in essence, to "creat[e] the void and thereby introduc[e] the possibility of filling it" (120). By staging the void through aesthetic means, Poe allows the reader to examine the melancholic nature of desire itself.

My hope is that this reading will enact what Jean Starobinski, a noted critic and practitioner of psychoanalytic criticism, has called a "'free-floating attentiveness'-a sort of vigilance in suspense, a watchful benevolence," that allows the "complex presence" of a work to develop through the reader's critical engagement (143). Starobinski's vision of the reader/critic implies an ethics of reading that marks a contrast with what he perceives to be two problematic tendencies in the tradition of psychoanalytic criticism: namely the (now mostly outmoded) attempt to psychoanalyze the author through an analysis of his or her works ${ }^{2}$ and, alternatively, what we might describe as the potential of the psychoanalytic discourse to overwhelm (or displace) the literary work with an insistence on preconceived models and theoretical assumptions. The former tendency is reflected in that species of criticism which attempts to link "literary expression" to an author's "underlying desire, as if the literary were a mask to be torn away" (144); the latter tendency, Starobinski suggests, is the consequence of the fact that psy-

${ }^{2}$ Many foundational works of literary scholarship on Poe belong to this tradition. Well-known examples of this approach include Marie Bonaparte's Life and Works of Edgar Allan Poe: A Psychoanalytic Study (1949) and Joseph Wood Krutch's Edgar Allan Poe: A Study in Genius (1926). Krutch's work is not overtly psychoanalytical; however, its biographical approach emphasizes the possible relationship between Poe's literary representations and his psychological and social identity as a "spiritual outcast from his age" (158). Making reference to Poe's letters and notes, Krutch muses that "there must have been times when [Poe] knew" that in tales such as "The Black Cat" he "was confessing to himself and others the giddy instability of his own mind" (116-117). See also David M. Rein's Edgar A. Poe: The Inner Pattern (1970). Regarding fiction as a form of dream-work (103), Rein argues that Poe's gothic fictions reveal a "relationship between [Poe's] desire for horrible experiences and his feeling that he was destined to have them" (32). 
choanalysis is "constantly in danger of being carried away by the intrinsic inventiveness of its own rhetoric" (142). ${ }^{3}$ While contemporary psychoanalytical criticism has generally turned away from the task of "unmasking" the author's desire, it is still, especially with the introduction of Lacanian discourse, vulnerable to being "carried away" by its own self-referential rhetoric, or trapped, as it were, within the walls of its own discursive apparatus. ${ }^{4}$

Nevertheless, psychoanalytic criticism has, in my view, proven extremely useful in the examination not only of the peculiar representations of the psychological subject at the center of many of Poe's works, but also the ways in which his texts generate aesthetic effects, which induce affective responses in the reader. In his influential essay, "Poe and the Powers of the Mind" (1970), for instance, Robert Shulman "returns" to psychological criticism while simultaneously acknowledging the limitations of biographical criticism and warning against the reductiveness of overly facile

\footnotetext{
${ }^{3}$ Key here is Starobinski's point that the discourse of psychoanalysis is, itself, heavily indebted to the terminologies of other disciplines (sociology, anthropology, philosophy, and literature) for its central concepts. Psychoanalysis cannot, therefore, view itself as "objectively" distinct from its literary object of study. As Starobinski observes, because its tools are often figurative, psychoanalysis threatens to let "its figurative rhetoric run away with itself, transforming the discipline into a literature of speculation that readily bends the malleable language of metaphor to its own purposes" (142).

${ }^{4}$ See, for example, Daneen Wardrop's essay "Quoting the Signifier 'Nevermore': Fort! Da!, Pallas, and Desire in Language" (2011). Wardrop's piece is, in many respects, a brilliant analysis; and yet, one may feel as though the nuance of Poe's work itself has been left behind and replaced by the Lacanian narrative of subjectivity formation. Wardrop's suggestion that "The Raven" may be viewed as a "postmodern allegory" of the "entry of the subject into the signifying chain" (163) ultimately necessitates the typological translation of the poem's images to fit within the Lacanian discourse. In Wardrop's analysis, therefore, the bust of Pallas takes on the role of the mother, and the raven's repeated utterance "Nevermore" signals the entrance of the Name-of-the-Father. All tends toward the allegorical conclusion that "the narrator's want-to-be takes the form of a Fort! $D a$ ! expression-that is, 'Nevermore'-as he begins to realize that signification signals the end of his prior bliss and oneness" (173). As this passage demonstrates, diegetic and aesthetic questions related to the poem are occasionally superseded by a purely formal Lacanian master narrative.
} 
Freudian interpretations of Poe's works. ${ }^{5}$ The most compelling aspect of Shulman's discussion, however, is the fact that it utilizes a psychological perspective in order to examine the "symptomatic" discord between Poe's generally optimistic critical writing and the "emphasis on darker qualities" in his tales (246). For Shulman, this discord can be traced to Poe's ambivalent pairing of cosmological Unity and annihilation in Eureka (1848). The meaning of this ambivalence will become significant for us as we link the aesthetic effects of Poe's "The Raven" to the historical advent of the uncanny and the concomitant psychological model of self that serves as the basis for the poem's speaker.

More recent critical examinations of "The Raven" by Jonathan Elmer and Daneen Wardrop have, in distinct ways, utilized psychoanalytic approaches to decipher the dynamic interplay between subjectivity, desire, and signification in Poe's writing. Elmer focuses on the reader's oscillating patterns of frustration and pleasure in the text, suggesting that "The Raven," as an historical artifact which follows the "cultural logic of the hoax" (201), may be viewed as a "Barnumesque object, more an occasion for a circulatory desire than an object able to bind, order, and validate that desire" (210). Wardrop, by contrast, emphasizes the peculiarly post-modern, specifically Lacanian, terms of subjectivity that may be teased out in an explication of "The Raven." Following the critical tradition of these writers, the present study hopes to demonstrate that the uncanny aesthetic effects of "The Raven" and its theme of melancholia are indicative not simply

\footnotetext{
${ }^{5}$ Shulman notes, for example, that while he is specifically interested in how contrasts in the text's rhetoric and imagery reveal "the chaotic depths of the mind" (253), "Freudians might more particularly identify the smooth, funnellike whirlpool with an entry through the mother-sea into the womb" (253).

${ }^{6}$ I should note here as well the significant study of the rhythmic aspects of "The Raven" by Nicolas Abraham and Nicholas Rand entitled "Psychoanalytic Esthetics: Time, Rhythm, and the Unconscious” (1986). In their paper, Abraham and Rand argue for the interrogation of the unconscious dimension of poetic texts, specifically the rhythmic figures which operate on the reader through a dialectics of alternating "expectation and fulfillment" (8).
} 
of the "darker qualities" in Poe's romanticism, but in fact signal modern conceptions of both subjectivity and art.

\section{Das Ding and Poe's Psychology of Primordial Nihility}

In his writings from the late 1940s to the early 1960s, Lacan argues that prior to entering the world of language, the human child experiences itself as a "fragmented body" (Écrit 4). It is during the period he refers to as the "Mirror Stage" that the infantile subject begins to assume the alienating image of its external reflection as the basis for the formation of its ego. Only then can the subject experience the "deflection of the specular $I$ into the social $I$ " (5) as it takes other signifiers as substitutions/representations for itself within the signifying chain. This creates a strange sort of paradox at the heart of subjectivity itself. Without the alienating experience of entering into the signifying order, one could never be known as a subject; and yet, according to Lacan, the assumption of language is experienced as the "moment of fading or eclipse of the subject" which "suffers from its subordination to the signifier" (313). The psychoanalyst Bruce Fink observes that "the subject exists-insofar as the word has wrought him or her from nothingness, and he or she can be spoken of, talked about, and discoursed upon-yet remains beingless" (52). It is because of the potential for being that results from alienation that the subject experiences lack, the feeling that something essential to one's sense of being is missing. For Lacan, Oedipal "castration" means precisely the assumption of language which institutes the myth of the primordial mother as a former source of subjective wholeness. According to Lacan the question of das Ding centrally concerns the representation of this loss or lack and the concomitant state of desire that results from the subject's fading.

In Seminar VII: The Ethics of Psychoanalysis (1959-1960), Lacan begins his examination of the role das Ding plays in the development 
of the subject by marking an important distinction between two German words for "thing." While the word Sache, he explains, refers to "a product of industry and human action as governed by language," Ding "is found somewhere else" (45). Das Ding, to use Herman Melville's famous phrase, concerns that "ungraspable phantom" (18) that drives our desire, holding out the promise of absolute knowledge and transcendent being. Lacan states that:

It is in its nature that the object as such is lost. It will never be found again. Something is there while one waits for something better, or worse, but which one wants.

The world of our experience, the Freudian world, assumes that it is in this object, das Ding, as the absolute Other of the subject, that one is supposed to find again. It is to be found at the most as something missed. One doesn't find it, but only its pleasurable associations. (VII 52)

As a "lost object," das Ding designates for the subject a mythical state of wholeness on the horizon of its being. While das Ding "will never be found again," its effects are felt as an organizing principle of psychic life and desire, like the Aristotelian notion of the Good as "that at which all things aim" (Aristotle 1). Das Ding names, in general, whatever is retrospectively barred from the subject when it enters language, including its fantasized union with the primordial mother. Consequently, Lacan maintains that das Ding can be thought of as the "first outside" which results from the "original division of the experience of reality" (VII 52). However, das Ding also, and as a consequence of its position as "barred," designates the absolute Other of the subject, a point of radical alterity that potentially threatens the subject's consistency within the social symbolic by exposing it to forbidden jouissance (Lacan's term for unbearable enjoyment) in the form of "primary affect" or affect that occurs "prior to any repression" (54). This is because structurally das Ding, in fact, marks not the site of lost ontological presence but rather the void in being itself. Glimpses of the Janus-faced aspect of das Ding theorized by Lacan may be detected in Poe's account of the periodical reunification of the cos- 
mos into nothingness that looms in the background of human (un)consciousness published in Eureka one hundred years earlier.

According to Poe's cosmology, the great arc of the universe bends toward a state of "absolute unity," a process through which matter will come to be, paradoxically, "Matter without Matter" (Eureka 310-11). He observes that "In sinking into Unity, it will sink at once into that Nothingness which, to all Finite Perception, Unity must be-into that Material Nihility from which alone we can conceive it to have been evoked-to have been created, by the Volition of God" (311). This periodic swelling and then "subsiding into nothingness," Poe explains, may be viewed as the "throb of the Heart Divine," a heart that "is our own" (311). Primordial knowledge of the origin of all matter and the violent destiny of the cosmos lies, therefore, at the foundation of human psychological experience. Poe writes:

We walk about, amid the destinies of our world-existence, encompassed by dim but ever-present Memories of a Destiny more vast-very distant in the bygone time, and infinitely awful.

We live out a Youth peculiarly haunted by such dreams; yet never mistaking them for dreams. As Memories we know them. During our Youth the distinction is too clear to deceive us even for a moment. (311-12)

While Poe suggests that the state of nothingness from which being emerged cannot be known in empirical terms, it nonetheless serves as a key feature of human psychical development and organization. From the cosmological view, absolute unity represents the highest spiritual attainment of the cosmos, unity with and of the divine. On the other hand, such a unified state, when viewed from the finite perspective of the human psyche, simultaneously represents an ontological void, a state of primordial nonbeing that haunts human (un)consciousness. As such, Poe's myth resembles Freud's notion in Beyond the Pleasure Principle (1920) that all biological organisms have an "instinct to return to the inanimate 
state" (38). The memory of primordial nihility functions, therefore, as a "lost object" in the precise sense that, even though one cannot know it empirically (like das Sache), it is experienced psychically, nonetheless, as a traumatic "cause" that is continuously repeated (we emerged from it, are haunted by it, have memories of it, view it as our terrible destiny). The cosmological origin of being in Poe's theory, therefore, like das Ding, functions as the excluded center of human consciousness, or what Lacan calls "the prehistoric Other that is impossible to forget ... something strange to me, although it is at the heart of me" (VII 71). Poe's intuitive psychological analysis of the subject anticipates das Ding by locating the human psyche at the nexus of desire and fear, the desire for ontological completion and the latent knowledge that such completion comes at the price of the subject's own disappearance in the void. 'Because Poe's writing often emphasizes what Lacan calls the "Fremde [alien], strange and even hostile" (52) aspect of das Ding, the point of extreme alterity, which implicitly threatens subjective coherence, it is useful to briefly consider how das Ding may appear as an exemplary expression of the uncanny.

According to Freud, the unheimlich represents not simply the frightening appearance of something altogether unfamiliar and threatening but rather the resurfacing of "something familiar that has been repressed" ("Uncanny" 247). Specifically, in terms that anticipate Lacan's formulation of das Ding's structural ambiguity, Freud maintains that the uncanny reflects both the subject's latent anxiety regarding its dismemberment or fragmentation, which he associates with the "castration-complex," and its desire for the lost pleasure of the "wholeness" found in "intra-uterine existence" (244). For Lacan, the fantasy of "intra-uterine" (or pre-symbolic) unity with the mother, and the ontological wholeness such unity

\footnotetext{
${ }^{7}$ Shulman suggests that the paradox of Poe's theory of divine unity is apparent even at the level of the conflict between Poe's well "ordered prose" and "irrational subject matter" (251). If the rational powers of the conscious mind are represented at the level of Poe's smooth rhetoric and syntax, the images of "chaos and disintegration" (251), a form of representational double-vision, attest to something threatening beyond conscious control.
} 
promises, is precisely what the subject's desire for the illusion of das Ding represents. He observes that "the mythic body of the mother [is] at the central place of das Ding" because it represents something "primordial," the "most archaic of objects" (VII 106). The realization of such a desire, however, would entail the subject's disappearance via a radical desubjectivation and loss of symbolic identity.

Importantly, the conceptual domain mapped out by the terms uncanny and das Ding should not be taken (even within the psychoanalytic discourse that claims to discover them) as transcendental or universal; rather, they designate the terms of a specific form of historical subjectivity. The psychoanalytic theorist Mladen Dolar has pointed out, for example, that the uncanny is itself an effect of "the particular historical rupture brought about by the Enlightenment" (7). In brief, Dolar argues that what was once designated as the sacred and therefore excluded/veiled source of power in premodern societies is conceptually displaced or made "unplaceable" by modernity (7). Dolar maintains, more particularly, that the nineteenth century's growing fascination with monsters, vampires, and ghosts may be linked to the broader Enlightenment attempt to decipher the "missing link between nature and culture, the point where the spiritual would spring directly from the material" (17). Significantly, in "The Raven" the uncanny is not represented by a monster, but rather through evocations of presentabsence, the specter of the void itself that comes to be occupied by the raven at the conclusion of the poem. ${ }^{8}$ In this precise sense, I would argue that Poe's gothic romanticism, in fact, gestures toward modern art.

\footnotetext{
${ }^{8}$ Timothy Farrant and Alexandra Urakova have suggested that the raven is, itself, endowed with an aura of uncanniness due to its cultural associations and, in particular, its ability to bridge conceptual dichotomies. Birds, they argue, "suggest elevation, but also abjection" (159); because of their "familiarity and apparent triviality" (159), they embody "the 'heimlich' without which there can be no 'unheimlich"” (159). Consequently, Farrant and Urakova maintain that birds "also intimate some absolute which is glimpsed but never fully seen" (159).
} 
As the cultural philosopher Slavoj Žižek has suggested, the task of modern art is not that of "filling in the Void" or sacred place with some suitably beautiful object (as would be the case in premodern society), but rather that of "creating the Void," in order to ensure that "this Place itself will 'take place"” (27). Žižek's point is that the role of art in modernity is to "re-place" (or re-designate as sacred) what Dolar calls the "unplaceable" uncanny in art via the act of sublimation, or what Lacan describes as the act of raising an ordinary object to "the dignity of the Thing" (VII 112). As the title of this paper suggests, I believe "The Raven” reflects Poe's attempt to create the void in art. More precisely, the reader of Poe's poem follows the speaker's melancholic passage from the (gothic) traumatic encounter with the uncanny Thing-as-Void early in the poem to the "modern" sublimation of an ordinary raven at the conclusion.

\section{The Staging of Das Ding: Poe's Aesthetic of Present-Absence}

In the opening stanzas of “The Raven," Poe presents a constellation of familiar images that convey an atmosphere of sorrow. The events of the poem occur during "a midnight dreary" (line 1) in "the bleak December" (7), when "each separate dying ember" from the speaker's fireplace "wrought its ghost upon the floor" (8). The emotional power of these images chiefly relies on the respective symbolic weight each contributes to the common motif of death. Poe's own reading of "The Raven" in "The Philosophy of Composition" implies that while such images do not "overste[p] ...the limits of the real" (207), that is, the denotative level of the narration, they may function, when viewed retrospectively, as objective correlatives to the central theme disclosed at the conclusion of the poem. Poe explains that the raven itself may be regarded as "emblematical," "but it is not until the very last line of the very last stanza, that the intention of making him emblematical 
of Mournful and Never-ending Remembrance is permitted distinctly to be seen" (208). According to Poe's analysis, it is the power of the sentimental metaphor, expressed by the grotesque image of the raven's beak in the speaker's heart, that effectively anchors the poem's meaning by imposing a degree of what he calls poetic "suggestiveness" (207) on all that has come before. According to this perspective, it is the disposition of the mind to seek a unifying theme that ultimately gives the poem its meaning and aesthetic effect.

What is even more striking, in my view, are the ways in which Poe's negative poetics, his representation of lack as a positive remainder, allow das Ding to emerge as a viscerally-felt structural effect prior to and in spite of any metaphorical or symbolic overdetermination. To be precise, much of the imagery and rhetoric of "The Raven" serves to dramatize not the metaphorical coherence of language but, on the contrary, the fundamental incapacity of language to achieve its aim, the tendency of signification to generate excesses of (non)meaning in symptomatic expression of its constitutive lack. For Poe, this lack accounts for the material opacity of language, which, like a veil, induces the specter of some palpable-be it ideal or terrible-“beyond." It is ultimately the speaker's traumatic repeated confrontation with this lack in the uncanny figure of das Ding, in the image of the mysterious tapping, the fantasy of his angelic beloved, and his encounter with the enigmatic raven itself, that mirrors his own lack and provokes his melancholic despair into madness. ${ }^{9}$

\footnotetext{
${ }^{9}$ Stephanie Sommerfield's recent argument regarding Poe's production of textual sublimity in "The Purloined Letter" is relevant here. Sommerfield maintains that Poe's poetics may be linked to the "negative" form of the sublime which affords the reader pleasure not through his or her diegetic encounter with transcendence (which she suggests is the typical expression of the Emersonian romantic sublime); rather, she argues that "the reader willingly subjects himself to the narration's domination and sublime effects, trusting that his 'suffering'-that is, his pain, or rather pains, to control the narration and establish order-will afford pleasure. Vainly trying to master the text, the reader will experience the text's sublime effects and consequently become an astonished
} 
In the opening of "The Raven," Poe's speaker is presented as "nearly napping" (line 3), reading "many a quaint and curious volume of forgotten lore" (2). This description frames the poem in two significant ways. On the one hand, the mention of the speaker's hypnagogic state emphasizes the liminal or divided status of the speaker who is neither entirely awake nor asleep, neither fully conscious nor unconscious, as the drama unfolds. If we are inclined to attribute the speaker's psychological instability throughout the poem to the loss of his beloved, Poe reminds us that subjectivity itself is constituted on the basis of an internal division and decentering. In contrast, the reference to "forgotten lore" serves as a metonymy for the notion that there exists an ancient knowledge of reality inaccessible to and invisible from the perspective of modern day scientific empiricism. Rather than merely establishing a dichotomy between empirical certainty and superstition (and negating the latter by the former), however, Poe's conceptual/aesthetic framework emphasizes the notion that the lack in the order of knowledge may "return" as an uncanny site of present-absence.

For Poe's speaker, there would, at first, seem to be no mystery at all regarding the meaning of the "gentl[e] rapping" (line 4) that has roused him, since he quickly attributes the sound to "some visiter ... / Only this and nothing more"” (5-6). And yet, the auditory intrusion becomes, early in the poem, the enigmatic point around which desire (the speaker's and the reader's) circulates. The

witness experiencing a 'perfect agony of joy'-that is, a Burkean mixture of pain and pleasure" (77). In Reading at the Social Limit (1995), Jonathan Elmer has also suggested that Poe's poetics leverage the reader's desire for textual mastery in the production of aesthetic pleasure. In his reading of "The Raven," Elmer observes: "Just as the narrator finds himself caught up in the contradictory pleasure-pain brought about by a disjunction between the performance power and the paralyzing referential import of the signifier 'Nevermore,' we too are divided between the poem's effect and its ostensible meaning" (209). Important to my analysis is the notion that the various moments of ambiguity, lacunae, and undecidability which drive the narration also serve to signal the pleasurable appearance of the uncanny and the over-proximity of Das Ding. From this perspective, the loss of meaning is a metonym for the loss of being. 
door itself functions both as a veil, directing the reader's attention to what is seen and unseen, known and unknown, and the bar between the signifier (the tapping sound) and the signified (the meaning of that sound). Because the enigmatic tapping has the effect of creating a gap or suspension in meaning, it functions as a signifier without a signified. The speaker's fantasy of a midnight visitor may be viewed, therefore, as a "makeshift" signified, seeking to "fill the hole" exposed in the signifying order in an effort to maintain a world of safely-enclosed, empirical certainty. Similarly, the speaker's refrain, "nothing more," repeated five times in the first third of the poem, reflects his overt attempt to impose epistemological limits on the shape of reality ("it is what it is and nothing else"); however, by positivistically demarcating an "inside" of knowledge, the phrase generates its own conceptual excesses, evoking the specter of what is unknown or even unknowable.

The speaker's initial impulse of disavowing or concealing the gap in his knowledge by fabricating a story resembles the adoption of what Lacan calls a "fixion," or the "fixed sets of identifications" used to "fil[1] up the place of the central void ... in knowledge" (Ragland 4). According to Lacan, identity is premised on the subject's unconscious ability to retroactively interweave visual experience, symbolic understanding, and the effects of the libidinal drives in ways that support the belief in a coherent, stable reality. According to the psychoanalytic theorist Ellie Ragland, affect is generated as "Fantasies seek to fill up lack, cycling rapidly through an interior void" (11). One of Poe's key poetic strategies in "The Raven" is the interruption of this "fixion"-making process, allowing the void in the subject's identity to emerge as a reflected effect of the void in knowledge.

In stanza four, when Poe's speaker finally opens the door and beholds only darkness, and not the expected visitor he had imagined, the tapping sound becomes legible for the speaker as both a sensible mystery and a conscious source of fear. The tapping sound functions earlier in the poem, however, as a potent site of unconscious anxiety. In stanza three, for example, the uncanny aspect of 
the tapping is visually rendered in or displaced onto the dramatic image of rustling curtains:

And the silken, sad, uncertain rustling of each purple curtain

Thrilled me-filled me with fantastic terrors never felt before;

So that now, to still the beating of my heart, I stood repeating

"'Tis some visiter entreating entrance at my chamber door-

Some late visiter entreating entrance at my chamber door;-

This it is, and nothing more." (lines 13-18)

Beyond the romantic projection of the speaker's feelings of grief onto his surroundings, the sibilant description of the curtains' "silken sad and uncertain" rustling highlights the function of the veil as a vehicle for the representation of the "hidden reality" (Lacan, VII 141) of das Ding apart from, and in excess of, what Poe calls "the limits of the real" ("Philosophy" 207). Poe's speaker is filled with "fantastic terrors never felt before" ("Raven" line 14) not because of his irrational assumption that something or someone is behind the curtains, but because the veiling effect of the curtain itself stages the void as an uncanny, threatening presence. Within the context of Poe's negative poetics, the curtains signal the paradoxical appearance of lack, which is not so much seen (as something empirically "missing") but felt in its appalling excess. For the speaker, a flight into the domain of fantasy-the plausible narrative of impending social intercourse-is the only available defense.

\section{"The most poetical topic in the world": Lenore and the Fantasy of Woman as Ideal}

In "The Philosophy of Composition," Poe infamously declares that "the death ... of a beautiful woman is, unquestionably, the 
most poetical topic in the world" (201). For Poe, this claim is true for the "obvious" reason that, as "the most melancholy of topics" (201), the death of a beautiful woman allies sentimental affect with aesthetic taste. Like many of Poe's observations in what is generally taken to be the tongue-in-cheek commentary of "The Philosophy of Composition," the selection of the motif is, he claims, the inevitable result of a demanding aesthetic calculus which takes universal aesthetic pleasure as its primary goal. While we may disagree with Poe's particular assessment of the aesthetic value of Lenore's death in "The Raven," there is little doubt that her fleeting, idealized image serves an important purpose to the aesthetic design and emotional impact of the poem as a whole, specifically with regard to the representation of and defense against das Ding.

In "The Raven," the reader is not introduced to any particular aspect of Lenore's beauty, which might humanize her as a character. Her beauty is, on the contrary, portrayed in the abstract and conceptualized in the universal. In the second stanza, for example, she is briefly described as "the rare and radiant maiden whom the angels name Lenore- / Nameless here for evermore" (line 11-12). Poe's minimalist description blurs what the reader takes to be the earthly, innocent beauty of Lenore with what would appear to be her spiritualized, otherworldly essence (rare $=$ rarefied). The very same description is repeated near the conclusion of the poem, in stanza sixteen, with the additional designation of the beloved as a "sainted maiden" (94). Even the name "Lenore," Greek for "light," supports the notion of disembodied purity and transcendental beauty. In stanza thirteen, we are provided with images of Lenore, but only as a figure of present-absence when the speaker, reclining his head on a "cushion's velvet lining that the lamplight gloated o'er" (76), realizes that "She shall press, ah, nevermore!" (78). There is no content specific to the speaker's memory (no anecdote, no incident) but only the brief evocation of a sublimated presence attached to the otherwise ordinary cushion and the charged atmosphere, created by the negative outline of the lover's absent body. 
The speaker's descriptions of Lenore constitute less an inventory of mourning, a recital of the deceased's most beloved earthly traits, than a tenuous defense against the reality of her death, and death itself, via an abstract image of celestial perfection. The image of Lenore functions thereby as a kind of narcissistic reflection of the speaker's desired subjective unity, imagined as a state of transcendent wholeness, which exists beyond the threat of subjective fragmentation posed by death. As Ragland, citing the work of JacquesAlain Miller has observed, such a fantasy "create[s] the effect of a 'distant interior" by maintaining one's relation to a "lost cause" (15). This type of fantasy, which concerns the maintenance of a "cherished object," Ragland explains, is significant "not only [because of]... what the fantasy hides" but for its role in maintaining "the belief in a 'beyond"” (15). Rather than mourning Lenore's particularized image in a way that would allow her to "live" on as a site of sublimated investment for his love and desire in his memory, Poe's speaker effectively disavows her death by attempting to find refuge in the "distant interior" and heavenly "beyond," represented by the fantasy of the beloved's celestial maidenhead. As an impossible ideal of purity and goodness and a defense against the void of death, the image of Lenore would, on the surface, seem to allow the speaker to maintain a relation to das Ding from a safe distance. In this sense the speaker's depiction of Lenore functions in a way reminiscent of the Lady in medieval courtly love poetry.

In Seminar VII, Lacan argues that in such poetry, in which an unattainable, noble Lady is addressed by a poet-singer, the "feminine object is emptied of all real substance" (149), that is, the mimesis of social realism, and is reimagined as the site of an impossible ideal. The speaker's relation to the woman is marked by "privation and inaccessibility" (149), such that courtly love poetry functions for the speaker as a mirror onto which "the subject's ideal is projected," a mirror that "fulfills ... [the] role as limit," indicating "that which cannot be crossed" (151). The image of the Lady thereby functions as both a limit-defense against the void of das Ding at the same time that it allows a sublimated relation with 
the object to be sustained via the embodiment of the transcendent Good. I should note here that Lacan's own descriptions of the differences between idealization and sublimation become confusing at times. The primary distinction, according to Lacan in Seminar $V I I$, is that while idealization is merely a defense against das Ding, a "barrier to desire" (218), sublimation involves the structures of the partial drives and "raises an object ... to the dignity of the Thing” (112). My intention here is to suggest that the speaker's fantasy of Lenore functions primarily as a phantasmagorical defense against the void in being. It is only at the end of the poem, when the speaker's melancholia dismantles this idealization that sublimation occurs in the figure of the raven itself.

According to the literary critic Frederick Goldin, courtly love poetry, from a cultural perspective, represents a site of anxiety due to the fact that the relation between social reality and poetic artifice is always uncertain. If the poet's ideal portrayal of the noble Lady were proven false, the knight-poet's entire moral enterprise would be undermined. The poet's life, therefore, is characterized by the "alternation between faith and doubt" (132). In other words, the maintenance of the cultural ideal in the figure of the Lady, the Good upon which the singer-poet's social and moral existence are based, depends upon a fundamental disavowal: his refusal to know the truth of the object of his affections. The singer-poet must maintain a safe distance from the social reality of the Lady and her class or risk exposing the potentially lethal void at the center of social-symbolic reality.

Like the Lady in courtly love poetry, Lenore is inaccessible (because of her biological death) and maintains the privileged status as an ideal, which we may view as the speaker's fantasy of a "distant interior." However, in "The Raven," the notion of Lenore's angelic existence functions solely at the level of the phantasmagorical, an image which seeks to conceal the void of das Ding as a limit that cannot be crossed, specifically through the representation of a "beyond." In contrast to the Lady, whom Lacan describes as an ordinary object that is raised "to the dignity of the Thing" (VII 
112) via sublimation, the speaker's fantasy of Lenore is merely an idealization, or what Lacan calls the "identification of the subject with the object” (111), whose efficacy depends upon the foreclosure of Lenore's name. The speaker suggests that for his beloved to attain a spiritual "rebirth" in the realm of the angels, she must be "Nameless here for evermore" (Poe, "Raven" line 12). Consequently, when the forbidden name, resignified across the gulf of biological death and symbolic resurrection, is whispered in stanza five, its echo assumes the uncanny aspect of the undead:

Deep into the darkness peering, long I stood there wondering, fearing,

Doubting, dreaming dreams no mortal ever dared to dream before;

But the silence was unbroken, and the stillness gave no token,

And the only word there spoken was the whispered word, "Lenore?"

This I whispered, and an echo murmured back the word, "Lenore!"

Merely this and nothing more. (25-30)

The speaker, a modern day Narcissus, embraces his own image of unity in the fantasy of the angelic beloved, while his lover, like the rejected nymph, Echo, "returns" in the uncanny trace left by the material opacity of the signifier. The foreclosed status of the name essentially divides the signifier from itself, doubling it along two divergent trajectories of meaning, one "full" (the fantasy of idealization) and one "empty" (the empirical reality of her death). The signifier "Lenore," now only spoken by the angels, is left, to borrow Ralph Waldo Emerson's convenient phrase, as “an outcast corpse" (47) in the speaker's symbolic reality; consequently, the speaker's whispered utterance of the name, "Lenore," results not in the unifying image of the celestial maiden but rather the specter of the void itself. Through the repercussions of the echo, the signifier traces the hollow of the void left in the social-symbolic by 
Lenore's death; however, because his echoed voice returns to him in the distorted form of an enigmatic address from the Other, Poe's speaker glimpses an uncanny reflection of his own internal division. When the speaker has returned to his chamber, he finds "all [his] soul within [him] burning" ("Raven" line 31), reflecting the anxiety and affect induced by his close encounter with das Ding.

\section{From Idealization to Sublimation: The Raven as Representative of Das Ding}

Before I extend my analysis to the figure of the raven itself, I want to briefly examine Poe's own interpretation of how peculiar aesthetic strategies lead to specific effects in this section of the poem. In "The Philosophy of Composition," Poe describes the speaker's dialogue with the raven in terms that brilliantly evoke the image of an intricate machina poetica, a rotating dial whose incremental "turns" occasion unexpected semantic tensions as the refrain "Nevermore," a "monotone of sound" (199), is dramatically inserted into new contexts of "thought." He explains:

The pleasure is deduced solely from the sense of identity-of repetition. I resolved to diversify, and so vastly heighten, the effect, by adhering, in general, to the monotone of sound, while I continually varied that of thought: that is to say, I determined to produce continuously novel effects, by the variation of the application of the refrain-the refrain itself remaining, for the most part, unvaried. (199)

Poe suggests that the aesthetic effect of his monotonous refrain is the poetic equivalent of an enharmonic change in music. In both cases, intellectual pleasure and emotional responses are derived from the novelty of a shifting background (harmonic or conceptual) in contrast to a static phrase (melodic or linguistic). Recent scientific research on the emotional and physiological responses of listeners to enharmonic changes in music would seem to lend support to Poe's claim that a similar production of novelty 
in the scene of reading might also produce pleasure. ${ }^{10}$ Neuroscientific studies indicate that physiological responses to enharmonic changes, including tears and chills, are the result of the autonomic arousal of the brain's startle reflex, a reflex that is tied to the primitive fight or flight survival instinct. As David Shariatmadari points out in his September 2, 2015 article in The Guardian, because arousal itself is "emotionally neutral," whether such an arousal response would be interpreted as positive or negative would largely depend upon the subject's perception of his or her own emotional state.

In the first half of "The Raven," as we have seen, Poe generates affect, especially perceptions of the uncanny, by linking the death of Lenore, and the concept of death more generally, to the threat of subjective disintegration and primordial nihility. More specifically, the speaker employs fantasies of empirical certainty and the celestial permanence of Lenore as defenses against the void of das Ding; however, when these "fixions" are interrupted, affect is produced in the sudden appearance or "return" of an uncanny remainder (the rustling curtains, the echo). The specter of the external void of das Ding reflects the "interior void" in the subject, generating what Lacan calls "primary affect" (VII 54). In the final section of the poem, nevertheless, Poe adopts a new aesthetic strategy. While the exchange between Poe's speaker and the raven may indeed produce pleasure (for the reader and initially for the speaker) through the types of symbolic novelty which arouse the brain's startle reflex, the emotional context for such arousal must increasingly be attributed to the repetitive structure of what Freud calls the death drive (Todestrieb). Here a form of pleasure is generated through what Freud calls the "compulsion to repeat," which, paradoxically, "overrides the pleasure principle” (Beyond 22). No

\footnotetext{
${ }^{10}$ For an overview of research on the effect of music on the brain, see Anne J. Blood and Robert Zatorre, "Intensely Pleasurable Responses to Music Correlate with Activity in Brain Regions Implicated in Reward and Emotion” (2001). Also see John A. Sloboda, "Music Structure and Emotional Response: Some Empirical Findings" (1991).
} 
longer are fantasies employed as a defense against das Ding; rather, fantasy becomes the very vehicle through which das Ding is experienced in the form of a traumatic encounter with the mysterious raven.

In stanzas seven through eleven, the speaker quickly puts to rest the previous mystery of the tapping as he observes, with ironic detachment, the entrance of the raven into his chamber. The speaker reports that the raven enters with the "mien of lord or lady" (Poe, "Raven" 40), demonstrating "Not the least obeisance" (39) as it sits "Perched upon a bust of Pallas just above [his] chamber door" (41). The speaker thereby playfully enlists the creature in the drama of his evening's woe:

Then this ebony bird beguiling my sad fancy into smiling, By the grave and stern decorum of the countenance it wore, "Though thy crest be shorn and shaven, thou," I said, "art sure no craven,

Ghastly grim and ancient Raven, wandering from the Nightly shore- Tell me what thy lordly name is on the Night's Plutonian shore!"

Quoth the Raven, "Nevermore." (43-48)

For Poe's speaker, the raven's appearance initially becomes the source for outlandish fancy. The creature is addressed as a knight errant whose wandering has brought him to the speaker's chamber from the kingdom of the underworld. In the midst of the anthropomorphic fantasy, the speaker's query as to the bird's name is answered with the single word: "Nevermore." The speaker's reaction is very much like his initial response to the tapping sound earlier in the poem: he quickly invents a fantasy which explains away the mystery and supports his desire for subjective unity. Furthermore, he assumes that the raven's "plainly" spoken "discourse" (49) has "little meaning" or "relevancy" (50) because it does not appear to fit within the terms of his own narcissistic fantasy. Along these lines, the speaker, in stanza eleven, imagines another scenario in which his own feelings of loss-"On the morrow be will leave me, 
as my hopes have flown before" (59)-are mirrored in the raven's former "unhappy master" (63). In this scenario, the raven is imagined to communicate a kindred sympathy between its former master and the speaker, forging a brotherhood in sorrow.

A sudden shift in the speaker's perspective and tone occurs in stanza twelve, however, revealing the destabilization of his identity and the anxiety-provoking appearance of das Ding. Poe's speaker observes:

But the raven still beguiling all my sad soul into smiling, Straight I wheeled a cushioned seat in front of bird, and bust and door;

Then upon the velvet sinking, I betook myself to linking Fancy unto fancy, thinking what this ominous bird of yore- What this grim, ungainly, gaunt, and ominous bird of yore

Meant in croaking "Nevermore." (67-72)

As he "link[s] / Fancy unto fancy" (69-70) in search of the bird's meaning, the speaker's emotional state quickly modulates from one of "smiling" bemusement to apprehension and even fear. The word "Nevermore" functions, initially (in stanzas seven through eleven), as an empty signifier, ${ }^{11}$ a signifier not simply missing a signified, but rather a signifier whose "open" ambiguity makes it available to potentially infinite signifieds. The raven, consequently, becomes a blank screen for the speaker's narcissistic fantasies. The raven begins to take on an "ominous" aspect, yet, as soon as the signifier is repeated, causing the speaker to entertain the dark possibility that the formerly "meaningless" word, "Nevermore," is actually a message addressed directly to him from the "Plutonian shore" (47). To be clear, it is the formal structure of the refrain as a repetition, rather than any specific content, that induces the speaker's anxiety and prompts his subsequent hysterical outburst. At this stage in the "dialogue," the speaker cannot

\footnotetext{
${ }^{11}$ Wardrop refers to "Nevermore" as a "pure signifier" (167); Elmer uses the term "arbitrary" signifier (205).
} 
determine whether the raven's utterance is simply the harmless mimicry of an automaton or an oracular missive to be deciphered.

It is in this precise sense that the raven's enigmatic visage and monotonous refrain represent the threatening aspect of das Ding as "the stranger, the hostile figure" (VII 55) that Lacan witnesses, unexpectedly, in the enigmatic smile of the 1930s film icon, Harpo Marx. The irreducible ambiguity of Marx's facial feature, Lacan observes, "leaves us unclear as to whether it signifies the most extreme perversity or complete simplicity" (55). Such "absorbing ... disruptive ... nauseating" ambiguity, he maintains, is "calculated to thrust everything that takes place before us into the abyss or void" (55). There is, likewise, nothing inherently "perverse" or "hostile" about the raven, and yet Poe's speaker feels the raven's "fiery eyes ... bur[n] into [his] bosom's core" ("Raven" line 74). This moment, as a consequence, echoes earlier scenes in which the speaker feels himself "penetrated" by the gaze of some invisible Other. Recall, for example, that the rustling of the curtains in stanza three fills him with "fantastic terrors never felt before" (14) and, in stanzas five and six, the echo of his own voice whispering his lover's name in the darkness leaves "all [his] soul within [him] burning" (31). In none of these episodes is Poe's speaker actually threatened by some human or nonhuman agent; rather, his emotional responses signal the primary affect or forbidden jouissance associated with the appearance of das Ding.

In the final episode of the poem, when the raven finally enters the speaker's chamber, it assumes a place already prepared for it, as if by fate, within the poem's topography of present-absence. By stanza twelve, the raven has, in effect, assumed the "dignity of the Thing"-as-Other within the field of the speaker's desire. The moment of crisis for the speaker is accompanied by the presentabsent image of Lenore:

This and more I sat divining, with my head at ease reclining On the cushion's velvet lining that the lamplight gloated 
o'er, But whose velvet-lining with the lamp-light gloating o'er,

She shall press, ah, nevermore! (Poe, "Raven" lines 75-78)

Soon after, in stanza fourteen, the speaker's fantasy takes the form of auditory and olfactory hallucinations, as "the air grew denser, perfumed from an unseen censer" (79) and the "tinkled" sound of angels' "faint foot-falls" (80) are heard in the room. With these strange images, Poe attempts to render the entrance of das Ding (and the shift to the finale of the poem) explicitly visible to the reader by implicitly linking it to psychological or supernatural phenomena.

If we return to the original proposition of this essay, that "The Raven" dramatizes the speaker's melancholia as, specifically, the pursuit of the lost object of das Ding, it becomes evident, by the end of the poem, that the speaker's "linking / [of] Fancy unto fancy" (Poe, "Raven" lines 69-70) in an effort to decipher the meaning of the cryptic raven represents both his original desire to suture symbolic reality through the assumption of some determinate and unifying meaning and the contradictory, self-destructive desire to undermine those fantasies through the calculated anticipation of the raven's nihilistic refrain. These divergent desires roughly correspond to Freud's description of the vicissitudes involved in the manifestation of melancholia. In "Mourning and Melancholia," Freud observes that as "object-loss ... [is] transformed into egoloss" erotic cathexis splits along two paths (249). On the one hand, the loss of the love object results in the subject's "regression ... to original narcissism” (249). As we have seen, Poe's speaker reflects this form of regression in his attachment not to the living memory of Lenore but rather her phantasmagorical idealization. This corresponds to Freud's claim that narcissistic identification represents the ego's desire "to incorporate [the lost love object] into itself" (249). The idealized image of Lenore, I have attempted to demonstrate, reflects the speaker's desire for subjective unity, which the reality of his lover's death has compromised. It is through this fan- 
tasy that the speaker disavows death and maintains a belief in what Jacques-Alain Miller calls a "distant interior" (qtd. in Ragland 15), a state of permanent transcendence in a celestial beyond. Conversely, Freud argues that in melancholia, the conflict over the loss of the love-object proceeds to an unexpected and pronounced, selfdirected sadism. At first, Freud admits that he cannot "conceive how ... [the] ego can consent to its own destruction" ("Mourning" 252). This would only be possible, he concludes, if the ego "can treat itself as an object" (252). In order to explain the phenomenon, Freud draws an analogy to the work of mourning. If mourning reaches its conclusion when the subject finally withdraws from the love-object, "declaring the object to be dead and offering the ego the inducement of continuing to live," melancholia, at the level of the unconscious, proceeds in a "struggle of ambivalence" in which the ego attempts to "loosen the fixation of the libido to the object by disparaging it, denigrating it, and even as it were killing it" (257). While Freud's theory allows us to understand the status of the speaker's idealization as an object that comes under attack in his questioning of the raven, it does not, for our purposes, adequately account for the role of repetition in the final section of "The Raven." For it is not only the speaker's attack on his ideal fantasy that is at question in this section of the poem, but also the fact that he aligns the "automatic" repetitions of the raven's nihilistic refrain with the internal structure of his own unconscious desire for negation, represented by das Ding.

The paradoxical inclination toward self-destruction that Freud finds so difficult to conceive in "Mourning and Melancholia," precisely because his prior theoretical observations emphasized the "necessary" resolution of instinctual processes, is the point of departure for his theories of repetition and the death drive developed in Beyond the Pleasure Principle a few years later. Rather than viewing sadistic impulses as the indirect mechanism for psychic resolution, he begins to view the psychological repetition of trauma as a more primitive psychic structure productive of a kind of pleasure that functions "beyond the pleasure principle." 
According to Freud, the "compulsion to repeat" reflects an "urge inherent in organic life to restore an earlier state of things" (36), a drive "to return to the inanimate state" (38). In this regard, Freud's theory is reminiscent of Poe's own conception of the return to primordial unity that backgrounds human (un)consciousness described in Eureka. It would be a mistake, however, to argue simply that Poe's speaker is "gripped by the death drive" and plunging headlong into the abyss of das Ding, symbolically represented by the mysterious raven. As I have pointed out already, the raven's conjunction with the empty signifier "Nevermore" creates ambiguity which both spurs the production of fantasy and a feeling of the uncanny that we have associated with das Ding. Nevertheless, the raven cannot be viewed as das Ding itself because, like Poe's theory of primordial Unity, the notion of the primordial mother, and Freud's conception of a return to an "inorganic state," das Ding is ultimately a retrospective illusion, an effect of the subject's entrance into language.

The function/object of the drive, then, is not to achieve the annihilation of the subject but, on the contrary, to afford it some of the jouissance that it relinquished upon its entrance into the signifying realm. As the psychoanalytic theorist Joan Copjec puts it, "the $o b$ ject of the drive ... simultaneously brakes the drive and breaks it up, curbs it, thus preventing it from reaching its aim" (34). In other words, there is not one drive but many "partial drives," and these are characterized by what Lacan calls their "drift" and "deflection" (VII 110). Repetition represents precisely the fact that, as Lacan explains, "The satisfaction of the Trieb [drive] is ... paradoxical, since it seems to occur elsewhere than where its aim is" (111). If the aim of the speaker's drive is the confrontation with the void of das Ding via the destruction of his idealizations (as the trajectory of his melodramatic rhetoric would seem to suggest), the satisfaction of his drive concerns the sublimation of the raven as a new object of the unconscious. Specifically, the raven becomes, within the poem's topography of present-absence and within the structure of the speaker's melancholia, a representative of das Ding, 
what Lacan calls a Vorstellungsrepräsentanz, a "representativ[e] of representation" (102).

Each of the speaker's questions addressed to the raven correspond to some potential resolution not only to the speaker's loss of his beloved but also to the problem of death and, by implication, the return to primordial nihility. With each subsequent query, however, the speaker seems driven by the compulsion to repeat the trauma of the previous glimpse into the abyss, representing what Poe calls "the human thirst for self-torture" ("Philosophy" 207). In stanza fourteen of "The Raven," the speaker appeals to the raven as a messenger of God-"by these angels he hath sent thee" (line 81)-for some "kind Nepenthe" to help him "forget this lost Lenore!" (83). In the next stanza, stanza fifteen, the speaker addresses the raven as a "Prophet," (85) possibly sent by the "Tempter," (86) Satan, and inquires "Is there-is there balm in Gilead?-tell me-tell me, I implore!" (89). If the question is indeed, as G.R. Thompson has intimated, an allusion to the biblical book of Jeremiah, in which the speaker's line would be followed by the question "is there no physician' who can restore the 'health of the daughter' of the prophet's people" (60), it implies the speaker's dark desire for some cure that would bring his lover back from the dead. The speaker then demands of the raven, presumed either a messenger of God or instrument of evil, to inform him of whether or not he will find Lenore in heaven: "Tell this soul with sorrow laden if, within the distant Aidenn, / It shall clasp a sainted maiden whom the angels name Lenore" (Poe, "Raven" lines 93-94). To each question-Will you make me forget her? Will you bring her back to life? Will I see her in heaven?-the raven famously responds with the ominous refrain: "Nevermore!"

I would argue that the refrain reflects neither the raven's "refusal to respond to the plea for an answer" (148), as William Freedman has suggested, nor an impasse in meaning. On the contrary, in his compulsive questioning, the speaker makes his appearance one Freud describes as "pursued by a malignant fate or possessed by some 'daemonic power" (Beyond 21). The speaker's questioning 
does, in fact, take on the structure of fatalism in the precise sense that his discourse circles around, is retroactively caused by and is consequently the effect of the empty signifier, "Nevermore." Through the process of repetition, the refrain, "Nevermore," takes on the structural significance of a master signifier. Because it is empty, the signifier not only retroactively sutures the speaker's discourse around the concept of negation but also images forth the void itself as the aim of the death drive. The speaker's fantasies do not simply cover over the void but name it, holding it open precisely by enabling the drive to circulate around the object that has been installed in its place, in the guise of the enigmatic raven. The final question posed to the raven is thus perversely directed at the negation of the fantasy of Lenore's celestial existence, and, by extension, the possibility of an afterlife. The speaker thereby undermines the fantasy at the core of his attempt to maintain subjective unity via the belief in a transcendent "beyond."

If the speaker has "killed" the object of his unconscious that defends against the unbearable jouissance of das Ding, he does so, fortuitously, linking the repetitive circuit of the drive to the raven as objet $a$, what Lacan calls the "sublime" object around which the drive turns. Through the sublimation of the raven, in other words, the speaker is able to access part of the forbidden jouissance that, earlier in the poem, caused eruptions of uncanny primary affect. The meaning of the death drive, therefore, is not the realization of the subject's self-destruction but rather the continuation (and satisfaction) of the drive itself.

Ultimately, it is the arrival of the raven that allows the speaker to overcome his romantic deadlock, the traumatic oscillation between idealization (the phantasmagorical defense against his desire) and the "impossible" and threatening void of das Ding. The speaker's longing for the eternal state associated with the angelic Lenore is replaced by the eternal return of the drive itself. To return to Žižek's remarks on modern art for a moment, we can say that the raven, which now has the eyes of "a demon that is dream- 
ing" (Poe, "Raven" line 105), gives form and place to the void. The shadow that the raven casts on the floor emphasizes its uncanny double status: it is both an ordinary object with "normal" physical properties and a representative of the void that surrounds it (the nothing that has been staged prior to its appearance on the scene). It is only through the outline of the ordinary object, in other words, that the darkness, the void, is visible at all.

While I have suggested that the episode involving the raven helps to resolve the speaker's prior romantic deadlock between the idealization of Lenore and irruptions of uncanny jouissance, I do not mean to imply that by the end of "The Raven" the speaker's position, his existential condition, to be precise, is improved. If we interpret the speaker's assertion that his soul has joined "that shadow that lies floating on the floor" (Poe, "The Raven" line 107) as simply a piece of romantic melodrama, we miss the hints of modernist despair and ironic resignation, even comic absurdity, inherent in the speaker's position at the conclusion of the poem. For some of Poe's contemporary readers, in fact, the ending of "The Raven" became the object of humor. This may have something to do with Poe's own account of his methods and aims in the penning of the poem, described in "The Philosophy of Composition." According to Poe, the line-"Take thy beak from out my heart, and take thy form from off my door!" (101) - establishes the key metaphor that casts a retrospective umbra of "suggestiveness" over the poem, linking the theme of "Mournful and Never-ending Remembrance" ("Philosophy" 208) to what he suggests is a straight-forward narrative. The problem, of course, is the fact that the next line- "And the Raven, never flitting, still is sitting, still is sitting" ("Raven" line 103)-strains the metaphor to the point of grotesque collapse. The passage from what Poe calls the "limits of the real" to the metaphorical and back again, led some of his readers to imagine all manner of cartoonish uninvited house guests in comic revisions of the poem. In Graham's Magazine, for example, appeared "The Vulture: An Ornithological Study" (1853), an early, anonymous spoof 
of "The Raven" in which an ill-mannered vulture gulps stout and ruins the speaker's carpet. ${ }^{12}$

The power of "The Raven" is not derived, as Poe perhaps wryly claims in "The Philosophy of Composition," from the inherent emotional value of certain, "sonorous" vowel sounds or the over-determining "suggestiveness" of a particularly apt metaphor. Rather, the effects of "The Raven" follow from the ability of Poe's negative poetics to frame the void, linking "ordinary" gaps in meaning to manifestations of uncanny present-absence. Spoofs of "The Raven" like "The Vulture" help to highlight the ways in which Poe's gothic aesthetic anticipates the nihilism and absurdity of modernism. If the speaker began "The Raven" haunted by his desire and fantasies of a celestial beyond, he concludes the poem, not in romantic death (joining with das Ding via his merging with the angelic Lenore), but rather in a state we can only describe as one of nihilistic absurdity and Kafkaesque endurance.

\section{Works Cited}

Abraham, Nicolas, and Nicholas Rand. "Psychoanalytic Esthetics: Time, Rhythm, and the Unconscious." Diacritics 16, no. 3 (Autumn 1986): 2-14. doi: $10.2307 / 464948$.

Aristotle. Aristotle's Nicomachean Ethics. Translated by Robert C. Bartlett and Susan D. Collins. Chicago: University of Chicago Press, 2011.

Blood, Anne J., and Robert J. Zatorre. "Intensely Pleasurable Responses to Music Correlate with Activity in Brain Regions Implicated in Reward and Emotion." PNAS 98, no. 20 (2001): 11818-11823.

${ }^{12}$ The concluding stanza of the anonymous poem, styled "after the late Edgar A. Poe" (657), reads:

And the Vulture never flitting, still is sitting, still is sitting, Gulping down my stout by gallons, and my oysters by the score;

And the beast, with no more breeding than a heathen savage feeding, The new carpet's tints unheeding, throws his shells upon the floor.

And his smoke from out my curtains, and his stains from out my floor, Shall be sifted never more. (659) 
Copjec, Joan. Imagine There's No Woman: Ethics and Sublimation. Cambridge: MIT Press, 2004.

Dolar, Mladen. "I Shall Be with You on Your Wedding Night: Lacan and the Uncanny." October 58 (Autumn 1991): 5-23. doi: 10.2307/778795.

Elmer, Jonathan. Reading at the Social Limit: Affect, Mass Culture, and Edgar Allan Poe. Stanford: Stanford University Press, 1995.

Emerson, Ralph Waldo. "Nature." In Emerson's Prose and Poetry: Authoritative Texts, Contexts, Criticism, edited by Joel Porte and Saundra Morris, 27-55. New York: W.W. Norton, 2001.

Farrant, Timothy, and Alexandra Urakova. "From 'The Raven' to Le Cygne': Birds, Transcendence, and the Uncanny in Poe and Baudelaire." The Edgar Allan Poe Review 15, no. 2 (Autumn 2014): 156-74.

Fink, Bruce. The Lacanian Subject: Between Language and Jouissance. Princeton: Princeton University Press, 1995.

Freedman, William. "Poe's The Raven." The Explicator 57, no. 3 (Spring 1999): $146-48$.

Freud, Sigmund. "Beyond the Pleasure Principle." In The Standard Edition of the Complete Psychological Works of Sigmund Frend: Beyond the Pleasure Principle, Group Psychology, and Other Works, edited and translated by James Strachey, vol. 18, 1-64. London: Hogarth Press, 1981.

-. "Mourning and Melancholia." In The Standard Edition of the Complete Psychological Works of Sigmund Frend: On the History of the Psycho-Analytic Movement, Papers on Metapsychology, and Other Works, edited and translated by James Strachey, vol. 14, 237-58. London: Hogarth Press, 1981.

-. "The Uncanny." In The Standard Edition of the Complete Psychological Works of Sigmund Freud: On Infantile Neurosis and Other Works, edited and translated by James Strachey, vol. 17, 217-58. London: Hogarth Press, 1981.

Goldin, Frederick. The Mirror of Narcissus in the Courtly Love Lyric. Ithaka: Cornell University Press, 1967.

Krutch, Joseph Wood. Edgar Allan Poe: A Study in Genius .New York: Russell and Russell, 1965.

Lacan, Jacques. Écrit: A Selection. Translated by Alan Sheridan. New York: W.W. Norton, 1977. 
-. The Seminar of Jacques Lacan, Book VII: The Ethics of Psychoanalysis. Edited by Jacques-Alain Miller. Translated by Dennis Porter. New York: W.W. Norton, 1992.

Melville, Herman. Moby Dick, or the Whale. Edited by Hershel Parker and Harrison Hayford. New York: W.W. Norton, 2002.

Poe, Edgar Allan. "Eureka”. In The Complete Works of Edgar Allan Poe: Marginalia. Eureka. Bibliography, edited by J.A. Harrison, vol. 16, 179-315. New York: Thomas Y. Crowell, 1902.

-. "The Philosophy of Composition." In The Complete Works of Edgar Allan Poe: Essays and Miscellanies, edited by J.A. Harrison, vol. 14, 193-208. New York: Thomas Y. Crowell, 1902.

-. “The Raven." In Collected Works of Edgar Allan Poe: Poems, edited by Thomas Ollive Mabbott, vol. 1, 350-374. Cambridge, MA: Belknap, 1969.

Ragland, Ellie. "Psychoanalysis and Courtly Love." Arthuriana 5, no. 1 (Spring 1995): 1-20.

Rein, David M. Edgar Allan Poe: The Inner Pattern. Washington: Folcroft, 1970.

Shariatmadari, David. "Why Does Music Give Us Chills? You Asked Google-Here's the Answer." The Guardian, September 2, 2015. http://theguardian.com/ commentisfree/2015/sep/02/why-does-music-give-us-chills-google.

Shulman, Robert. "Poe and the Powers of the Mind." ELH 37, no. 2 (June 1970): 245-62. http://www.jstor.org.proxy.library.nyu.edu/stable/2872376.

Silverman, Kenneth. Edgar A. Poe: Mournful and Never-ending Remembrance. New York: Harper Collins, 1991.

Sloboda, John A. "Music Structure and Emotional Response: Some Empirical Findings.” Psychology of Music 19, no. 2 (October 1991):110-120.

Sommerfield, Stephanie. "From the Romantic to the Textual Sublime: Poesque Sublimities, Romantic Irony, and Deconstruction.” In Deciphering Poe: Subtexts, Contexts, Subversive Meanings, edited by Alexandra Urakova, 75-85. Bethlehem, PA: Lehigh University Press, 2013.

Starobinski, Jean. The Living Eye. Translated by Arthur Goldhammer. Cambridge, MA: Harvard University Press, 1989. 
Thompson, G.R., ed. The Selected Writings of Edgar Allan Poe. New York: W.W. Norton, 2004.

“The Vulture." Graham's American Monthly Magazine of Literature, 43 (July - December 1853): 657-59. http://babel.hathitrust.org/cgi/pt?id=inu.32000000690034; view $=1$ up;seq $=673$.

Wardrop, Daneen. "Quoting the Signifier 'Nevermore': Fort! Da!, Pallas, and Desire in Language." In Critical Insights: The Poetry of Edgar Allan Poe, edited by Steven Frye, 163-87. Pasadena: Salem Press, 2011. Originally published in ESQ: A Journal of the American Renaissance 44, no. 4 (1998): 275-99.

Žižek, Slavoj. The Fragile Absolute, or Why is the Christian legacy worth fighting for? New York: Verso, 2000. 


\title{
4 The Doppelgänger, Psychology, and Poe
}

\author{
TATIANA PROROKOVA
}

\begin{abstract}
"You have conquered, and I yield. Yet henceforward art thou also dead - dead to the World, to Heaven, and to Hope! In me didst thou exist - and, in my death, see by this image, which is thine own, how utterly thou hast murdered thyself."

Edgar Allan Poe, "William Wilson"
\end{abstract}

\section{Introduction: Poe and the Psychology of the Human Mind}

Already in the middle of the nineteenth century, one of the most famous dark romantics Edgar Allan Poe meticulously examined the problem of human mind in his oeuvre. Investigating the connections between one's behavior and the psyche, Poe doubtlessly became one of the pioneers of psychology. It is, indeed, important not to underestimate the role that Poe played in the development of psychology at times when, as Benjamin F. Fisher writes, "[m]edical science . . . was just beginning to take strides away from superstition and folksiness" (22). In his literary works, Poe explored the notions of psyche and mental disorder, broadening 
the cultural and scientific knowledge about psychology as a science. Although Poe was as a literary author, it would be wrong to claim that the plots he invented were mere strolls on the unknown ground of the just-emerging psychiatry and psychology. These works surely were more than that, for they provided clinical presentations, describing multiple cases of mental disorder that resulted and manifested themselves in different ways.

Poe's interests in medicine, with a visible dominance of psychiatry and psychology, have been described by literary scholars as crucial to his works, for all his stories include characters suffering from various mental disorders: "Nearly all of Poe's protagonists evince paranoias, and some also power mania" (Fisher 22). Noteworthy, Poe was not the only author of his time interested in these issues. Romanticism as a literary movement was largely characterized by the "fascination with the human mind" that romantics (including dark romantics) expressed (23). Yet, while such representatives of the movement as, for example, Ralph Waldo Emerson attempted to scrutinize the mind in order to uncover its predominantly sanguine characteristics, the dark romantic Poe was interested in the reversely opposite (23-24). Fisher writes:

For him [Poe] the mind was a far more shadowy area, occasionally illuminated by unpleasant lights. The corridors of the mind reveal twisted pathways, which may provide surprises to the explorer, but those surprises are often the frightening discoveries that negative passions inhabit these environs. Yearning for outreach leading to harmonious relationships with another or others are often hampered by reluctances to engage such bondings, be those reluctances mild or be they egoistical, brutal, murderous in nature. Poe's mistrust of mob rule may also have encouraged such skepticism, just as his shock at John Allan's [Poe's foster father] refusal to provide him with financial security may have caused him to be skeptical even of individuals who seemed to be friendly. (24) 
Poe, thus, criticized the transcendental idea of human perfection, focusing on the issue of sin as the key concept in the construction of the human nature. Questioning human morality and overtly hinting at the depravity of individuals and society in general, Poe undermined the idea of mental sanity, thus, to borrow from Fisher, "[having] created terror that was rooted in the soul" (24).

While literally each story written by Poe deals with the problem of human psyche, this chapter focuses on four works of his, namely "The Fall of the House of Usher" (1839), "William Wilson" (1839), "The Tell-Tale Heart" (1843), and "The Black Cat" (1843). Closely examining the concept of madness as illustrated in the four tales, the chapter contends that Poe views insanity as a result of human peccancy, thus understanding sin as a destructive yet inevitable factor in the human existence. Through numerous vile sins, among which are murder, incest, and alcoholism, Poe investigates how the human mind decomposes, revealing humanity's true nature. One of such manifestations of madness, as Poe makes it apparent in numerous stories, is the problem of mental dualism. Poe's doppelgängers serve to illustrate the existence of the dichotomy of the "good" self vs. the "bad" self, which inevitably results in the split of one's personality. The chapter's primary aim is, thus, to understand the problem of one's psychological mutilation and its various manifestations, with a particular stress on the concept of doppelgänger, as represented in Poe's short stories.

\section{Madness and Sin in Poe's Short Stories}

Poe does not view madness as an extraordinary phenomenon. One might even speculate that Poe does not see it as an illness proper but rather reasons it to be an inherent human characteristic that at a certain moment manifests itself. The lack of clarity - mental clarity, of course - that leads to inadequate, dangerous, and a priori wrong actions is perhaps most vividly illustrated through the emergence of the characters' doppelgängers that "The Fall of 
the House of Usher," "William Wilson," "The Tell-Tale Heart," and "The Black Cat" so distinctly display. How do Poe's investigations of the human mind become central to the questions of human corruption? I contend that it is through the exploration of Christian goodness (that in Poe's stories is virtually indexed as a non-existent quality) and human sinfulness that Poe reaches the climax in de-crusting the concept of madness, ultimately revealing it as an almost primitive and expected part of one's true self. This true self, according to Poe, is never unified, but rather it exists in collision of good and evil, yet, significantly, with a considerable prevalence of the latter. The disturbance that emerges due to the inner confrontation ultimately results in the mental instability that reveals itself in one's duplicated ego.

How does Poe tackle the problem of mental derangement and its symptoms in his fiction? Poe's stories present a so-called "motiveless crime," making the reader explore "the mystery of motive" and "not who did it and why" (Benfey 29). This mystery, however, frequently remains a mystery to the reader (excluding, of course, the generalized explanations based on the character's insanity only). The crux of the matter, according to Agnieszka Soltysik Monnet, is that Poe's narrators are always unreliable; yet they are unreliable in a very distinguished way: "they often have no conscience" (38). Deprived of conscience, i.e., "the sense or consciousness of the moral goodness or blameworthiness of one's own conduct, intentions, or character together with a feeling of obligation to do right or be good" (The Merriam-Webster Dictionary n.p.), the characters, in principle, cannot control their actions, for they are not aware of certain norms - the norms that help the reader distinguish a bad person from a good one, or, alternatively, a mentally sick character from a healthy one. Poe, however, blurs the boundary between sanity and insanity (in the minds of both his protagonists and his readers) not to intensify the mental weakness of certain characters, but rather to demonstrate the tight connection between sinning and madness. To illustrate 
this idea, let us consider the mad protagonists from the four stories.

The narrator of "The Fall of the House of Usher" arrives in the house of his old friend Roderick Usher. Roderick and his sister Madeline, as the narrator has found out earlier from a letter, are ill. For example, Roderick's state is described as follows: "He suffered much from a morbid acuteness of the senses; the most insipid food was alone endurable; he could wear only garment of certain texture; the odours of all flowers were oppressive; his eyes were tortured by even a faint light; and there were but peculiar sounds, and these from stringed instruments, which did not inspire him with horror" (235). The narrator stays with Roderick, realizing how dreadful his condition is. He looks through the paintings in the house and listens to Roderick sing "The Haunted Palace." Soon, Roderick tells the narrator that Madeline has died of "the severe and long-continued illness" (235), and the two men bury the body of the young woman. As a storm starts, the narrator reads out "Mad Trist" to distract Roderick from the uncalm weather. They then hear some sounds inside the house. Realizing that these are made by his sister, Roderick confesses that Madeline was alive when they buried her. The young woman soon appears, and as she has come towards her brother, they both fall dead. The narrator immediately leaves the house that a moment later splits in two right at the crack that was only slightly visible to the narrator upon his arrival.

In the story, Poe explores the issue of mental and physical health through the character of Roderick. Thus, Roderick is described not only as a "hypochondriac" (240) but also as a madman:

There were times, indeed, when I thought his unceasingly agitated mind was laboring with some oppressive secret, to divulge which he struggled for the necessary courage. At times, again, I was obliged to resolve all into the mere inexplicable vagaries of madness, for I beheld him gazing upon vacancy for long hours, in an attitude of the profoundest attention, as if listening to some imaginary sound. It was no 
wonder that his condition terrified - that it infected me. I felt creeping upon me, by slow yet certain degrees, the wild influences of his own fantastic yet impressive superstitions. (241)

It seems thus that Roderick's poor psychological condition worsens as he continues to keep secret the fact that Madeline might still be alive, thus slowly murdering herself. Toward the end of the story, he confesses that "We have put her living in the tomb!" and reveals to the narrator that he has, indeed, kept hearing "the rendering of her coffin, and the grating of the iron hinges of her prison, and her struggles within the coppered archway of the vault" (245, italics in original).

It is interesting that the narrator, having participated in that vile sin of murdering the woman (although, indeed, being fully unaware of that), starts to feel the effects of madness on himself, too. Specifically, "late in the night of the seventh or eighth day after the placing of the lady Madeline within the donjon," the narrator felt "the full power of such feelings," i.e., "the nervousness which had dominion over me" (241). Thus, when Madeline is most probably already dead, the narrator, who now appears to be an accomplice in committing the sin of murdering another human being, turns mentally ill, as well. Indeed, Roderick's exclaiming "Madman!" (245) twice at the end of the story is ambiguous in this context and might refer to both Roderick and the narrator, who are murderers.

"William Wilson" focuses on a young man William Wilson. William once meets another man who resembles himself, has the same name, and was even born on the same day. William's new acquaintance starts to communicate with him - always in whisper - and soon William realizes that the man's face has become exactly like his. He immediately leaves the school. Some time later, William enrolls in another school where he "so immediately and so recklessly plunged" in "the vortex of thoughtless folly" (634). His "miserable profligacy - a profligacy which set at 
defiance the laws, while it eluded the vigilance of the institution" resulted in the "rooted habits of vice" (634). Once at a party, where "[t]he wine flowed freely" (634), William - who describes his condition as follows: "[m]adly flushed with cards and intoxication, I was in the act of insisting upon a toast of more than wonted profanity" (634) - having become by that moment a great gambler, cheats a man at cards. Instantly, the man who resembles William so much appears again. Towards the end of the story, the reader finds William at a carnival in Rome, where he, having "indulged more freely than usual in the excesses of the wine-table" (640), decides to seduce "the young, the gay, the beautiful wife of the aged and doting Di Broglio" (640). The other William Wilson appears again, and, enraged William stabs him. As he has done so, William realizes that he has stabbed himself.

Here, again, Poe correlates madness with committing sins. While alcoholism seems the key sin that the author explores, he also discusses gambling, stealing, seduction, and adultery (which, indeed, are all the outcomes of heavy alcohol consumption). It is at the moment of sinning that the protagonist experiences a fit of madness during which he sees his duplicate. This symbolically turns madness into a special force that helps differentiate good actions from evil ones. Yet the character's aggressiveness (which results from acute psychopathy) stands for his unwillingness to acknowledge his actions as bad and accept the good side. Madness, like a defense mechanism, keeps him on the side of evil, conserving his sinfulness and thus sustaining his depravity.

"The Tell-Tale Heart" narrates the story of the man who murders the old man whom he shares an apartment with. The protagonist dismembers the corpse and hides it in the room. When the police arrives to interrogate the protagonist - for the neighbors heard screams during the night - he lets the policemen sit exactly on the place where the body is hidden. The protagonist manages to mislead the officers until the moment he starts to hear a heartbeat sound. As the sound grows louder, the narrator confesses of the murder and shows the disfigured corpse. 
Poe's character is overtly mad. Yet the man refuses to acknowledge that, believing that madness is not a disease but rather a gift. $\mathrm{He}$ reckons: "True! - nervous - very, very dreadfully nervous I had been and am; but why will you say that I am mad? The disease had sharpened my senses - not destroyed - not dulled them. Above all was the sense of hearing acute. I heard all things in the heaven and in the earth. I heard many things in hell" (303, italics in original). And while the protagonist reveals certain affection to the old man in the beginning, he ultimately murders him, which, one might speculate, is a manifestation of a bipolar disorder. The murder itself arguably happens in a fit of madness. Madness thus helps the protagonist showcase his evil self; it gives him certain "superpowers," like, for example, a better hearing, but, most importantly, it teaches him how to use those powers and what to do. The murder, which is, indeed, the vilest sin, is thus a manifestation of the character's dark side that is reinforced by his mental disorder.

The main character in "The Black Cat" is the narrator who is obsessed with animals and alcohol. His cat Pluto remains his best friend until the moment the man, who has started to suffer from severe alcoholism, once cuts out the cat's eye. Although the cat tries to avoid his master, the man eventually hangs the cat on a tree, thus killing the animal. As the house of the man is burnt in fire next day, he sees the image of the hung cat on the wall of the house - the only part that remained to stay after the fire. The narrator eventually starts to miss the cat but once finds a similar one (surprisingly, it has also only one eye; the only difference is the white patch that the new cat has on its chest). When the cat's patch reminds the narrator of a gallows (thus resurrecting the murder of Pluto), the narrator attempts to kill the animal with an axe, but murders his wife instead. According to the narrator, the temporary-disappeared cat helps the police discover the corpse of the woman that the man has hidden in the wall: having been bricked up together with the woman, the cat starts to produce sounds, making everyone aware of the morbid secret that the narrator keeps. 
In this story, Poe skillfully combines alcoholism with madness, showing the co-dependency of one on the other. The author posits that alcoholism helps the protagonist uncover his true feelings about those whom he claimed to love in the beginning. As a result, he admits that for a few years "my general temperament and character - through the instrumentality of the Fiend Intemperance had (I blush to confess it) experienced a radical alteration for the worse" (224), informing the reader about his deteriorating health. Therefore, the "ill temper" (224) that results from alcohol consumption is viewed as a symptom of a disease. Yet, while the narrator calls that illness alcoholism, claiming "my disease grew upon me - for what disease is like Alcohol!" (224), the reader evaluates the state of the protagonist in more profound terms, and, based on the committed actions, concludes that the narrator is mad. While alcoholism and madness are generally disconnected illnesses (they might overlap in certain cases but it is not always so), Poe's story seems to suggest that human misconduct and sinning should be considered madness proper.

The four stories thus underscore the intricate yet apparent-inPoe's-oeuvre connection between sinning and madness. For Poe, committing sins is an integral part of human life. It comes from the dualism of the human nature that is divided into a good side and a bad one. While he pessimistically believes in the ultimate victory of the latter, Poe foregrounds an inevitable struggle between the two. This struggle is intensified and made sharply illustrative through the employment of madness, which allows the protagonists to communicate with their duplicates, better known as doppelgängers.

\section{Doppelgängers: Mental Dualism of Poe's Protagonists}

The connection between sinning and madness is crucial in the concept of doppelgänger, as represented in Poe's short stories. The 
doppelgängers whom Poe introduces to his readers are the characters who seem to balance the relationship between sin and virtue or, to speak in more general terms, between good and evil. They emerge at the moments (or shortly after them), when the protagonist, in a fit of madness, commits some of the worst acts and thus needs guidance not to be fully lost in the world of sin. This guidance is provided by the doppelgänger.

Scholars have attempted to define the notion of doppelgänger, deconstructing its multiple representations in literature and film. Andrew J. Webber, for example, looks at the doppelgänger from multiple perspectives, arguing that it is "a figure of visual compulsion"; "[i]t echoes, reiterates, distorts, parodies, dictates, impedes and dumbfounds the subjective faculty of free speech"; it is "an inveterate performer of identity ... to represent the performative character of the subject"; it "subjects its host to an ambivalent sexual agency"; there is a strong idea of "power-play between ego and alter ego" informed through "[k]nowledge and sexuality"; it "operates as a figure of displacement" being "temporally out of place, appearing at the wrong time"; it "returns compulsively both within its host texts and intertextually from one another"; it "axiomatically gendered as male"; it is "typically the product of a broken home. It represents dysfunction in the family romance of structured well-being, exposing the home as the original site of the 'unheimlich"' (3-5). While all these characteristics are crucial to one's understanding of the doppelgänger, I would like to accentuate the function of the doppelgänger to be "a figure of displacement," i.e., to emerge at specific times. In Poe's stories, these are the moments when the characters commit sins or shortly after them, which arguably stands for the birth of conscience within the characters' sinful nature.

In "The Fall of the House of Usher," Madeline is a doppelgänger of Roderick. Scholars have extensively commented on the complex relationship between Roderick, Madeline, and the House of Usher in the story. It is, indeed, first of all, the House that needs a detailed examination, for it arguably causes Roderick's madness and 
influences his further actions. E. Arthur Robinson shrewdly observes that "Usher alone is responsible for perception of the bond between his mansion and his incipient madness" ("Order and Sentience” 72). Pivotally, the House as is does not exercise any power over Roderick; yet Roderick believes that it is the House that is to be blamed for his illness. The narrator clarifies:

He [Roderick] was enchained by certain superstitious impressions in regard to the dwelling which he tenanted, and whence, for many years, he had never ventured forth - in regard to an influence whose supposititious force was conveyed in terms too shadowy here to be re-stated - an influence which some peculiarities in the mere form and substance of his family mansion had, by dint of long sufferance, he said, obtained over his spirit - an effect which the physique of the gray walls and turrets, and of the dim tarn into which they all looked down, had, at length, brought about upon the morale of his existence. (235, italics in original)

Nonetheless, shifting the blame for Roderick's mental disorder onto the House might be somewhat misleading, for while one might assume that the gloomy atmosphere in a large mansion as well as the house's rather isolated location might have, indeed, influenced the psychological state of its inhabitant, it would be more accurate to consider the House a metaphorical representation of Roderick himself. In this regard, Louise J. Kaplan contends: "Usher's person and fate are intertwined with the decaying foliage and crumbling ornate architectural scrollwork of his House. We are repeatedly reminded of the sentience of nonliving matter and the decay of living matter back into nonbeing" (48). James Goho makes a similar observation: "The house is the family - is the personality of Roderick Usher - is the world of the living dying. At the end of the story, the Ushers all die, the house cracks apart and falls into its mirror image in the tarn - it is the end of life - the house is like a human body in its decay" (28). And while Kaplan's and Goho's speculations concerning the symbolism in Poe's story seem plausible, I refute the idea that the house repre- 
sents the physical and claim that it is the mental the Poe explores through the intricate relationship between the House and Roderick. When the narrator arrives at the House, he notices slight yet visible changes in the House: "Perhaps the eye of a scrutinizing observer might have discovered a barely perceptible fissure, which, extending from the roof of the building in front, made its way down the wall in a zigzag direction, until it became lost in the sullen waters of the tarn" (233). Through these details, Poe figuratively reveals the irrevocable changes in Roderick himself. It is particularly important that the crack starts at the roof and goes down, threatening to destroy the whole House. When considering the House a symbolic reflection of Roderick, one might assume that the roof is Roderick's head that started to dysfunction in a certain way, infecting him throughout, consequently turning him into a madman.

In fit of madness, Roderick murders his sister Madeline, burying her alive. Yet, she returns to remind her brother of what he has done to her. Robinson accentuates the fact that Roderick and Madeline are twins and foregrounds the special connection that exists between the two people. The scholar adds that, in principle, the two are "[in]complete being[s]," for Roderick personifies "the intellectual aspect," whereas Madeline "the physical" ("Order and Sentience" 75). Thus, the split of one into two is apparent. Robinson continues: "On a completely symbolic level, Usher becomes the only actual character in the story, with house, narrator and Madeline all objectifying elements or clashes within his personality" (75). Moreover, considering Madeline Roderick's doppelgänger literally puts her very existence into question. Madeline could have been only a mental projection - Roderick's conscience - that comes to prevent him from sinning or punished for the sins he has already committed. The murder of Madeline thus can be interpreted as Roderick's suicide: he buries himself in the House alive, which is figuratively represented through the burial of Madeline; then he suffers for a long time and when he hears Madeline's screams he, in truth, hears his own screaming; and lastly, only 
when Madeline appears - Roderick's realization of what he did does he finally die.

This motive is similarly echoed in "William Wilson" - the story that perhaps most legibly discusses the concept of doppelgänger. The duplicate of William Wilson, whom he encounters on several occasions, appears to be William's second self. Like in all the other analyzed here stories, the doppelgänger is the good side of the protagonist - his conscience - that comes either to prevent the character's sinning or to punish him for the committed sin. William describes himself as follows: "I grew self-willed, addicted to the wildest caprices, and a prey to the most ungovernable passions" (626-27). He leads a dissipated life, which includes drinking alcohol, gambling, cheating, and seducing women. Significantly, the doppelgänger emerges only during such episodes. The characteristic "very low whisper" (631, italics in original) that the doppelgänger talks in supports the idea that it is William's conscience appealing to him - his inner voice that is audible to himself only. The fact that William's "first mental development had in it much of the uncommon - even much of the outré" (629, italics in original), only reinforces the doubts in the doppelgänger to be a real person or perhaps even proves that the man who reminds William himself so much is nothing more than a vision that is stimulated by his disordered mind.

The "rivalry" (630) that distinguishes the relationship between William and his doppelgänger reveals the differences in their views and beliefs; yet the facts that William "could not bring myself to hate him altogether" (630) as well as that "his [the doppelgänger's] singular whisper, it grew the very echo of my own" (632, italics in original) prove that the two are parts of one whole. The murder that William executes, desiring to get rid of the officious character, is, accordingly, suicide - the only means by which the voice of the doppelgänger mutes. In the murder-scene, Poe uses a mirror only to intensify the idea of mental dualism that is so characteristic of William Wilson. Discussing the use of such a technique in film, Caroline Ruddell argues that the mirror serves as "a formal de- 
vice to denote fragmentary identity" (13). The scholar continues: "The use of the mirror reflection emphasises the fact that the character's identity is being split into two" (13). Having stabbed the doppelgänger, Williams sees "[a] large mirror" appearing, where "mine own image, but with features all pale and dabbled in blood, advanced to meet me with a feeble and tottering gait" is reflected (641). In that reflection, William recognizes his "antagonist" who "stood before me in the agonies of his dissolution" (641). The doppelgänger's ultimate speaking "no longer in a whisper" that William, it seems, confuses for his own speaking (641) displays an integration of the two - William and his doppelgänger, his sinful and virtuous selves. The attempt to murder the doppelgänger the virtue - results in the death of the protagonist.

The appeal to the protagonist's conscience in "The Tell-Tale Heart" is audible when, after having murdered the old man whom he shared an apartment with, the narrator starts to hear a heartbeat. Since the narrator is absolutely deprived of any "sense of guilt," which is overt in the scene, when the policemen interrogate the man, the heartbeat can virtually be the narrator's "own heart beating out of guilt" (Shen 335). In this respect, Robinson diagnoses the narrator as a mentally unstable person on the basis that the murderer "mistak[es] his own heartbeat for that of his victim, both before and after the murder" ("Poe's 'The Tell-Tale Heart" 374). Just like in the short stories that were discussed previously in this chapter, the narrator is, indeed, mad; moreover, his mental disorder leads to the split of his identity and the emergence of a doppelgänger, who is portrayed through the old man. The narrator confesses that he "loved the old man," yet the desire to murder him appears when the narrator starts to feel uncomfortable seeing the old man's eye that "resembled that of a vulture," and, hence, "I made up my mind to take the life of the old man, and thus rid myself of the eye forever" (303). Poe employs here a similar technique he used in William Wilson: while in the previous story it is the distinct whisper that provokes psychological discomfort in the character, here it is the eye, i.e., while the second self of 
William Wilson could have told someone about his sins, in "The Tell-Tale Heart" the doppelgänger could have seen those deeds. In both cases, it is the desire to get rid of witnesses that possess the characters and determines their actions. Underlining "the murderer's psychological identification with the man he kills," Robinson draws attention to the fact that is only "one eye that is mentioned, never two" ("Poe's 'The Tell-Tale Heart” 374), which, indeed, helps construct the image of a split identity, when one eye belongs to the old man, whereas the other one to the narrator. Concurring with Douglas Anderson that the old man's eye is symbolically "accumulations of wisdom" and thus "turned figuratively inward by the film of age and experience" (156), I argue that the narrator's will to kill the man stands for his strong fear of the appeal of conscience that he might hear. Yet, the murder of his doppelgänger figuratively murders the protagonist, too, for the guilt he feels drives him mad and makes him confess the murder. The "hideous heart" (306) that he refers to, although meant to be the heart of the old man, is, in fact, his own, which symbolizes the triumph of evil over good; yet evil that the madman embodies will ultimately become isolated from society, for the confession will bring the narrator either into a prison or, most probably, into a mental asylum.

Finally, a similar storyline is plaited into "The Black Cat." The murder of the cat that the narrator commits being drunk can be viewed as both a sin and a mad act. The narrator describes his action as follows: "Who has not, a hundred times, found himself committing a vile or a stupid action, for no other reason than because he knows he should not?" (225, italics in original) Here, Poe, of course, succinctly comments on human depravity in general, but he also underscores the corrupt nature of the protagonist. The narrator provides a detailed explanation of why he murdered the cat:

One morning, in cold blood, I slipped a noose about its neck and hung it to the limb of a tree; - hung it with the tears streaming from my eyes, and with the bitterest remorse at 
my heart; - hung it because I knew that it had loved me, and because I felt it had given me no reason of offence; - hung it because I knew that in so doing I was committing a sin a deadly sin that would so jeopardize my immortal soul as to place it - if such a thing were possible - even beyond the reach of the infinite mercy of the Most Merciful and Most Terrible God. (225, italics in original)

The passage is crucial in many ways. First, it reveals the inner fight that exists within the narrator between his evil and good selves and his taking the side of the dark self. Considering the cat the character's doppelgänger, one can speculate that Poe's protagonist again endeavors to get rid of the virtue and be a part of the world of sin. Second, it underscores human corruption, claiming that the moral is dead, that human souls are rotten because it is in the human nature to choose the tempting dark side. Finally, it attempts to question the virtue of God, suggesting that even He embodies the conflicting selves - one of which is mercy and the other terror.

Significantly, the cat starts to annoy the protagonist when the latter becomes addicted to alcohol. The animal is thus the voice of conscience that reminds the man of his sinning. And while Robert Shulman contends that "fear, hatred, and guilt that animate the narrator's terrified obsession with a common-place animal ... are among the causes of the narrator's alcoholism" (256), I refute this viewpoint and claim that it is exactly the opposite, namely that the narrator was in complete harmony with his inner self (metaphorically represented through the love to Pluto) until the moment he started to drink. Hence, it is not "the madness [that] caused the drinking," as Shulman suggests (256), but, on the contrary, alcoholism turns the narrator into a madman, stimulating the split of his identity and generating hatred towards virtue.

The ghost of the character's second self, his doppelgänger - the cat - continues to haunt the narrator later on, as he confesses: "For months I could not rid myself of the phantasm of the cat" (226). The fact that both cats have only one eye - Pluto because the narrators violently cuts it out, and the second cat naturally 
being one-eyed - corroborates the idea that they are the narrator's doppelgängers, his second selves. While Pluto, however, is the character's good self, the second cat is his dark self that seems to have taken full reign over the narrator's mind. It is also important that after having murdered his good self, the narrator is not only unwilling to accept his dark self, feeling "aversion" to it, but he is literally afraid of it: "At such times, although I longed to destroy it [the cat] with a blow, I was yet withheld from so doing, partly by a memory of my former crime [the murder of Pluto], but chiefly let me confess it at once by absolute $d r e a d$ of the beast" (227, italics in original).

The protagonist attempts to get rid of his doppelgänger for the second time, yet that leads to his merciless killing of his wife. He bricks up the woman in the wall of their house, and when the police arrive, just like the protagonist from "The Tell-Tale Heart," he is sure that he will be able to keep the kill secret. But he, too, is betrayed by his own conscience, for he hears "the voice from within a tomb," "a cry," "one loud, loud, and continuous scream, utterly anomalous and inhuman - a howl - a wailing shriek, half of horror and half of triumph, such as might have arisen only out of hell, conjointly from the throats of the damned in their agony and of the demons that exult in the damnation" (230). The feeling of guilt makes him confess. John Cleman makes a curious contention: "It is killing the cat that torments the narrator's conscience, that makes him believe he is beyond God's mercy. By contrast, when he kills his wife he shows almost no signs of remorse" (636). It is, indeed, so, for the narrator starts to experience psychological tortures when he murders Pluto and continues to suffer from this psychological discomfort only in the episodes connected to either of the cats, i.e., to his doppelgängers, his second selves. For the murder of his wife, he blames his dark self - the cat that he sees on top of his wife's corpse: "Upon its [the corpse's] head, with red extended mouth and solitary eye of fire, sat the hideous beast whose craft had seduced me into murder, and whose informing voice had consigned me to the hangman" (230). 
"The Fall of the House of Usher," "William Wilson," "The TellTale Heart," and "The Black Cat" thus largely reflect on the problem of mental disorder, yet the stories do that through the prism of mental dualism, discussing the split of identity that results in the emergence of doppelgängers. While madness is the arch-theme of Poe's stories, it is the idea of human depravity and sinning that interests this dark romantic the most, making him investigate the darkness and the light within the human soul and mind.

\section{Conclusion}

Poe's visits of the human mind that are vividly reflected in his oeuvre are both fascinating and unique. Like no other literary author, he investigates the nature of the human psyche in an attempt to define and describe madness. As the four stories examined in this chapter demonstrate, Poe skillfully correlates the issue of mental disorder with the problem of human depravity. Being confident that human nature is corrupted, one of the most famous representatives of Dark Romanticism explores the darkness of the human soul that apparently comes from the darkness of the mind. Poe analyzes human identity not as a unified but rather as an always divided state. The split of one's ego into good and bad selves that in Poe's works vividly illustrated through the characters and their doppelgängers is not only inevitable but also crucial in the formation of one's true self. Being malicious sinners, Poe's protagonists encounter their doppelgängers in the fit of madness. Unable to overcome the guilt that the doppelgängers either symbolize or remind them of, the protagonists die - either literally or symbolically - only to intensify the pessimism and despair that, according to Poe's works, the author feels toward humanity as a whole. 


\section{Works Cited}

Anderson, Douglas. Pictures of Ascent in the Fiction of Edgar Allan Poe. New York: Palgrave Macmillan, 2009.

Benfey, Christopher. "Poe and the Unreadable: 'The Black Cat' and 'The Tell-Tale Heart." In New Essays on Poe's Major Tales, edited by Kenneth Silverman, 27-44. Cambridge: Cambridge University Press, 1993.

Cleman, John. "Irresistible Impulses: Edgar Allan Poe and the Insanity Defense." American Literature 63, no. 4 (1991): 623-640. doi:10.2307/2926871.

"Conscience." In The Merriam-Webster Dictionary. Accessed October 3, 2017. https://www.merriam-webster.com/dictionary/conscience.

Fisher, Benjamin F. The Cambridge Introduction to Edgar Allan Poe. Cambridge, MA: Cambridge University Press, 2008.

Goho, James. "Poe's 'The Fall of the House of Usher': A Predecessor to Lovecraft's 'The Outsider'?” In Journeys into Darkness: Critical Essays on Gothic Horror, 21-33. Lanham: Rowman \& Littlefield, 2014.

Kaplan, Louise J. "The Perverse Strategy in 'The Fall of the House of Usher." In New Essays on Poe's Major Tales, edited by Kenneth Silverman, 45-64. Cambridge: Cambridge University Press, 1993.

Monnet, Agnieszka Soltysik. The Poetics and Politics of the American Gothic: Gender and Slavery in Nineteenth-Century American Literature. Farnham: Ashgate, 2010.

Poe, Edgar Allan. “The Black Cat." In The Complete Tales and Poems of Edgar Allan Poe, 223-30. New York: Vintage Books, 1975.

-. "The Fall of the House of Usher." In The Complete Tales and Poems of Edgar Allan Poe, 231-45. New York: Vintage Books, 1975.

-. "The Tell-Tale Heart." In The Complete Tales and Poems of Edgar Allan Poe, 303-06. New York: Vintage Books, 1975.

-. "William Wilson." In The Complete Tales and Poems of Edgar Allan Poe, 626-41. New York: Vintage Books, 1975.

Robinson, E. Arthur. "Order and Sentience in 'The Fall of the House of Usher."' PMLA 76, no. 1 (1961): 68-81. doi: 10.2307/460316. 
-. "Poe's 'The Tell-Tale Heart." Nineteenth-Century Fiction 19, no. 4 (1965) 36978. doi: $10.2307 / 2932876$.

Ruddell, Caroline. The Besieged Ego: Doppelgangers and Split Identity Onscreen. Edinburgh: Edinburgh University Press, 2013.

Shen, Dan. "Edgar Allan Poe's Aesthetic Theory, the Insanity Debate, and the Ethically Oriented Dynamics of 'The Tell-Tale Heart.'” Nineteenth-Century Literature 63, no. 3 (2008): 321-45. doi: 10.1525/ncl.2008.63.3.321.

Shulman, Robert. "Poe and the Powers of the Mind." ELH 37, no. 2 (1970): 245-62. http://www.jstor.org/stable/2872400.

Webber, Andrew J. The Doppelgänger: Double Visions in German Literature. Oxford: Clarendon Press, 1996. 


\title{
5 All Things in Heaven and Earth: The Ethics of Vision in "The Tell-Tale Heart"
}

\author{
PHILLIP GRAYSON
}

After all is said and done, after the senseless murder, the mutilation of the body, after the remorselessness of the killer, Edgar Allan Poe leaves us with a sort of daunting optimism. Likely his most famous piece of prose, "The Tell-Tale Heart" provides us with madness, murder, and betrayal, and it builds out of these grisly materials a kind of ethical foundation for the importance of fictions and of the fictional beings that populate them. After the old man is killed and the narrator locked away, after the hallucinatory horrors of the story's world, we are left with something close to a happy ending. After all is said and done, we are left, afterall, with a story. A story that asks us what our ethical obligations to fictional beings are, asks how these are established, and why they matter. It is a story that provides with a happy ending that also bears with it (as if the cost was almost too high) a tremendous, maybe overwhelming responsibility. It is a story that establishes the ethical demands of the non-human, particularly the fictional, other. That exposes the durability of these beings and our relationships with them, and expresses a sort of spectral afterlife (a heaven or hell) made accessible, or conversely, perhaps, unavoidable, through the cultivation of these relationships.

"The Tell-Tale Heart" tells the story of a seemingly inexplicable murder, and the gnawing guilt it brings on through the imagination of the narrator. The murder is, according to the narrator, mo- 
tivated by the victim's eye, "the eye of a vulture -a pale blue eye, with a film over it." (792). This eye is presented as non-human, and the sole reason for the killer's actions. He or she tells us: "I loved the old man. He had never wronged me. He had never given me insult. For his gold I had no desire" (792). The only motive is the eye, "eye, his Evil Eye" (793). Meanwhile, the killer claims to experience sensations that exist outside the real world, in heaven and hell. "I heard all things in the heaven and in the earth. I heard many things in hell," she says (792). Despite killing and dismembering the old man, the narrator is haunted by the imagined sounds of his heartbeat. This sound begins as a "ringing in [the] ears," (797) then becomes "such a sound as a watch makes when enveloped in cotton," (795) but soon grows "louder - louder - louder!" (795) and then "louder! louder! louder! louder!” (797) until it drives the killer to confess his crime, certain that the sound is "the beating of his hideous heart!" (797). This imagined heartbeat unravels Poe's narrator, and while it is clearly a manifestation of guilt, the specificity of the metaphor allows it to function as so much more than that.

The persistence of the imagined old man, the model of him held in the killer's mind - not the memory of him, or any abstract idea of him, but rather a beating, physical, existence that carries on in the imagination of the narrator-leads to the killer's arrest. There must be, then, something, some existence beyond the bodily that the old man possessed and continued to possess after his corporeal death; a fictional version of him that goes on living, complete with hallucinatory beating heart. This fictional old man, embodied in the dead eye that cannot project its vision outward, but instead only receive beams of light and imagination projected into it, nonetheless asks not to be killed, and proves, ultimately, to not be killable, at least not completely. 


\section{Fictional Beings}

\section{The Unimagined Life}

"The Tell-Tale Heart" accomplishes its ethical work by manipulating our understanding of fictionality itself, and by accentuating its role in our own moral calculus. To begin, the story presents us with three levels of fictiveness. The first is the Fictional Real: all the characters in the story fit within this realm, including the killer, the old man, and the detectives. Second, we have the Fictional Unreal: this is the imagined old man, both before and after the death of his Fictional Real body. And finally, a realm that we will recklessly call the Really Real: the realm of the man named Edgar Allan Poe who imagined and wrote the story, as well as his readers. In explicitly separating these different realms of existence or levels of reality, the story forces its audience to consider the place these different degrees of reality have in their own lives, and in particular, the moral demands such fictional being can make on us.

Most importantly, the relationship between the Fictional Real and the Fictional Unreal quite closely mirrors the relationship between the Really Real world we live in and the fictional worlds created by Poe and all other authors. The relationship between the Fictional Real murderer and the Fictional Unreal specter of the old man runs roughly parallel to our own relationship to each and all of these fictional beings. To begin, then, we have to consider this relationship.

Ghosts Helpless and Not The reality of fictional beings, or more precisely, perhaps, the nature of their existence has been a perennial concern for writers, readers, and philosophers alike, from Plato's discussions of poetry in the Ion, the Republic, the Gorgias, and the Phaedrus and Aristotle's seminal Poetics. More recently and more directly related to the reality of fictional beings, 
the topic was carried forward by Bertrand Russell, in his Introduction to Mathematical Philosophy. ${ }^{1}$ Here, Russell's key point is that the "real" world must be carefully distinguished from the "unreal." According to Russell, logic "must no more admit a unicorn than zoology can; for logic is concerned with the real world just as truly as zoology," (169). And yet, as we know, zoology could easily admit a unicorn if one happened to occur. It certainly does admit new species on a daily basis. The reason Russell feels he must so staunchly guard against it is because logic's own claims to the "real world" are much less clearly defined than those of, say, zoology.

The strange, outsized importance of physicality for Russell is most clear when he posits that "to maintain that Hamlet, for example, exists in his own world, namely, in the world of Shakespeare's imagination, just as truly as (say) Napoleon existed in the ordinary world, is to say something deliberately confusing, or else confused to a degree which is scarcely credible" (169). This is so because, as Russell points out, "if no one had thought about Napoleon, he would have soon seen to it that some one [sic] did" (170).

This is troublesome from the beginning. Not only could Napoleon do nothing now to prove that he had lived if anyone for any reason happened to think he had not, and not only have endless numbers of "real" people lived and died that we know nothing about now, but most importantly, it discounts the fact that, mentioned by Russell just moments earlier, that "Shakespeare's imagination is part of [the real world], and the thoughts that he had in writing Hamlet are real. So are the thoughts that we have in reading the play" (169). It is this kind of non-corporeal existence, in fact, that prolongs the importance, the reality, of Napoleon himself. And just as Russell insists that Napoleon achieved or secured his own reality by seeing to it that people thought of him, so too does

${ }^{1}$ Russell, Bertrand. Introduction to Mathematical Philosophy. 2nd Edition. Macmillan. New York. 1920. Print. 
Hamlet, so too do the other fictional beings that persist in the world.

For Russell, the ephemerality of fictional beings trivializes them. They are ineffectual; helpless ghosts. And yet as Edgar Allan Poe knows all too well, ghosts are not always so helpless, not always so trivial at all.

At Best Shadowy and Vague These specters, these ghostly, fictional beings, so often do insist on their reality. They must insist, because, as Russell suggests, the airiness of their immateriality means that we need to define the existence of fictional beings more rigorously. In his Inquiry into Modes of Existence, Bruno Latour notes that fictional beings are forced as such to impose themselves on us. While physical bodies provide a constant reassurance of their own existence, have constant recourse to making sure that they are known, the reality experienced by fictional beings is both precarious and, as a result, demandingly rigorous.

Latour points out that beings of fiction are not based on falsity or illusion, but rather on "what is fabricated, consistent, real." They must maintain the audience that provides their consciousness, projecting it into them. They require eyes to see them, because they are not present in the world waiting to be perceived. Rather, they emerge directly from these emitting eyes, a quality that Poe demonstrates an unnerving awareness of throughout "The Tell-Tale Heart."

These fictional beings are not merely imaginary, because, "without any doubt," Latour tells us, "there is some exteriority among the beings of fiction; they impose themselves on us after imposing themselves on those responsible for their instauration." ${ }^{3}$ Those responsible, of course, are the author, but not only the author. There is also the vast network of entities must interact in order to

${ }^{2}$ Latour, Bruno. An Inquiry into Modes of Existence: An Anthropology of the Moderns. Print. 238

${ }^{3}$ Ibid. 240 
create a text in the first place, and to function as what we consider the author or creator of a text (fiction, poetry, film, etc.). If we attempt to deny the power of the fictional being, as we will see in our examination of "The Tell-Tale Heart," comes with tremendous risk.

Latour emphasizes the exteriority of fictional beings in order to defend them from the ephemeral status of signs and symbols, loaded with meaning but deprived of ontological weight. He points out that "if listeners are gripped by a piece, it is not at all because they are projecting their own pathetic subjectivity on it"; rather, he claims, "it is because the work demands that they," as audience members, "become part of its journey of instauration." He goes on to claim, moreover, that "imagination is never the source, but rather the receptacle of beings of fiction" [emphasis in original]. "One becomes imaginative," he claims, "when one is gathered in by works of fiction." 4 This insistence on the exteriority of fictional beings is familiar from Russell, but in affirming rather than denying fictional beings access to such exteriority and the more concrete reality it promises, Latour is better able to account for the vast, vast importance such beings have in our lives and world.

\section{A Hideous Veil}

"The Tell-Tale Heart" presents us with two indelible images that define its own and its characters' relationships to fictional beings, and in doing so, reveals the way such fictional beings infiltrate our lives, make themselves real, and demand that we engage them as such. They do this with their eyes.

The counterfactual belief that vision moves outward from the eyes is known as extramission, and it is the key to understanding the deep, intuitive link between vision and consciousness.

\footnotetext{
${ }^{4}$ Ibid. 275
} 
The scientifically inaccurate but stridently durable belief in extramission reveals genuine and oft-overlooked properties of consciousnesses. By its strictest definition, extramission is the theory that vision is accomplished through the emission of some substance or force from the eye. A smooth, gentle fire emerges from the eyes and apprehends the world. As a scientific belief, we can trace extramission back at least to Plato. ${ }^{5}$

Galen of Pergamon, ${ }^{6}$ perhaps the most renowned and influential medical researcher of antiquity, believed that he had found, in the optic nerve, the channel through which the substance of extramission made its way from the rear of the brain, where it was manufactured, to the eyes, from whence it was sent out into the world. Despite having long since been scientifically disproven, even now, a third of American college students continue to believe that vision is reliant on some sort of emission from the eyes.

Beyond this scientific misunderstanding, extramission exists as an underlying assumption in a wide array of beliefs and instincts. These range from the fanciful prevalence of lasers that can be fired from the eyes to widespread superstitions involving the evil eye; common instinctive beliefs that we can feel someone watching us; and even the ingrained impulse to look into people's eyes as a window to the soul or locus for the revelation of some inner truth that might emerge therefrom. Extramission is, in sum, a remarkably perennial and universal misprision, and despite having no claim to scientific accuracy, it holds a massive place in the intuition.

Extramission's hold on the popular imagination stems from the way it so elegantly encapsulates the way we project consciousnesses, both our own and others', onto the world around us. Neuroscientists have long known and clearly established the fact that we create models of others' attention, and use these models to fab-

${ }^{5}$ Plato. Timaeus; Critias; Cleitophon; Menexenus ; Epistles. Trans by Robert G. Bury. London: W. Heinemann, 1929. Print.

${ }^{6}$ Clark, Stuart. Vanities of the Eye. Oxford: Oxford University Press, 2009. 
ricate a notion of their inner life. ${ }^{7}$ Creating these models is largely, and most immediately, accomplished by tracking the gaze, ${ }^{8}$ and while tracking another's gaze may be most obviously linked to understanding the focus of their attention, this information, in turn, reveals a tremendous amount about the consciousness behind it. ${ }^{9}$ We experience this as a "somewhat ethereal property of awareness" that we attribute to others, "and that, in violation of the physics of optics, emanates from [an individual] toward the object of his awareness." 10 This model operates in violation of our knowledge about vision, but endlessly useful in tracking attention, recognizing the mental states of others, and predicting their future behavior. It is inaccurate, but useful. This is true for our interactions with human beings, who we may assume are conscious in and of themselves, but is also an irresistible habit, a deeply embedded aspect of our own minds, and we cannot help but apply it much more broadly.

Appreciating and understanding the focusing of attention, in turn, is a critical (perhaps the most critical) element in ascribing a consciousness to others, as well as to ourselves. Neurobiologist Michael Graziano writes: "We intuitively understand the dynamics and behavioral consequences of attention, and we perceive it as awareness originating in other agents." ${ }^{11}$ In order to get to the cogito, there must also be an object of thought, and it is this object of awareness that allows us to infer a consciousness directing it. Consciousness springs from precisely focusing attention, defining an existence that picks and chooses, that carves out a reality rather

${ }^{7}$ Baron-Cohen, Simon. Mindblindness: An Essay on Autism and Theory of Mind. Cambridge, MA: MIT, 1995. Print.

${ }^{8}$ Haxby, James V., Elizabeth A. Hoffman, and M.ida Gobbini. "Human Neural Systems for Face Recognition and Social Communication.” Biological Psychiatry 51.1 (2002): 59-67. Print.

9 Nicholas, Cheryl L. "Gaydar: Eye-gaze as Identity Recognition among Gay Men and Lesbians." Sex Cult Sexuality and Culture 8.1 (2004): 60-86. Print.

10 Graziano, Michael S. A.Consciousness and the Social Brain. Oxford UP, 2013. Print. 86

11 Graziano, Michael S. A.Consciousness and the Social Brain. Oxford UP, 2013. Print. 97 
than floating through an undefined void indistinguishable from itself.

We direct our attention toward something. Our vision, in turn, is directed, similarly, toward that object. Finally, we can understand the focus of the attention of others by observing where their vision is directed. This is useful and efficient, and it assumes that vision flows outward from the eyes. It is evidence of, and stands in for, the direction of attention. Attention, in turn, is the most directly tangible evidence of the consciousness of others. In this outward movement we can perceive the roots of extramission. You are, indeed, sending your attention outward toward its object, and doing so via your eyes.

If the link between extramission and attention is fairly easily established and intuitive, and if the role of attention in the construction of consciousness is clear, we can move to the idea that consciousness itself can be projected. This idea is at once simpler and more fraught. Simpler, because clearly consciousness can be projected outside of the mind, otherwise interaction with others and with the world around us would be impossible-it is necessary that some representation of ourselves be sent out into the world to conduct our affairs there. And yet, once we have established that our consciousnesses must be able to leave our body and mind, we have to account for its spectral existence outside them.

In Graziano's neurological definition, attention is the focus on particular stimuli, and consciousness is essentially composed of a schematic representation of this attention, giving rise to awareness. We construct a simplified, roughly accurate map of our brain's perception of stimuli. This map, this Attention-Schema, is consciousness.

This allows us to perform the same operation that perceives an Attention-Schema in ourselves on others. If attention lies at the heart of consciousness, and our schematized awareness of our own attention is what gives rise to our consciousness, then the attention of others implies a consciousness within them, too. We can see 
then that the myth of extramission persists and persists so widely because we associate vision closely with things that are projected: attention, which is directed outward at an object of focus, and consciousness, which we construct for people and things that exist outside of our own bodies. As such, a close examination of extramission and its implications can shed a tremendous amount of light on the way consciousness functions within literature, as a realm for the creation of fictional consciousnesses, and as a site, via these fictional consciousnesses, for a transformative encounter with a compound, plural, and hybrid alterity.

\section{The "Real" Old Man, the Imagined Old Man, the Real Poe, His Narrator}

There is a sharply bifurcated nature to "The Tell-Tale Heart." Its characters bridge different realms of reality and reveal that the ethical demands they make are not contingent upon being "real" in a narrowly defined corporeal, chronological sense. This is evident in the relationship between the old man and the unnamed narrator. The connection between these two characters is never explicitly stated, and very little information is given to even allow the audience to infer what it might be. A convincing case can be made that the narrator is the man's son, or a household servant. Less often suggested, but just as likely, based solely on the text, the narrator could be a wife or lover, or daughter.

We know that the narrator claims to love the old man. To have no hatred of him, and no desire for his money. We know that he or she has access to the old man's room at night, and the physical prowess to murder him in close quarters. Considering that the story is delivered to us in the first-person by the narrator himself, it is striking that these facts are so impersonal, based as much on physical actions as on explicated thoughts or emotions. Despite the implied intimacy of the relationship between them, there is a 
coldness and distance in the way the narrator engages with the old man.

This distance, this coldness, facilitates the murder of the old man, but where does it come from? And what in this cold, distant relationship goes on after death, building in intensity to unbearable levels? What is there in the old man that does not die? That insists on its continuing existence after his body has been murdered and disassembled?

\section{The Heart and the Eye}

The old man is defined by two key features, one before he is killed, the other after. During his life, his key feature is his eye: clouded, white, veiled, hideous. The eye both permits and instigates the murder of the old man. It haunts the narrator and it nullifies the old man's ethical claims on him, even the first, most urgent and elemental plea: To not be killed.

In death, the old man's defining feature becomes his heart. The heart that beats on long after it should have ceased to do so, and beats on with increasing intensity. Moreover, the ethical demands of the heart cannot go unanswered as the eye's do. The heart is not a product of the killer's guilt, but rather, the source of it. It is the heart in its beating that demands a confession, and perhaps much more.

The Eye The eye of the living man is described as specifically not living, and not the eye of a man. The eye fails to communicate the inner reality of the old man. It fails to emit his consciousness, his essential humanity, his full reality. Its failures, its unreality, leaves the man outside the ethical duties of the killer. When the old man is reduced to solely this eye, held in it as it is held in a beam of light, then and only then can he be killed. More than this, though, the eye incites the narrator to violence. Intriguingly, the narrator can only kill the old man when his dead, pale eye 
is visible. We can understand through this that the eye not only fails to convey the old man's reality, but actively does convey an unreality that is more than the narrator can bear.

The eye is hideous, but it is also worse than that. We can understand that the narrator must see the eye and the eye alone in order to commit his murder, but in the solipsism of the narrator's tale, and in our own attention to that man's madness and guilt, a key element of the story threatens to slip past unnoticed: When the single beam of light is thrown from the narrator's lantern onto the old man's eye, the eye remains in the light. This is deeply unnatural. The eye's instinct, when subjected to a light like this, is to move immediately. The iris contracts, the head jerks.

The condition of looking from light into darkness is a vulnerable one, and to remain in a spotlight, unmoving, is, in a word, unrealistic. And yet the old man remains frozen, his eye illuminated, for "some minutes." There is a haunting uncanniness in this reaction. It is not a natural human response.

The old man must come to us in vulnerability. The Lithuanian philosopher Emmanuel Levinas tells us that another person, when encountered, immediately places ethical demands on us specifically because they are vulnerable, human (because their vulnerability defines their humanity, or creates it). "[A]ccess to the face is straightaway ethical," he writes. "The face is exposed, menaced, as if inviting us to an act of violence. At the same time, the face is what forbids us to kill." ${ }^{2}$ We see this beautifully realized in the face of the elderly man. More than his face, it is his eye, in its blind vulnerability, that allows him to be killed.

The killer himself tells us that he cannot kill the old man when his eye is closed or obscured by darkness. "I found the eye always closed; and so it was impossible to do the work; for it was not the old man who vexed me, but his Evil Eye" (793). The "Evil Eye," marks the old man as vulnerable, and yet, it does not forbid the

12 Levinas, Emmanuel, Ethics and Infinity: An Essay on Exteriority. Trans. Alphonso Lingis, Pittsburgh, PA: Duquesne University Press, 1969. 85-86 
narrator to kill, as Levinas would have it. The eye fails to establish the old man's humanity and his ethical demands. This is a failure of extramission. The eye does not project the old man outward into the world, not in a way the narrator can perceive, and it is this failure that drives the narrator mad. He finds in the old man a sort of quasi-humanity, and hybridity or a halfway-ness that he cannot in the end countenance.

The failure of extramission is a failure to establish the reality of the old man. He becomes only a figment of the narrator's imagination. The shining of the lantern's beam onto the old man, indeed, directly onto his eye, establishes that it, that he, is a receiving surface for the projected imaginings of the narrator, and not a living being who demands that he not be killed, "at length a simple dim ray, like the thread of the spider, shot from out the crevice and fell full upon the vulture eye" (794). As an unreal entity, a piece of the projecting mind of the narrator, the old man can be killed with impunity. As he tells us, "I could see nothing else of the old man's face or person," nothing of his humanity (795).

The Heart The narrator is, of course, famously wrong in assuming that the old man could be killed with impunity, though. The reality of the man's existence and his ethical demands reassert themselves through and incessant and imaginary heartbeat. We can understand that the killer does not feel guilty about the real man, whom he never perceived (through a supposed or apparent failure of extramission on the eye's part). His only guilt involves the imaginary sensorium. The death of the fictional being (the failed death) haunts him, drives him mad. The ethical obligation to the fictional being (the imagined old man) is felt in a way the ethical obligation to the real old man (the fictional old man of the story) never is, never materializes because of the failure of the eye.

This is a deeply unsettling gambit for Poe, and has caused "The Tell-Tale Heart" to be one of the most enduringly popular and affecting stories ever written. It succeeds in this way because it is not only a testament to the power of guilt (though it is that), 
but also because it reveals to us crucial details about the way we perceive and create reality, and the role that stories play in that process.

The "real" old man, of course, is fictional, too, as is the narrator. So the obligation felt toward the fictional old man in the imagination of the narrator is, by implication, the obligation Poe also demands toward his characters. The narrator, the fictional Poe, who perceives and asks that we perceive unreal things, wants to make an ethical claim on us. Wants to survive the death of his "real" counterpart. He wants to exist, in some real way, beyond his corporeal death. And in that, he has been stunningly effective. So how do fictional beings make an ethical claim on us? And how does Poe use this in order to so positively affirm the vitality of fictional beings and the reality of our relationships with them?

As shown in "The Tell-Tale Heart," author and audience collaborate to create what we can call an Authorial Consciousness. This Authorial Consciousness is non-human, but real and Other. It is like the inhuman eye of the old man. For as we see by the story's conclusion, the inhuman eye of the old man does project a mind, a reality, afterall, but not naturally, only in the heavenly, hellish mode, the Fictive Mode of the imagination.

Fictional beings must exist within fictions because they are, in their essence, a single component held within a larger consciousness that we are experiencing only indirectly: the Authorial Consciousness. Whereas fictional beings take their place in our minds alongside the plethora of other consciousnesses we hold there, those of teachers, of buildings, of friends, the Authorial Consciousness is unique in that it is not one mind of many within our own. It is, instead, an entity with many component consciousnesses of its own, existing outside of ours but still evident to us.

The relationship with this Authorial Consciousness is the richest and most profound contact with alterity for precisely this reason; richer even than our encounters with the imagined consciousnesses of real people. We think of even other real people as singu- 
lar. They may be complex, but they are a unity, singular, constructed, and projected out from within ourselves-contained as a singular element within ourselves. Literature, though, presents us with unremitting proof that the Authorial Consciousness, like our own, contains multitudes within a subjectivity we cannot contain. This disallows the incorporation of their consciousness into our own. The Authorial Shakespeare cannot take his place beside the fictional Hamlet. Instead, that consciousness remains held out, its gibbous complexity compounding and introducing an impermeable secrecy. It is a mind that is like ours, not within it.

These consciousnesses are movable. They can be transferred and replicated, and most importantly, they exist meaningfully outside of the bodies we might assign them to. We project our own consciousness into the world to meet the others that we meet. We absorb the consciousnesses of these others, too, as they meet us. We fill ourselves with the consciousnesses of others, and between us, we construct mutually interacting, spectral consciousnesses.

For society, for friendship, for lovers, these spectral entities, intertwined and interacting, the overlapping consciousnesses we use to bind ourselves loosely to one another, suffice. But we can sense in ourselves bottomless depths, and the promise of such depths in others is bottomlessly alluring. Yet, inasmuch as these friends and lovers, these others both real and fictional, remain singular, remain mere components within the compound plurality of ourselves, any real connection is held at bay. The eye of the old man, its failure to humanize him, exemplifies this type of relationship.

Naturally, then, we can think of this in terms of extramission. The world, the universe, comes from within us somewhere, issuing out from our eyes. Or else we have, somewhere within us, a substance we can send forth that is capable of apprehending the entire world. The things we meet in the world emerge from us or are contained within us. The mind that animates my computer is one that I construct for it, project into it. When I imagine the emotions and motivations of a storm, its consciousness is one that I create for it 
and send out into the world to inhabit it. So much of everything is contained within us and created to a significant extent by our own minds.

These others remain opaque, solid and singular, with "no overflowing sets of constitutive but partially incompatible objects packed-away inside," or else "perfectly transparent objects that, with clean efficiency, convey us without deformation to the 'real' objects behind them." ${ }^{3}$ They are contained under a single label, singular entities within our own compound mind. They can provide us with mystery, but it is also only secret in the way that a hand beneath a table cannot be seen, and whose appearance, once the hand is lifted up and placed atop the table, becomes a mystery no more. While they remain singular, the consciousnesses of others can only provide us this penetrable form of secrecy. They hold none of the alluring bottomlessness that we sense or at least hope must surely be present in someone, something besides ourselves.

So it is that the projected consciousness, the transferable and movable consciousness, real and pragmatic and spooky as it is, has to give way to a stranger and less certain interaction. The outward motion that sends us into the world to interact with others is met (though rarely, though only at specific times, only with great trepidation) with an inward impulse that drives us back along the course of extramission into the emitting eyes, back to the source, the infinite and projecting other.

Because we do look people in their eyes. As if behind the eyes lay a deeper reality about the other (a source for everything that issues forth from the eyes, which may be, the instinct for extramission tells us, the whole world, everything). This is an impulse born of a belief in extramission. We look in people's eyes because we believe, intuitively, that that is the portal they come out through, and through which we might get a glimpse of the undeniable reality within, the unending beating of the imagined heart.

${ }^{13}$ Miller, Adam. Speculative Grace. New York. Fordham University Press. 2013. Print. pg 129 


\section{Works Cited}

Baron-Cohen, Simon. Mindblindness: An Essay on Autism and Theory of Mind. Cambridge, MA: MIT, 1995.

Clark, Stuart. Vanities of the Eye. Oxford: Oxford University Press, 2009.

D. I. Perrett, P. A. J. Smith, D. D. Potter, A. J. Mistlin, A. S. Head, A. D. Milner, and M. Jeeves. "Visual Cells in the Temporal Cortex Sensitive to Face View and Gaze Direction.” Proceedings of the Royal Society of London 223, no. 1232 (Jan. 22, 1985): 293-317.

Graziano, Michael S. A. Consciousness and the Social Brain. Oxford: Oxford University Press, 2013.

Haxby, James V., Elizabeth A. Hoffman, and MI Gobbini. "Human Neural Systems for Face Recognition and Social Communication." Biological Psychiatry 51, no.1 (2002): 59-67.

Hoffman, Elizabeth A., and James V. Haxby. "Distinct Representations of Eye Gaze and Identity in the Distributed Neural System for Face Perception." Nature Neuroscience 3, no.1 (2000): 80-84.

Latour, Bruno. An Inquiry into Modes of Existence: An Anthropology of the Moderns. Cambridge, MA: Harvard University Press, 2013.

Levinas, Emmanuel. Ethics and Infinity: An Essay on Exteriority. Translated by Alphonso Lingis. Pittsburgh, PA: Duquesne University Press, 1969.

Miller, Adam. Speculative Grace. New York: Fordham University Press, 2013.

Nicholas, Cheryl L. "Gaydar: Eye-gaze as Identity Recognition among Gay Men and Lesbians." Sexuality and Culture 8, no.1 (2004): 60-86.

Pelphrey, Kevin A., Viola Ronald J., and McCarthy Gregory. "When Strangers Pass: Processing of Mutual and Averted Social Gaze in the Superior Temporal Sulcus." Psychological Science 15, no.9 (2004): 598-603.

Plato. Timaeus, Critias, Cleitophon, Menexenus, Epistles. Translated by Robert G. Bury. London: W. Heinemann, 1929.

Russell, Bertrand. Introduction to Mathematical Philosophy. 2nd ed. New York: Macmillan, 1920. 



\title{
6 Mapping German Poetics onto the American Psyche: Masculinity and Metaphysics from E.T.A. Hoffmann to Edgar Allan Poe
}

\author{
Gerardo Del Guercio
}

While Romantic story-tellers in general offered their own artistic dilemmas as metaphors for the production and reproduction of life, this phenomenon of the "experimenter's syndrome", as Margaret Fuller says, spans not just the landscape within the stories but the self-portrayal of the short story genre as well. Edgar Allan Poe existed just as much in an anomalous position in both old and new canonical configurations as his German contemporary and oft-acknowledged inspiration E.T.A. Hoffmann was in his role of the "unfortunate genius". Imbued with an artistic perfectionism and-in Poe's case-the creation of a new national literature, their similarities go beyond the often cited "phantasy pieces" and disturbing pseudo-horror.

This paper argues that the German influence on Edgar Allan Poe was indeed essential in the latter's formation of the short story form that arguably best maps out the motions and poetics of the mind that is freed from the divisions between language, sensation, and elevated perception. It is Poe's attempt to venture into borderlands of the creative process that was intended to bridge the gap between hyperrational poetics and metaphysical speculations. 
As the work of his contemporary Fuller shows, this movement towards a higher state of wholeness and union was closely tied to the dualism between male and female attributes and spheres.

United in their criticism against the supposedly less revolutionary poet Longfellow, both Poe and Fuller claim that terror is, on the one hand "not of Germany, but of the soul" (as Poe says) and, on the other hand, that "all attempts to construct a national literature must end in abortions like the monster of Frankenstein, (...) the instincts of form, but soulless, and therefore revolting" (Wade 359-60). Equally mesmerized by the malleability of the material world to imaginative faculties, they take Hoffmann's prejudiced stories dealing with the "feminine in men (that) inevitably results in destruction or a life half lived"1 even further to create a space where unifying forces replace the new psychological language of a woman's creative energies and harmonizing center.

It is Margaret Fuller who is occupied with German literature of the Romantic period and describes it as one that allows feelings and intuition to speak at the same time. She demands a similarly "modern" literature for the US that is not tainted by Britain's utilitarian tendencies. ${ }^{2}$ In order to develop a uniquely American cultural identity, Fuller turns to Herder's definition of a national literature as worthy of respect as it is a mirror of the national spirit and soul alongside language and nature. Individual independence, however, is just as important. Her version of women's declaration of independence resembles these sentiments closely: "It is a love that has caused this, - love for many incarcerated souls, that might be freed, could (...) the weakening habit of dependence on others be broken up." ${ }^{3}$ The German Romanticists', particularly

${ }^{1}$ Meyers, Helene. "Joseph Adriano. 'Our Ladies of Darkness: Feminine Demonology in Male Gothic Fiction.” Studies in Short Fiction 31.3 (1994): 527.

2 Maas, Christel-Maria. Margaret Fullers transnationales Projekt: Selbstbildung, feminine Kultur und amerikanische Nationalliteratur nach deutschem Vorbild. Universitätsverlag Göttingen, 2006. p. 48.

${ }^{3}$ Ibidem. p. 143. 
Hoffmann's, view of women places many restraints on that gender, though.

Feminine forms being an integral part of Romanticist discourse, ETA Hoffmann writes in the tradition of woman as poesy and unattainable ideal, which I will speak about in more details later in this essay. While much criticism has concentrated on that connection, I would like to move from a purely gender-based analysis to one of the form of the short story of Hoffmann, then to Poe's versions. In mapping out the poetics of the genre, Poe is seemingly critical of Hoffmann's mixture that to him contains many of the elements for which he rebukes Longfellow. "Were it possible to throw into a bag the lofty thought and manner of the 'Pilgrims of the Rhine', together with the quirks and quibbles and true humour of "Tristram Shandy", not forgetting a few of the earlier drolleries of Rabelais, and one or two of the Phantasy Pieces of the Lorrainean Callot, the whole, when well shaken up, and thrown out, would be a very tolerable imitation of $\mathrm{Hy}$ perion" (Vitt-Maucher 36). Nowhere closer to Hoffmann as the Lorrainean Callot, Poe is seemingly less aware of many of his own requirements for the short story in Hoffmann's stories.

Common to both authors' stories is the single effect, an allencompassing tone, whose continued realization requires a narrative "I" that is both participant and experiencing persona. While Poe is himself often claimed to be an author whose poetic sentiment lies in the creation of "novel forms of beauty" and pure organization, this single effect resonates with receptive states of consciousness. Hoffmann's intention is pure seeing, nonetheless, in which an inner state is carried into the outer world, a so-called serapiontic effect. ${ }^{4}$ The danger with this latter description is a certain egotism and solipsistic desire. Both Poe and Hoffmann concentrate on the imaginative process or creative impulses of the writer as art becomes a narcissistic mirror. Interestingly enough,

\footnotetext{
4 Saul, Nicholas. The Cambridge Companion to German Romanticism. Cambridge, UK: Cambridge UP, 2009. p. 56.
} 
this echoes one of Poe's assessments of Fuller's work: “The faculty of [the unexpected], too, springs from her subjectiveness, which leads her to paint a scene less by its features than by its effects."

This inclination toward seeing and sensation can also be seen in Hoffmann's introductory story to his collection Phantasy Pieces, which establishes the figure of Ritter Gluck in a process of audiovisual imaginative power as a hallucination of sorts. Via the formular "bringing to the eyes of the reader", Hoffmann defines imagination as the force to metaphorically illustrate the character and provide evidence on the nature of a narrative character. In danger of "swimming figureless through an empty space", as the text's commentator states (Hoffmann 174), the hallucinatory character of these beings has often been interpreted as ghostly or mad. Yet, as the text teaches us: "never did I see such a head, nor such a figure that impressed me so deeply and quickly" (Hoffmann 20). His final "I am the knight Gluck" seems more like a mockery, but gives the reader only the option of believing either him or the narrator-a dilemma of duality. It is also a question of metanarrative concern that posits a being as either mere type or full-blown figure, which hinges on the narrative abilities of the story.

Embracing a logic of cause and effect, Poe similarly tests the limits of the short story in undercutting his own meaning, forced boundaries and seeking the same legitimation through referentiality that is visible in Hoffmann's stories. Hoffmann instructs his readers in "Jacques Callot" to recognize the strange and unknown in the familiar. "Could a poet or writer, to whom the figures of ordinary life appear in his inner romantic kingdom of ghosts, and who now portrays them in that glimmer that flows around them as through a strange, fantastical rendering, not at least apologize to the master and say: He wanted to work in Callot's manner?" (Hoffmann 18) Rather than leading to a dutiful sensualisation of the subject, Hoffmann's reference to a familiar figure is the only impediment

${ }^{5}$ Poe, Edgar Allan / Griswold, Rufus Wilmot (ed.). The Works of the Late Edgar Allan Poe. Part 3. Redfield, 1857. p. 74. 
to embarking on a journey of repetitive signification. The narrator's engagement with himself and others in Poe's "Raven" with the repeated line "nevermore" mirrors this creation of meaning through relatedness. In describing terror as of the soul, Poe further claims to "have deduced this terror only from its legitimate sources, and urged it only to its legitimate results" (n. pag). The haunting memory can never be escaped and the problem becomes once again that of mastery over the text.

The same retreat from the quotidian world is virtually total and, as William Freedman attests, resembles "the journey into the causal zones of psyche as often literal or direct as metaphoric" (Freedman 31). It is often described as the hero's essential task to break through the undistorted experience and archetypal sphere. The phantastic that both Poe and Hoffmann employ as a result is an expression of a chaotic psyche near collapse that expresses the chimeric, ugly and horrific. In short, it requires a borderline character. Hoffmann's figure Callot already commences the phantasy pieces with the statement: "Irony (...) only lives within a deep spirit and Callot's from humans and animals assembled creatures in their grotesqueness reveal to the serious, deeply penetrating visitor all the secret insinuations that are hidden under the veil of oddities" (Hoffmann 18). This tendency towards the distressing and horrible in Poe requires the additional realist vision that leads towards transcendental visions as he imagines them. Beyond blurring the boundaries between reason and madness, Poe's characters acquire truth by means of the senses and look beyond the materialistic towards the metaphysical.

The form of the short story is incomplete without an accompanying soul and spirit. Whereas many nativist American philosophers consider landscape the foundation of a truly American national literature, it is not a spirit of patriotism that forms the basis of Poe's vision. Instead, he goes along the lines of Margaret Fuller-who herself is an avid reader of Kant and Fichte-in critiquing the purely materialistic, ambitious and surface character of the American value system. Fuller delineates these ideas in her 
early essay "Present State of German Literature". ${ }^{6}$ German idealism focused on the interior world, feelings and intuition, which Poe then amends with his realist-materialist stance. Poe repeatedly called for the creation of an international law, although scholars have alternately interpreted this interest as either a promotion of national works in this safe space or the freedom from a moral purpose.

The creation of true art necessitates the artist to throw themselves into paradise or madness, whichever it may be, to attain their ultimate goals and unite the metaphysical with the real space. This resonates with Hoffmann's postulated paradox of his characters, the Serapion brothers. One of these claims that madness no longer exists when the weapons of reason can refute it, but asserts in the same breath that this requires acting from the perspective of madness. As Hoffmann's narrator states, "the evil creatures (...) are obviously the most paralyzed of all enemies that I conjured and I will beat them with their own weapons, those of reason" (Hoffmann 45). In order to achieve unity and balance of all forces within the mind, one needs to respond to outside impulses appropriately and regardless of a moral sense or one's own conscience. Instead of listening to the design of a Deity, Poe's characters are designed to remain romantic idealists in their pursuit of happiness. Ellison recognizes and lives according to these less traditional ethics and to fulfill more spiritual pleasures that know no bounds.

Hoffmann portrays the soul of an artist as someone removed from general society and engaged in the interplay of fantasies that enables him to balance the inadequacies of reality and his fellow human beings. Poe transforms this intuition of the artist into the "vivid yet candid reason of Leibnitz" and a keener observation or mirroring of his surroundings that does not require the with-

${ }^{6}$ Maas, Christel-Maria. Margaret Fullers transnationales Projekt: Selbstbildung, feminine Kultur und amerikanische Nationalliteratur nach deutschem Vorbild. Universitätsverlag Göttingen, 2006. p. 58.

7 Werner, James. American Flaneur: The Cosmic Physiognomy of Edgar Allan Poe. New York, NY: Routledge, 2004. p. 137. 
drawal of the writer. His tasks are unseen and arduous, but also painful and despairing. Yet, "The Philosophy of Composition" moves towards a unification of the realms of interior and exterior events in spite of this strenuous labor involved in the process of writing. As he says: "If two sittings (instead of a single sitting) be required, the affairs of the world interfere, and everything like totality is at once destroyed" (n. pag). It seems almost impossible to keep the real world out of this exercise in creative insight.

Just as history returns with many contradictions in "The Raven" and Poe cannot restrain himself from frenzied descriptions, it is rather the poet's desire to keep the process of writing secret to the public than remaining impervious to their outside world. In "The Philosophy of Composition", Poe advocates "Most writers-poets in especial-prefer having it understood that they compose by a species of fine frenzy-an ecstatic intuition-and would positively shudder at letting the public take a peep behind the scenes" (Poe n. pag). Sensation and perception-while they need to be kept to oneself as artists-cannot be separated from the surface world. Intended or not, the writer remains in a continuing state of transition on the border between the mental and public spaces. The aesthetic experiments conducted by Poe's narrators (and the portrayed artists) can no more resolve the disquieting mood and apprehension than Hoffmann's protagonists.

To Margaret Fuller, this state exemplifies that "all this conflict and apparently bootless fretting and wailing mark a transition state-a state of gradual revolution, in which men try all things, seeking what they hold fast, and feel that it is good" (Mills 114). In claiming that such mediums as poets embody in artistic actions the fluid state of nature, we might consider these personalities as reflections of the transitional state into which the debate about a national literature put them. While Hoffmann reflects the accepting atmosphere of the Romantics in Germany, Poe's attempts more fiercely to negotiate or even downplay his attempted unification of the forces of mind, soul and the public realm. Poe's textual cruxes, as 
PLS calls them, always have to do with the conversion between matter and spirit.

While he composed within the highly politicized atmosphere of a struggle to define American literary independence, he nonetheless despised the "entrapment of an author within the iterative but ultimately self-serving power of the press", which he labeled "bemirrorment" (McGill 274). Other critics, among them his contemporary Lowell, even accused him of an impossible maturity that discouraged thoughts of him ever having been in a dependent phase. Poe himself incorporates such thoughts in his "Philosophy of Composition" when he claims that "the true purposes seized only at the last moment ... the innumerable glimpses of idea that arrived not at the maturity of full view (n. pag)". This positions the author in a variety of roles that include spectator and critic at the same time as he authors the text. Unsurprisingly, he considered transcendentalism as an ideal form of revelation and insight. Whereas the artist can deliberately attempt to bring about the intended effect in the reader, he was averse to the idea that there is no spiritual impact of a godly creature on material things and people. As he became an icon of literary judgment, Poe's poetics remained culture-bound and continued to reveal strong historical undercurrents. The importance of forcing a frame to a poem-as his "Philosophy of Composition" details-similarly functions to avoid being erased from history. Authorship should be accompanied by ownership of one's voice and Poe's criticism of Longfellow after the latter published The Waif anonymously goes against this deeply ingrained sense of subjectivity. A corrupting influence compared to the fields of science and poetry is the field of metaphysics in early writings of Poe. He combines the terms metaphysics and morals in his writings (Carlson 350) and considers a sense of morality to be closely related to the human concern of metaphysics, namely the soul and personal taste. This idealism already emerges at the first mention of the term metaphysics in the "Letter to Mr. -" in 1831. He did not, however, preclude a combination of poet and scientist. 
One form of a double in Poe's poetics as a result emerges in the figure of the author or protagonist alike. It is closely tied to the figure of genius, but also the plagiarist. Poe's defense of plagiarism towards the later part of his career illustrates that the offending poet "is not only fully possessed by another's thought in the act of reading, he is subject to a kind of hair-trigger reproduction of his thought" (McGill 297). The author, in his opinion, is constantly in danger of self-loss and the book becomes a "sensible presence" in its own right whose circulation encompasses the danger of losing one's autonomy. This is one effect that authors can calculate since reality and the fictional product become closely entwined and can and should not only bring beauty to the reader but also endangers the author in a game of figures. The double becomes a grotesque form of deformation and disillusionment that matches Poe's own theory of the tale. His only essay on the subject, a brief preface to the Tales of the Grotesque and Arabesque (1840), refers to the grotesque and arabesque tenor of his tales. Poe's tale of terror itself is largely based on Scott's and Hugo's grotesque, which he used as sources for the tales.

Some critics have also previously claimed that Poe took both terms from Scott's essay on E.T.A. Hoffmann titled "On the Supernatural in Fictitious Composition", but Scott does not attach the same value to them as Scott (Carlson 283). Poe considers both the arabesque and grotesque features of the text as means to achieve a unity of effect and thus a certain transcendence, coherence as well as irony; nevertheless, Poe also published an anonymous review of his own Tales, in which he credits most of the tales' success to the author's genius and its power to protect other identities and consequently function as a safeguard from doubles. He claims that "a writer must have the fullest belief in his statements, or must stimulate that belief perfectly, to produce an absorbing interest in the mind of his reader" (Carlson 285). The reader becomes a coconspirator in the process of achieving unity and avoiding a split in identities. 
Hoffmann's notion of the split in identities is mainly reflected in narratives of tormented fantasy, making "his fictions profoundly rest-less, thriving on the interruptive power of strange desires" (Webber 117-118). This is exemplified in the constant transitions between speculative fantasy and subsequent earnestness that prevent the reader from settling comfortably into one mode of narration. His tale Das steinerne Herz takes us into a world in which father and son identify with each other, experience a mock abduction and open cases encompassing unfulfilled "strange" desires and diversions. Although the tale concludes with a fairy-tale marriage, this unity seems forced as the characters' psyche and hearts remain torn. The Nachtstücke, in Andrew Webber's view, are even more exemplary of "an uncanny sense of pathological potential, of the tormented heart and psyche" (Webber 117). This has also often been named as cause for many critics' tendency to place the emergence of the double in German literature into the same era as the beginnings of the Gothic novel.

This tendency is closely connected to Poe's disapproval of disowning ownership in his tales. Hoffmann's emphasis in his tales lies on visual clues and the need to sensually experience the setting and characters. Whereas Poe is often satisfied with converting even a lack of agency into a mark of identity (McGill 298), Hoffmann explicitly favors double visions, clarity of vision and the recognition of a duplicitous nature. Apart from the lifeless automaton Olimpia in Der Sandmann, he also creates characters like the Hofrat in Nachtstücke who is revived from the dead by a mesmeric expert and eerily alike in both body and spirit to his son. This play with resemblances culminates in the Hofrat's seeing sense as all other indications of madness are explained away. Even the previously mentioned Serapion's distinctions between real and ideal cannot be lifted entirely without the risk of seeing an image of pure terror. This sense of sublime threat corresponds to not only to the Romantics' sense of experience and originality.

Hoffmann also fits Poe's model of genius as an individual "with the power of projecting other identities. The effect of truth is 
best produced by the simulation of belief, and the tale so produced would appear to be a simulacrum, a copy with no original (Carlson 286). Even though Poe seems critical of the "Lorrainean Callot's" lack of unity in his stories, he does commend Hoffmann "a rich profusion of thought" and critics often cite the similarities between Ritter Gluck and The Man of the Crowd (VittMaucher 36). Yet, Hoffmann seems not able to transform this poetic ground into a female textual construct. His text Der goldne Topf allows for the male narrator's Anselmus' own self-definition, whereas the ideal woman is a snake that morphs into a maiden at will. She serves as inspiration for the poet Anselmus, but seems to lack any original will in her simulated roles. Whoever threatens his poetic production must be killed and thus violence emerges in the attempt to maintain an aura of truth. Nevertheless, Anselmus needs a guardian of texts to gain entry into the poetic world. In a way, Anselmus himself needs to become a simulacrum since he is required to copy in order to learn and gain literary power himself. Genius itself becomes a contested category within the text, although as a simulation of belief systems, Hoffmann creates the basis for the emergence of identities.

With the advent of Margaret Fuller's more feminist Transcendentalist self-reliance, the self-culture practiced by men limits them to one half of divine thought. Fulfilled human relationships become the pathway to human transcendence. Both the development of body and mind are vital components of this progression. Poe has also "never revoked his adherence to the notion of a higher sphere of supernal beauty" (Meindl 41). The excitement and pleasurable elevation of which Poe writes in his "Philosophy of Composition" in consequence affirms the Platonist principle of an intermingling of spheres. This intended combination of the earthly sphere and otherworldly ideal leads Poe towards the metaphysical heights of creation in his poetry.

His tales, however, portray a very different direction towards the existential grotesque and downward metaphysics. Nonetheless, he looked forward to "the dynamic organicism of the Romantic pe- 
riod" (Carlson 277) - a cosmology which he had derived from criticism of Augustus Schlegel, Coleridge or British periodicals.

Deriding thoughts of an "unprincipled man of genius" (Carlson 351), Poe attempted to combine both the poetic and the scientific in his tales. Morality seems of secondary importance and only emerges in the sense of principle. The protagonist in his crime tales, M. Dupin, for instance, is living proof of "the old philosophy of the Bi-Part Soul,... the creative [i.e. poetic] and the resolvent [i.e. scientific]." This corresponds to a deeply ingrained attempt at unification that pervades Poe's tales in general. In adherence to the Latin meaning of alter ego as a kind of double, "the alter ego must be seen as governed by a relationship of radical alterity to the primary ego. As a result, when one juxtaposes the two figures in a dialectic synthesis, the entire spectrum, the broad range of human personality traits is revealed" (Bär 68). Poe's concept of the bi-part soul combines the two different fields tempered by the third within a single person. The supernatural aura is subsumed in the character of the protagonist and is, to a large extent, aimed at metaphysical heights of experience. A fragmentation of the "I" becomes unnecessary.

Hoffmann, however, remains firmly within the grasp of an understanding of the double as a pathological estrangement from oneself, which is attested as a "chronic dualism" that affects most of the "case histories" he wrote (Webber 119). His fiction is usually described in terms of a master-slave dualism or, at the very least, threatens the mantle of selfhood, identity and desire. While Poe concentrates on the fulfillment of impulses and desires of the moment, Hoffmann's characters have the same wishes but the momentary scenarios and overall dynamics of the narrative collide much more frequently. The Serapion brothers may engage in living out scenes of their existence, but these seem devoid of a sense of living movement. Poe similarly argues for an enclosed setting and

${ }^{8}$ Mabbott, Olive (ed.). Collected Works of Edgar Allan Poe: Part 2. Cambridge, MA: Harvard UP, 1978. p. 533. 
circumscription of space, but this does not preclude his theory of unifying these concentrated scenes. Poe consequently reinterprets Hoffmann's more static narrative theory and ultimately allows for a transformation or even de-humanization of his characters without resorting to automata and similar mechanic creatures.

Rather than using merely de-humanized creatures or those transforming between human and animal states, Poe further reinterprets the notion of what death and the grotesque can mean in a metaphysical sense. Looking "for artistic inspiration in the depths of Being” (Meindl 41), he follows his contemporary's advice that "every artist of the grotesque must show a disposition 'to dwell upon Death-to associate with his lightest thoughts the ghastly presence of the Destroyer" (Meindl 41). This complicates Poe's relationship towards the double, which can be either a split identity or a double, for example, a second version of the self. While his stories are littered with dead and death-like creatures, the realm of death becomes another cosmos akin to a bleak and frightening world or outer space, perhaps simply a counterpoint to the heavenly empire. The level of ordinary experience is amended with a metaphysical power of a lost paradise, as Northrop Frye suggests. "On the fourth level, corresponding to the traditional hell or world of death, is the mysterious reservoir of power and life out of which both nature and humanity proceed" (Meindl 39). On the basis of Ralph Waldo Emerson's psychological dualism, critics have suggested that the "shadowed self" that is death merely leads to a peculiar and often tempting confrontation with oneself. The double in this sense, however, needs to be distinguished from a Jekyll and Hyde persona.

Poe's sense of this shadowy double can be compared to the kind of spiritual double as defined by Virginia Woolf. In warning that artists must not just revert to models of Gothic literature, she claims that the author

must seek to terrify us not by the ghosts of the dead, but by those ghosts which are living within ourselves. [...] A ratio- 
nal age is succeeded by one which seeks the supernatural in the soul of man, and the development of psychical research offers a basis of disputed fact for this desire to feed upon" (Bär 59).

The individual thus becomes a vehicle for deathly desires and ghostly presences. Nevertheless, he is tempered by what Poe terms "the pernicious influence of mortality" (Poe, "Berenice", n. pag). In order to transcend the realm of reality, his character Egaeus in consequence resorts to violence in the form of extracting body parts resulting in the collapse of the mind and epileptic seizures. It is thus possible to identify two different kinds of double in Poe just within that one story-first, a spiritual connection and second, the inclusion of body and matter.

The nature of the soul is one of the great metaphysical problems in Poe's writings, which is only surpassed by a profound materialism. A possible materiality of the soul is suggested in the tale "BonBon", where the soul becomes a delicacy to be eaten. He thus follows in the footsteps of mesmerism and Epicurus, to whom the soul is "a bodily substance composed of slight particles diffused over all the members of the body" (Carlson 355). Yet on other occasions, he considers matter and non-matter to be convertible into each other. However, he clearly values the metaphysical even beyond subjectivity, as illustrated by the letter in which he trades it for looking into his beloved's heart - the heart of the matter, so to speak. He was, above all, fascinated with Milton's heretical assimilation of body to soul. Poe's embrace of materialism was pervaded by the fear of a gross sensuality, nonetheless. The solution was to be found in a kind of ethical materialism, which was adapted to active energies all throughout nature and leading to various gradations of matter and an increased sensibility.

Apart from this critique of a purely materialist ethics, Poe claims in "The Domain of Arnheim" that the world might also never see "the full extent of triumphant execution, in the richer domains of art, of which the human nature is absolutely capable” (n. pag). 
The poet or writer consequently moves into the foreground and elevates taste to the highest position, higher than a moral sense which only ranks pleasures. He leaves traces not only in everyday objects but also within the text that he composes as another artificial or truthful product. In decomposing the text through his "Philosophy of Composition", Poe attempts to discern the state of the writer's mind and the resultant artistic forms. As Hoffmann states succinctly in his story "Knight Gluck": it is a world that is and should only be entirely accessible to the artist. "But I spilled the holy to the unholy, and an icy cold hand seized this glowing heart! It did not break, thus I was damned to walk among the unholy like a forsaken ghost-without form or figure that no one might know me, until the sun flower raises me once again into the circle of the eternal." Nathaniel, Hoffmann's protagonist in "The Sandman", notes that "passionate narrators like himself have a strange look in their eyes, as if they wanted to grasp figures in the empty space around them which nobody else can see" (Hoffmann 24). This becomes the image of a ghost-seer, to which Friedrich Schiller even devoted an entire novel fragment.

These utopian urges and creative energies are inspired by the male muse through which the artist gains access to the fluid poetic realm. Whereas the women in Hoffmann's stories rarely speak or sing, they are often embedded in male narration, instances of omitted storytelling, insipid conversation and through death. While this precludes the fulfillment of the artist through love and inspired relationships, it transforms male muses into precisely those figures. As Martha Helfer notes with regard to Novalis' writings, this "'powerfully built' poetic ground, with its 'completely clear, masculine proportions,' is metaphysical in nature" (Helfer 307). It is a connection predicated upon the self-reflexivity of the individual and reproducing part of that other rhetorically and artistically. As Hoffmann writes in "Knight Gluck", "I know what fills your breast with longing, the soft and tender young man, third, will step under the colossus, you will hear his sweet voice, see me again, and my melodies will be yours" (Hoffmann 
25). Not only has woman been replaced with the male gender, but the inner self can only be spoken to by those outer experiences to which it becomes receptive.

Poe similarly attempts to realize idealizing states of mind at the cost of sacrificing contingent relationships with women. In his case, however, the portrayal of the feminine in men or narrative downplaying of women does not emerge from the desire to overcome the fact that all declarations of love have been written before and are thus no longer authentic. Neither does Poe see women as the driving creative force behind poetic production as the early Romantics did. This is merely one stage in the project towards a specific determined feminine identity. Until then, however, Baudelaire's assessment of his women rings true: these women "burn amidst a supernatural vapor and are painted in the eloquent style of an ardorer" (Dayan 1993, 4). Where Poe portrays women saturated with love or unreceptive after death, however, Baudelaire sees a correction of the monstrous. Instead of seeing love as the link between humanity and divinity, it is the poet and his imaginings that create the connection between the two.

Haunted by a spectral love-object, as critic Daniel Hoffmann claims with regard to Poe, he creates narrators that hover dangerously close to madness and the demonic. The women need to be puzzling and inspiring these intense visions rather than be accepted and unquestioned representations of civil society and civil love. In Poe's story "The Domain of Arnheim"-to stay with the previous example -, the protagonist Ellison (a landscape gardener) devotes his time to both his creative impulses in gardening, his vision, the high spirituality of the object and the contempt of ambition, but most of all "it was in the sympathy of a woman, not unwomanly, whose loveliness and love enveloped his existence in the purple atmosphere of Paradise, that Ellison thought to find, and found, exemption from the ordinary." The narrator terms all these "the cares of humanity, with a far greater amount of positive happiness than ever glowed in the rapt day-dreams of De Stäel." Apart from the less than detailed typification of the woman, Poe 
seems to connect exemption from the ordinary and the attainment of greater truths with the need to delve into different realms of experience and spirituality.

There is, on the other hand, also a strange quality of the doppelgängers in Poe's writings that mark him as a more complicated analyst of the female gender as his predecessor Hoffmann. "There is something intrinsically, and weirdly, sexless about ... most of the arid Doppelgänger bachelors," as Robert Alter claims (Sencindiver 64). In most cases, women are symptomatic of the men's pathologies, but there is no deep-seated sexual interest in the other gender. Instead, it is a spiritual interrelatedness that exposes the incompleteness of man even without bringing a sense of castration into the equation. Just like Hoffmann's women are often unable to articulate their own sense of identity, Poe also utilizes a number of veils that need to be penetrated and thus lead the reader to focus on symbolic rather than spiritual or physical identities. Women such as Ligeia become floating signifiers for male characters, readers and even unveil some of the narrator's figurative blindness. In some sense, there is indeed the possibility that "the symbol of the woman transcends the world of abstract rationality, but only for the moment and in glimpses" (Goldbæk 115). She is further another sign of doubling as she transcends the boundaries between life and death-a feat that Hoffmann's women were not able to perform.

Poe's stories accordingly prove that fluidity and borderlands can transcend prior ideals of an arcadic sublime nature and idyllic culture, as creative energies become just as vital to literature as the activating energies are for matter. The supposedly psychological frontier "where unconscious drives and consciousness meet" (Achilles 1997, 359) mirrors the geographical frontiers of civilization and wilderness. In his attempt to bridge the gap between rationality and metaphysics, Poe accordingly not only includes a peculiar relationship between the three faculties, but also addresses national issues of nineteenth-century America. It seems fitting that the contemporary Smith links Poe and Jefferson in a 
speech that reminded audiences of Poe's Americanness as well as southern character. To quote Scott Peeples

And let the names of Jefferson and Poe, whose far-flung battle-lines intersected on this campus, forever remind us that this University is dedicated not to the mere routine of recitation rooms and laboratories but to the emancipation of those mighty constructive forces that touch the spirits of men to finer aspirations and mould their aspirations to finer issues (21).

As Poe's metaphysics emerges from the "laboratories" and scientific contexts, his perceived eccentricity slowly transforms into a sense of acceptance by his contemporaries.

Unquestionably, he is often linked to the "foreign theme", even stating in Graham's Magazine in 1842: "as if any true literature could be national" (Ernst 339). He rather wanted to avoid preferred treatment of national works despite what he terms their "stupidity". For the purposes of this argument, I ultimately advocate that Poe's integration of these idealist metaphysics supports his point-of-view to the degree that he rightly refuses to restrict the subject matter and potential depths to particular extraneous concerns in order to concentrate on what lies beneath the surface. His literature is oriented not with regard to ordinary events, but, like Hoffmann's, attempted to grasp the nature of the soul. It is, in Poe's words, made up of "active energies" and a "physical body... pervading the whole frame (...) but made up of matter in its more refined and subtle forms" (Carlson 355). In "The Domain of Arnheim" which reflected his own opinions most closely (as he claimed), the narrator informs us that not only is there a bias that apparently and sadly convinced the protagonist that "tinged with what is termed materialism all his ethical speculations" into thinking that "the most advantageous at least (...) lies in the creation of novel moods of purely physical loveliness."

${ }^{9}$ Poe, Edgar Allan. / Griswold, Rufus Wilmot (ed.). The Works of the Late Edgar Allan Poe. Part 4. Redfield, 1859. p.339. 
Cognizant of the pressure to be original and peculiar, Poe's theories of the short story take on a vital position in the establishment of a national literature that could constitute the dynamic and developing state of literature in general. It is then logical to heed his contemporary Margaret Fuller's words:

It is good for us in this bustling, ambitious, superficial country, where everybody is trying to do something new, where all the thought is for the future, and it is supposed the divine spirit has but just waked up to look abroad and learn to know the weakness which waits upon our strength by seeing the benefit of that state (Hurst 55).

This learning process depends to a large degree on gaining the interest of the public of which Poe was already acutely aware. In order to impede a potential onset of melancholy, Poe values the reader's interestedness and intellectual engagement with the text, as the protagonist in "The Man of the Crowd" exemplifies. His recourse into metaphysics is designed to create interest and fascination for the eccentric and otherness, similar to the sensitive feelings and acute spirit of the artist.

While this gesture in the direction of a concept of otherness has been connected to his intercultural character by Julia Kristeva (Achilles 1997, 373), the German critique of Poe has moved into a very different direction. The Frankfurt School, for one, has interpreted shock images and the looming abyss in Poe's writing as a foreshadowing of the problems of the twentieth-century. Walter Benjamin, in the spirit of this essay, hoped that Poe's writings "could destroy the illusions of progress and of the closed society, and thus transcend it into a state of hope and into an alternative way of life" (Bär 111). An exploration of Poe's metaphysics could then provide the vital link between the grotesque, historical interest and Poe's desire to convey the truth. The metaphysics and fluent gender boundaries that Poe adapted and greatly expanded from the German author Hoffmann function provide a unique glimpse into the American mind and the anxiety of the age at the same time as it catapults Poe and his national and literary concerns 
into the criticism of the twentieth-century. The "scarlet horror" of the grotesque evoked by Poe ultimately transforms into a rejuvenating force of spirit, soul and mind, creating a more complete and unified poetics of the short story amidst and by means of the figure of the Doppelgänger.

\section{Works Cited}

Achilles, Jochen. "Edgar Allan Poe’s Melting Pot: Skeptical Soundings of Cultural Composition.” Anglia 115, no.3 (1997): 352-74.

-. "Purgers and Montaged Men: Masculinity in Hawthorne's and Poe's Short Stories." Amerikastudien/American Studies 43, no.4 (1998): 577-92.

Annuß, Evelyn. "Maske und Maschine: Künstliche Frauen in Texten von Hoffmann, Villiers und Lem.” Literatur für Leser 20, no.2 (1997): 95-107.

Bär, Gerald. Das Motiv des Doppelgängers als Spaltungsphantasie in der Literatur und im deutschen Stummfilm. New York: Rodopi, 2005.

Benton, Richard P. "Friends and Enemies: Women in the Life of Edgar Allan Poe." In Myths and Reality: The Mysterious Mr. Poe, edited by Benjamin Franklin Fisher, IV, 1-25. Baltimore: Edgar Allan Poe Society, 1987.

Bliss, Ann V. "Household Horror: Domestic Masculinity in Poe’s 'The Black Cat'.” Explicator 67, no.2 (2009): 96-99.

Carlson, Eric W, ed. A Companion to Poe Studies. Westport: Greenwood Press, 1996.

Crowder, Ashby Bland. "Poe's Criticism of Women Writers.” University of Mississippi Studies in English 3 (1982): 102-119.

Dayan, Joan. "Amorous Bondage: Poe, Ladies and Slaves." In The American Face of Edgar Allan Poe, edited by Shawn Rosenheim and Stephen Rachman, 179-209. Baltimore: Johns Hopkins University Press, 1995.

-. "Poe's Women: A Feminist Poe?" Poe Studies/Dark Romanticism: History, Theory, Interpretation 26, no.1-2 (1993): 1-12.

Dougherty, Stephen. Poe and the Sacred Nation: Race, Imperialism and Enlightenment in Antebellum America. Indianapolis: Indiana University Press, 1998. 
Elbert, Monika. "Poe and Hawthorne as Women's Amanuenses.” Poe Studies/Dark Romanticism: History, Theory, Interpretation 37 (2004): 21-27.

Ernst, Jutta. Edgar Allan Poe und die Poetik des Arabesken. Würzburg: Königshausen und Neumann, 1996.

Freedman, William. The Porous Sanctuary: Art and Anxiety in Poe's Short Fiction. New York: Peter Lang Publications, 2002.

Goldbæk, Henning. "Poe in Progress: A Reappraisal." American Studies in Scandinavia 23 (1991): 105-127.

Helfer, Martha B. "The Male Muses of Romanticism: The Poetics of Gender in Novalis, E.T.A. Hoffmann, and Eichendorff." The German Quarterly 78, no.3 (Summer 2005): 299-319.

Hoffmann, E.T.A. Nachtstücke. Klein Zaches. Prinzessin Brambilla. Berlin: Deutscher Klassiker Verlag, 2009.

Hoffmann, Gerhard. "Edgar Allan Poe and German Literature.” In AmericanGerman Literary Interrelations in the Nineteenth Century, edited by Christoph Wecker, 52-104. Munich: Fink, 1983.

Hurst, C. Michael. "Bodies in Transition: Transcendental Feminism in Margaret Fuller's Woman in the Nineteenth Century." Arizona Quarterly 66, no.4 (Winter 2010): 1-32.

Jennings, Lee B. "Woman as Reality-Demarcator in Three Tales of E. T. A. Hoffmann." In Modes of the Fantastic: Selected Essays from the Twelfth International Conference on the Fantastic in the Arts, edited by Robert A. Latham and Robert A. Collins, 122-8. Westport: Greenwood, 1995.

Kayser, Wolfgang. "The Grotesque in the Age of Romanticism: Tales of the Grotesque and Arabesque.” Translated by Ulrich Weisstein. In The Grotesque, edited by Harold Bloom and Blake Hobby, 57-63. New York: Bloom's Literary Criticism, 2009.

Kennedy, J. Gerald. “Poe, 'Ligeia,' and the Problem of Dying Women.” In New Essays on Poe's Major Tales, edited by Kenneth Silverman, 113-29. Cambridge: Cambridge University Press, 1993.

Labriola, Patrick. "Edgar Allan Poe and E. T. A. Hoffmann: The Double in 'William Wilson' and The Devil's Elixirs." International Fiction Review 29, no.1-2 (2002): 69-77. 
Luker, Daniel J. "An Analysis of Observing: A Study of the Icon of the Flaneur in E. T. A. Hoffmann's My Cousin's Corner Window and Edgar Allan Poe's The Man of the Crowd." In The Image of the Outsider in Literature, Media, and Society, edited by Will Wright and Steven Kaplan, 152-55. Pueblo: Society for the Interdisciplinary Study of Social Imagery, University of Southern Colorado, 2002.

McGill, Meredith L. "Poe, Literary Nationalism, and Authorial Identity." In The American Face of Edgar Allan Poe, edited by Shawn Rosenheim and Stephen Rachman, 271-304. Baltimore: Johns Hopkins University Press, 1995.

Meindl, Dieter. American Fiction and the Metaphysics of the Grotesque. Columbia: University of Missouri Press, 1996.

Mills, Bruce. Poe, Fuller, and the Mesmeric Arts: Transition States in the American Renaissance. St. Louis: University of Missouri Press, 2006.

Nankov, Nikita. Edgar Allan Poe as an American Romantic. Des Moines: Orrin Frink, 1990.

Pahl, Dennis. "De-Composing Poe's Philosophy." Texas Studies in Literature and Language 38, no.1 (Spring 1998): 1-25.

Peeples, Scott. The Afterlife of Edgar Allan Poe. Rochester: Camden House, 2003.

Person, Leland S. "Poe's Poetics of Desire: 'Th'Expanding Eye to the Loved Object'." Poe Studies/Dark Romanticism: History, Theory, Interpretation 32, no.1-2 (1999): $1-7$.

Pitcher, Edward W. 'From Hoffmann's 'Das Majorat' to Poe's 'Usher' via 'The Robber Tower': Poe's Borrowings Reconsidered." American Transcendental Quarterly: A Journal of New England Writers 39 (1978): 231-36.

Poe, Edgar Allan. "Berenice." Southern Literary Messenger 1, no.7 (March 1835). https://www.eapoe.org/works/tales/bernicea.htm.

-. "The Philosophy of Composition." Graham's Magazine 28, no. 4 (1846). https: //www.eapoe.org/works/essays/philcomp.htm.

-. "Preface: Tales of the Grotesque and the Arabesque." In The Collected Texts of Edgar Allan Poe. Vol. II. Tales and Sketches, edited by Thomas Ollive Mabbott, 471-74. Cambridge, MA: The Belknap Press of Harvard University Press, 1978. https://www.eapoe.org/works/mabbott/tom2t037.htm.

Rippmann, Inge. “ “... statt eines Weibes Mensch zu sein’: Frauenemanzipatorische Ansätze bei jungdeutschen Schriftstellern." In Das Junge Deutscbland, edited by 
Joseph A. Kruse and Bernd Kortländer, 108-33. Düsseldorf: Hoffmann \& Campe, 1987.

Schürmann, Uta. "Hysterie und Mathematik: Die zwei Modelle der Kriminalerzählung: E. A. Poe und E. T. A. Hoffmann.” Weimarer Beiträge: Zeitschrift für Literaturwissenschaft, Ästhetik und Kulturwissenschaften 56, no.2 (2010): 284-96.

Sencindiver, Susan Yi. "Sexing or Specularising the Doppelgänger: A Recourse to Poe's 'Ligeia'." In Fear Itself: Reasoning the Unreasonable, edited by Stephan Hessel and Michèle Huppert, 63-77. New York: Rodopi, 2010.

Sherve, Margaret E. “The Dark and the Fair: Women in Hawthorne's and Poe's Fiction." In Honoring Human Herstory: A Celebration of Women's Heritage, edited by Michelle M. Sauer, 78-88. Minot: Minot State University, 2008.

Vitt-Maucher, Gisela. “Träumer und Phantast als narratives Medium bei Hoffmann, Poe, Dostojewski und Stolper.” Hoffmann Jabrbuch 1 (1992-93): 174-83.

Von der Lippe, George B. "The Figure of E.T.A. Hoffmann as Doppelgänger to Poe’s Roderick Usher.” MLN 92, no.3 (April 1977): 525-34.

Wade, Mason, ed. The Writings of Margaret Fuller. New York: Viking Press, 1941.

Webber, Andrew J. The Doppelgänger: Double Visions in German Literature. Oxford: Oxford University Press, 1996.

Williams, Michael J. S. "Poe on Women: Recent Perspectives." Poe Studies/Dark Romanticism: History, Theory, Interpretation 26, no.1-2 (1993): 34-40. 



\section{About the Contributors}

Gerardo Del Guercio is formerly of the Royal Military College of Canada (St-Jean), Collège Jean-de-Brébeuf, and l'université de Montréal. He is the author of The Fugitive Slave Law in The Life of Frederick Douglass, an American Slave and Harriet Beecher Stowe's Uncle Tom's Cabin: American Society Transforms Its Culture (Edwin Mellen, 2013). Additionally, he has published essays on Benjamin Franklin, Henry James, Nathaniel West, Edgar Allan Poe, Aldous Huxley, Joseph Conrad, Jean Toomer, and etc. His works have been published by Oxford University Press, The Gora University Press, Pearson-Longman Education, and Palgrave-McMillan, among others. He holds a bachelor's of arts from Concordia University, a master's of arts from l'université de Montréal, and a TESOL from York College, CUNY. At present, he is teaching English in Montreal, Quebec, Canada.

Phillip Grayson is Professor of Rhetoric and Composition at Missional University; Associate Editor of the Watchung Review; and author of The Creation of Reality: Consciousness in Contemporary American Literature.

Dr. Sean J. Kelly is Associate Professor of English at Wilkes University in Northeastern Pennsylvania where he teaches courses in nineteenth-century American literature, African American literature, critical theory, and writing. His articles and reviews have appeared in The Edgar Allan Poe Review, Papers on Language and Literature, Angelaki, Short Story, and Explicator. 
Rachel McCoppin, Ph.D. is a Professor of literature at the University of Minnesota at Crookston. She has published many scholarly articles in the areas of mythology and comparative literature. Her work has appeared in journals including: Symbiosis, Studies in American Humor, Studies in the Novel, and World Literary Review. She has also published articles in many scholarly books published by Palgrave Macmillan, McFarland, Atlantic, and Greenwood Press. She has also published the books: The Ecological Heroes of Amerindian Mythology (Kendall-Hunt 2019), The Lessons of Nature in Mythology (McFarland 2015), and The Hero's Journey and the Cycles of Nature (McFarland 2016).

Tatiana Prorokova is a postdoctoral researcher at the Department of English and American Studies, University of Vienna, Austria. Her current project examines representations of the environment and climate change in fiction since the Industrial Revolution. She holds a $\mathrm{PhD}$ in American Studies from the University of Marburg, Germany. She was an Ebeling Fellow at the American Antiquarian Society (2018) and a Visiting Scholar at the University of South Alabama, USA (2016). She is a coeditor of Cultures of War in Graphic Novels: Violence, Trauma, and Memory (Rutgers University Press, 2018).

Karen J. Renner teaches classes in American literature and popular culture, specializing in horror. Her book Evil Children in the Popular Imagination was published by Palgrave Macmillan in 2016, and she is currently writing a follow-up, tentatively titled Killer Kids: Juvenile Homicide in U.S. Popular Culture. She has also published articles on aging women in American Horror Story, masculinity in ghost hunting reality shows, and on the appeal of the apocalypse. 

This collection offers six critical essays on the topic of psychology in Edgar Allan Poe. It came together as a response to a visible absence of this subject in recent scholarship. The volume presents Edgar Allan Poe as one of the pioneers in psychology, who often anticipated major theoretical trends and ideas in psychology in his incessant explorations of the relationship between behavior and the psyche. Scrutinizing serial killer narratives, obsessive narratives through Jungian unconscious, Lacanian Das Ding, doppelgängers, intersubjectivity, and the interrelationship between the material world and imaginative faculties, the essays reveal the richness and the complexity of Poe's work and its pertinence to contemporary culture.

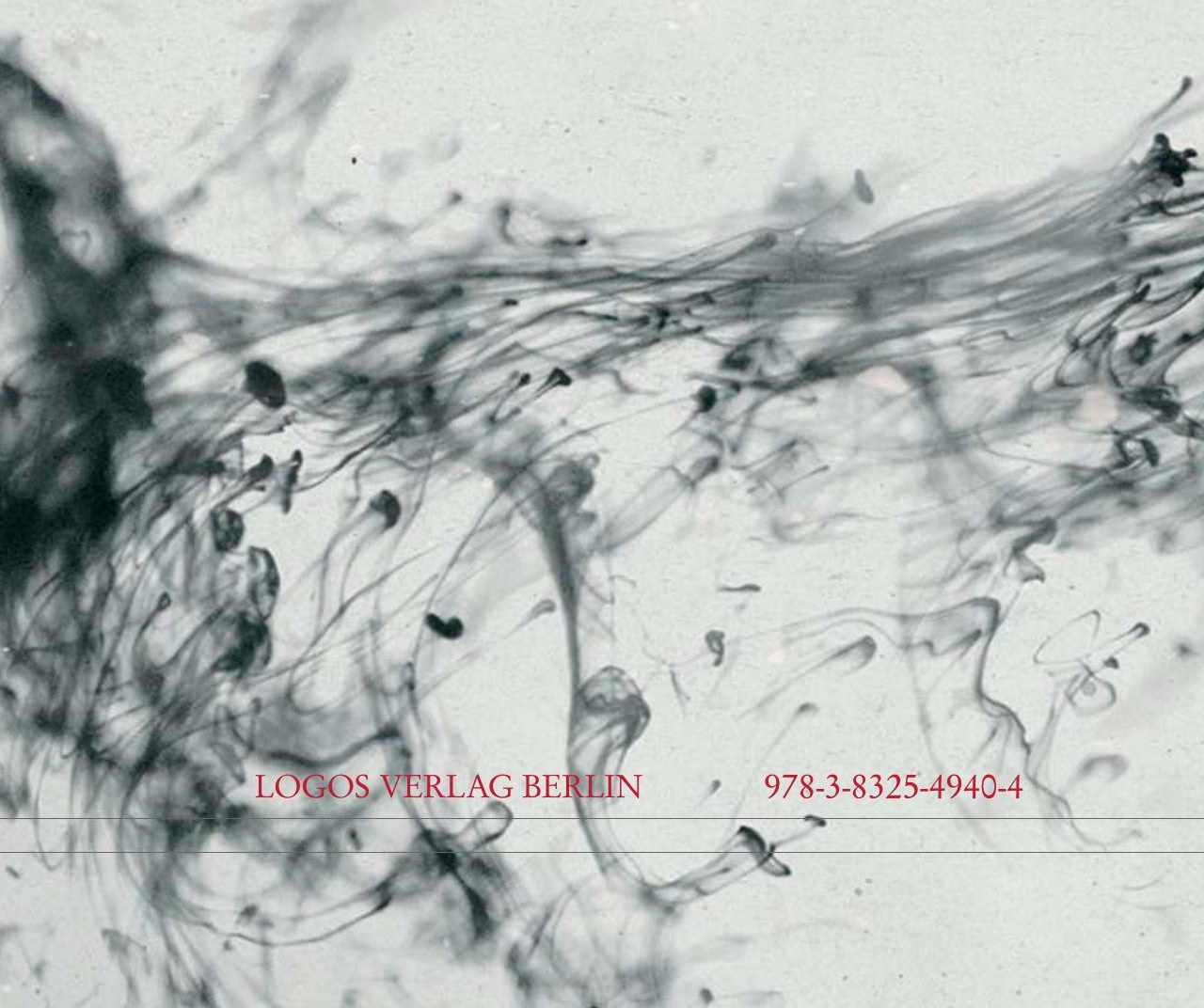

